CLINAL VARIATION AND NATURAL SELECTION

IN THE LAND SNAIL Pleurodonte lucerna

IN WESTERN ST. ANN PARISH, JAMAICA

By

GLENN A. GOODFRIEND

A DISSERTATION PRESENTED TO THE GRADUATE SCHOOL

OF THE UNIVERSITY OF FLORIDA IN

PARTIAL FULFILLMENT OF THE REQUIREMENTS

FOR THE DEGREE OF DOCTOR OF PHILOSOPHY

UNIVERSITY OF FLORIDA

1983 


\section{ACKNOWLEDGEMENTS}

I would especially like to thank my advisor Dr. H. Jane Brockmann and the other members of my supervisory committee, Dr. Lincoln P. Brower, Dr. E. S. Deevey, Jr., Dr. Thomas C. Emmel, Dr. Douglas S. Jones, and Dr. Walter S. Judd, for their guidance and helpful comments on earlier drafts. The extensive field work on which much of this study is based was greatly facilitated by the assistance of Mr. Peter Clarke of Clarksonville, St. Ann, Jamaica. Climatic data were provided by the Jamaican Meterorological Service. Mr. K. Palmer, Mr. Cecil Lindo, and Reynolds Aluminum kindly provided access to their properties for field studies. Dr. Ronald G. Wolff and Dr. H. Jane Brockmann provided facilities for photography. Dr. Fred G. Thompson (Florida State Museum), Dr. Arthur E. Bogan and Dr. George M. Davis (Academy of Natural Sciences of Philadelphia), Dr. Jorgen Knudson (Zoological Museum, Copenhagen), and Dr. Claude Vaucher (Museum of Natural History, Geneva) provided material of the Pleurodonte lucerna complex for study. Dr. Richard M. Mitterer carried out amino acid racemization analyses on subfossil $\underline{P}$. lucerna shells. Dr. Alan Solem originally suggested the $\underline{P}$. lucerna complex as an interesting group of beasts to study. Dr. Arthur J. Cain provided helpful comments on an earlier draft. Field work was supported by grants from the Alexander Bache Fund (National Academy of Sciences) and the Sigma Xi Society. 
ACKNOWLEDGEMENTS.................................

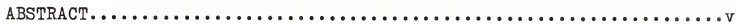

INTRODUCTION. . . . . . . . . . . . . . . . . . . . . . . . . . . .

CAUSES OF VARIATION IN LAND SNAIL SHELL FORM: A REVIEW.........6

Size..............................................

Whorl Number and Whorl Expansion Rate.........................

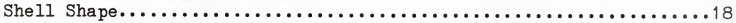

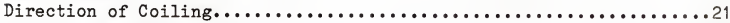

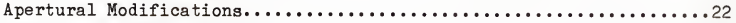

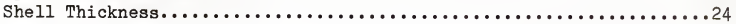

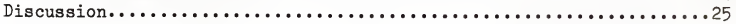

THE SYSTEMATIC CONTEXT...............................

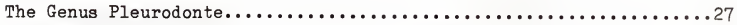

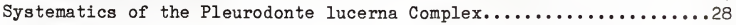

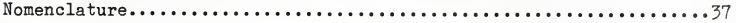

THE NATURAL HISTORY OF PLEURODONTE LUCERNA................. 56

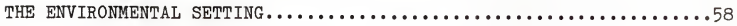

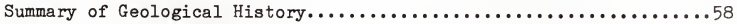

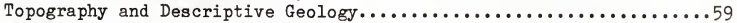

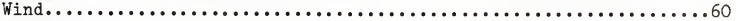

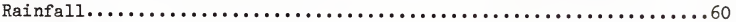

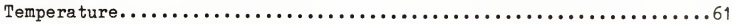

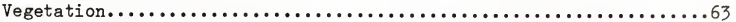

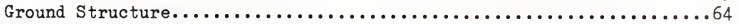

Environmental Variation along the Cline Transect............... 65

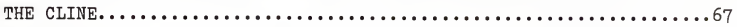

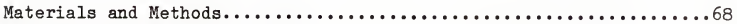

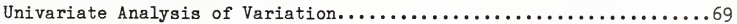

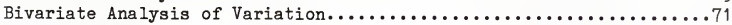

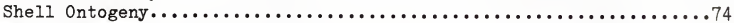

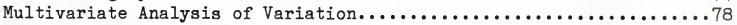

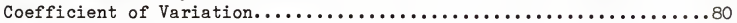

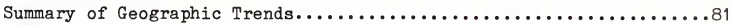


RELATION OF CLINAL VARIATION TO ENVIRONMENTAL VARIATION.........97

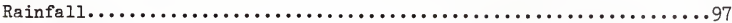

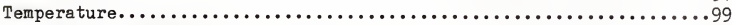

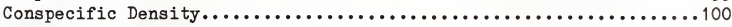

Presence of 0 ther Pleurodonte Species....................... 105

Predators and Potential Predators......................... 106

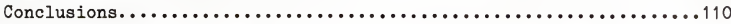

MORPHOLOGICAL VARIATION: ROLES OF ENVIRONMENTAL AND GENETIC

INFLUENCES . . . . . . . . . . . . . . . . . . . . . . . . 116

Laboratory Rearing Study...................................

Possible Controls of Adult Shell Size and Form...............118

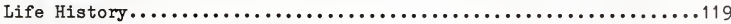

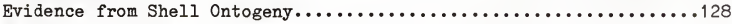

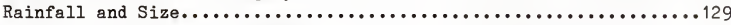

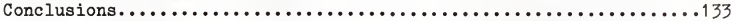

SHELL MORPHOLOGY AND NATURAL SELECTION $\ldots \ldots \ldots \ldots \ldots \ldots \ldots \ldots \ldots \ldots \ldots \ldots \ldots \ldots$

Water Loss and Shell Morphology.............................

Bird Predation and Shell Morphology .........................

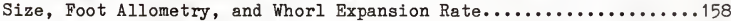

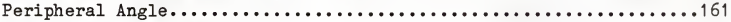

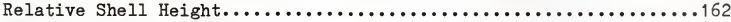

Summary of Proposed Selective Regime..........................

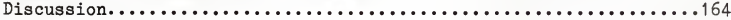

THE EVOLUTIONARY HISTORY OF THE CLINE......................

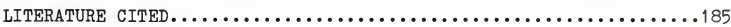

APPENDIX: LIST OF STATIONS CITED...........................

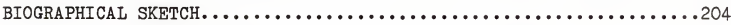




\begin{abstract}
Dissertation Presented to the Graduate School of the University of Florida in Partial Fullfillment of the Requirements for the Degree of Doctor of Philosophy
\end{abstract}

\title{
CLINAL VARIATION AND NATURAL SELECTION IN THE LAND SNAIL Pleurodonte lucerna \\ IN WESTERN ST. ANN PARISH, JAMAICA
}

By

\author{
Glenn A. Goodfriend \\ December, 1983
}

Chairman: Dr. H. Jane Brockmann

Major Department: Zoology

A cline in shell characters of the land snail Pleurodonte lucerna in western St. Ann Parish, Jamaica, is described and the causes and evolutionary history of the cline are analyzed. A review of literature on the causes of morphological variation in land snail shells is presented. $\underline{P}$. lucerna forms a semispecies complex with $\underline{P}$. sublucerna: the two taxa are distinct under sympatry but are connected by a narrow hybrid zone of secondary origin in another area. The cline transect runs from the coast up the coastal slope and across the interior plateau. At the coast, where rainfall is low, the shells are very small and relatively high, with a rounded periphery and two relatively large apertural denticles. At the edge of the plateau, where rainfall is high, the snails are large and relatively flat, with a keeled periphery and relatively small apertural denticles. Further inland in a rainshadow, the shells again become small and relatively high, with a rounded periphery and large apertural denticles. The trend reverses itself further inland with increasing rainfall; the 
shells again become large, relatively flat and keeled, with small apertural denticles.

Evidence on life history, shell ontogeny, and temporal relationships between shell size and rainfall are reviewed. These indicate that size differences among populations are not the result of differences in the rate or duration of growth, but rather, they are primarily the result of genotypic differences. The correlation between rainfall and genetically-based characters of the snails indicates that natural selection must be responsible for differentiation of populations. Experiments were conducted to evaluate the relationship between shell morphology and the rate of water loss from the shell. The narrower, more numerous whorls characteristic of shells from drier areas were found to reduce water loss. Positive allometry of the foot may limit narrow-whorled shells to a small size. More intense predatory activity by birds in drier areas also tends to select for small shells with narrow whorls and large denticles.

Evidence from subfossil shells indicates that the cline is of primary origin. A diminution of shell size has occurred along the entire cline in recent years. 


\section{INTRODUCTION}

Clinal variation in land snails has been the subject of numerous studies. However, only rarely has a correlation between clinal variation and spatial variation of the environment been shown. This implies either that selection is not often responsible for land snail clines or that the selective factors underlying clinal variation have rarely been identified. Below I examine a dramatic cline (or, more precisely, a linear series of clines) in the endemic Jamaican land snail Pleurodonte lucerna (Müller) in which shell characteristics (size, shape, size of apertural denticles) show a close association with geographic variation in rainfall. In dry areas, the shells are small and relatively high, with a rounded periphery and large apertural denticles, whereas in wet areas the shells are large and relatively flat, with a keeled periphery and small apertural denticles. Documentation of clinal variation is based on samples from 15 populations along a north-south transect in western St. Ann Parish from the central north coast toward the center of the island. After placement of the cline in a systematic and ecological context, the pattern of geographic variation is examined. The clinal character of the variation is shown and its relationship to spatial variation of the environment is documented. I next consider the evidence for the genetic basis of among-population variation and evaluate some 
hypotheses of the adaptive significance of the morphological variation. Lastly, I discuss the evolutionary history of the cline (whether it is primary or secondary), based in part on evidence from subfossil specimens.

Clines are classified as primary or secondary, according to the process by which intermediate populations arise (Mayr, 1963). Primary clines are those that have differentiated in situ in a continuous series of populations in response to selection. Such a cline results from a continuous gradient in the selective regime, but may be modified by dispersal, which would tend to produce a more gradual character gradient. Secondary clines are those that form from expansion, meeting, and subsequent intergradation of formerly allopatric populations. The differences between the original populations may have arisen through in situ selection, founder effect, or genetic drift.

Attempts to explain clinal variation in land snails in terms of geographic variation in selective pressures have rarely been successful. Numerous studies have documented clines on a local geographic scale (tens to hundreds of meters). Lewis (1977) documented a cline in banding frequency in the helicid Cochlicella acuta up the face of a sandy coastal hill. Darker substrates (on the lower slope of the hill) were found to be associated with higher banding frequency (hence darker shells), whereas lighter substrates (on the upper slope) were associated with lower banding frequency. Visual predation by Rooks (Corvus frugilegus) was proposed as a possible cause. Step clines between areas with populations of 
relatively uniform shell color morph frequencies are common in Cepaea (Cain \& Currey, 1963a, 1963b, 1963c; Goodhart, 1963; Carter, 1968; Arnold, 1971; Jones, 1975). These clines were often assumed to be related to unidentified environmental characteristics. However, recent studies by Cameron et al. (1977, 1980) make a convincing case for the secondary origin of area effects. They apparently represent populations that have recently expanded and met to form a secondary hybrid zone following cessation of sheep grazing. Other, more gradual clines in morph frequencies of Cepaea also do not appear to be related to environmental characteristics (Clarke \& Murray, 1962; Wolda, 1969 a, b). A number of clines have been documented in Cerion in the West Indies (Gould \& Paull, 1977; Galler \& Gould, 1979; Woodruff \& Gould, 1980), but these generally show no predictable relation to environmental characteristics. Clarke (1968) demonstrated an intriguing cline in shell color in Partula on the Polynesian island of Moorea over a distance of $200 \mathrm{~m}$. No relationship to environmental characteristics was found. A morph frequency cline in the helicid Theba pisana across a habitat boundary was shown to be due to differential movement of morphs (Johnson, 1981). Thus in only one case (Cochlicella) has a local cline been shown to be related to envi ronmental gradients.

Clines on a broader geographic scale (kilometers to thousands of kilometers) have been documented for several taxa. Jones et al. (1977) showed a general trend toward increasing frequency of the yellow morph of Cepaea nemoralis with increasing temperature from northern to southern Europe. This is apparently related to the 
greater reflective properties of the yellow morph, which decrease the probability of lethal overheating (Richardson, 1974). In Cochlicella acuta in western Europe (Lewis, 1977), unbanded morphs are more frequent in the south than in the north; climatic selection is a possible cause, although selection by climatic factors for color patterns in this species has not been demonstrated. The southeast African land snail Metachatina kraussi shows a regular increase in size toward the north (van Bruggen, 1969); the cause of the cline is unknown. A cline in shell dimensions between two Partula semispecies was observed across a series of valleys in eastern Moorea (Murray \& Clarke, 1980). In neither example was any relationship with environmental factors found. Heller (1979), studying Levantina caesareana in Israel, showed that the size and relative height of these snails increased gradually over ca. $12 \mathrm{~km}$ up to a hybrid zone with another Levantina sp. Reduction of interbreeding through character displacement was proposed as a possible explanation, but the transition zone is anomalously wide.

Thus the evidence presently available does not argue in favor of gradients in selective factors as a predominant cause of clines in land snails. In some cases this could be the result of failure to identify an existing gradient. However, at least in the case of area effects in Cepaea, clinal variation appears to be the result of secondary intergradation. Probably most of the land snail clines that have been documented result from this process.

Land snails are especially appropriate subjects for the study of the role of selection in the evolution of clines. They frequently 
show geographic variation. Their shells are often easily collected in sufficient numbers and present a number of precisely quantifiable features. Many land snails reach a definite adult size, marked by a reflected lip, and then grow no more. This enables comparisons to be made at a standard life-history stage (Gould et al., 1974). Furthermore, the ontogey of adult shell differences can be readily studied since the shell preserves the record of ontogeny of an individual. In some cases, there may be a fossil record which can be used to provide information on the evolutionary history of the cline (Cain, 1971; Heller, 1979). While selection has rarely been shown to be responsibel for producing clinal variation in land snails, local variation in land snail shell morphology is known in many cases to be produced by selection. 
CAUSES OF VARIATION IN LAND SNAIL SHELL FORM: A REVIEW

There is an extensive literature on geographic variation in the morphology of land snail shells. Much of the variation may be clinal but only in a relatively few cases has this been documented, as discussed above. Below I review our present knowledge of variation (primarily geographic) in land snail shell form and its causes. Unfortunately, the relative roles of genetics and environment in the production of morphological variation are known for only a few taxa. Consequently, few definite conclusions about the adaptive significance of shell form can be reached.

\section{Shell Size}

Laboratory and outdoor cage breeding experiments have shown that size has a high heritability in land snails. Cook \& Cain (1980) found size differences between two populations of Cepaea nemoralis to be due largely to genetic differences. However, rearing conditions also had an effect on size; the generations of each population hatched in captivity were of smaller size than the wild-caught parental generation. Working on the helicid Arianta arbustorum., Cook (1965) found size differences among populations to be largely genetic. Shell size variation among populations of Partula (Murray \& Clarke, 1968) and Murella (Rensch, 1937) also has a significant genetic component. 
Within-population size variation may also have a significant genetic component. For example, Oosterhoff (1977) found that within populations, faster growing individuals of $\underline{\mathrm{C}}$. nemoralis reach a larger adult size despite earlier maturation. Laboratory breeding experiments showed that growth rate has a high heritability. Within some populations of $\underline{\mathrm{C}}$. nemoralis, size may be correlated with banding or with shell color. This implies that size may be either a pleiotropic effect of color genes or that size-determining genes may be linked with color genes (Cook \& O'Donald, 1971). The evidence presently available thus indicates that size variation among populations generally has a significant genetic component.

Shell size, as measured by shell diameter, is geometrically determined by several variables: initial size of the embryonic shell, whorl expansion rate (the rate at which whorl width increases with increasing whorl number), and whorl number. Knipper (1939) found that shell diameter variation among populations of helicids may be the result of any one or more of these variables. Geographic variation in size has been found to be correlated with a variety of abiotic and biotic environmental factors. These relationships and their possible causes will now be reviewed.

\section{Moisture}

Land snails are frequently larger under wetter conditions. Examples include numerous European and Mediterranean species (size correlated with rainfall; Rensch, 1932), Levantina in Israel (size correlated with rainfall; Heller, 1979), Chloritis in the lowlands of Timor, Indonesia (size correlated with rainfall; Rensch, 1931), 
Clausilia in Germany (size correlated with moistness of habitat; Schmid, 1919), and Pleurodonte lucerna in Manchester Parish, Jamaica ("․․ acuta goniasmos", size correlated with moistness of habitat; Brown, 1911). Boycott (1920) found that populations of Clausilia bidentata and Ena obscura in more sheltered (therefore wetter?) areas tended to consist of larger snails. No such relationship was found in an earlier study of Clausilia (Boycott, 1919). Nevo et al. (1983) have suggested that in Israeli Levantina, larger species tend to occur in drier areas and smaller species in wetter areas. However, the pattern is rather weak and not established on statistical grounds. No trends in variation within species in relation to moisture was found. Tropical land snails tend to be smaller under very wet conditions at high elevations. This is seen in Chloritis on Timor (Rensch, 1931), Hawaiian Achatinella (Welch, 1938, 1954), and minute prosobranchs of the genus Diplommatina in the Solomon Islands (Peake, 1973). Other minute diplommatinine prosobranchs also show diminution of size with increasing rainfall in Malaya (Berry, 1963) and New Caledonia (Tillier, 1981). More studies of geographic variation of minute land snails are needed to determine whether this negative correlation between size and rainfall is a general pattern in such forms. Several hypotheses have been proposed to explain these correlations. Brown (1911) found that populations of Pleurodonte lucerna with larger shells have a higher whorl expansion rate; initial whorl size and total whorl number of adults were relatively constant. Brown believed this growth pattern to be induced by the greater food abundance and the more frequent feeding opportunities 
found in wetter places. Clessin (1897) and Sacchi (1965) proposed similar explanations for variation in size among populations of Helix pomatia in Europe and Iberus on Majorca, respectively. Geyer (1927, as discussed by Rensch, 1932) also considered that larger snail size in wetter areas was the result of increased food intake. Rensch (1932) considered larger size to be the result of higher growth rate, due to increased opportunity for activity in moister areas. In the Jamaican Lucidella aureola and L. granulosa, Brown (1913) found populations of smaller snails to have both fewer whorls and narrower later whorls. He believed that maturation was seasonally induced and that more slowly growing snails, i. e., those in drier areas, would attain a smaller size by the time maturation was induced. Welch (1938) believed that size variation in Achatinella was the result of variation in the age of maturation, with the smaller snails that live under wetter conditions maturing earlier.

Although the frequency of the association between size and moisture in land snails is well established by these various studies, none has established the causes of these relationships. Most of the proposed hypotheses assume environmental induction of size differences. However, as discussed above, the genetic basis of size differences among populations has been established whenever tested. Thus natural selection is likely to be responsible for many of the observed correlations. Clearly, the selective value of size differences in different moisture regimes has not been adequately considered. 


\section{Temperature and Insolation}

There is relatively little evidence for the effect of temperature or insolation on snail size. Lais (1925, as discussed by Rensch, 1932) found that in warmer areas, species that occupy generally cooler ranges are smaller, whereas species that occupy generally warmer ranges are larger. Rensch's (1932) extensive data do not show such a trend. He found, for example, that xerophilous species may be larger or smaller in warmer areas. Bengtson et al. (1979) found a positive correlation between mean adult shell diameter and mean minimum daily temperature in Cepaea hortensis at a series of sites in Iceland. At one site a positive temporal correlation was found between mean shell diameter in June and the average temperature of the previous winter. However, no change in mean diameter of the population was found during the winters. In neither case is the cause of the correlation evident. Whether size differences among sites or between years are due to genetic differences is not known. The snails might experience more rapid growth at warmer sites and thus attain a larger adult size during the growing season. Evidence of selection for snail size by insolation comes from outdoor cage experiments by Knights (1979). In unshaded cages, smaller snails had lower mortality, whereas larger snails had lower mortality in shaded cages. The significance of these findings in interpreting variation in natural populations is difficult to evaluate, since it is not possible to separate the effects of insolation from those of temperature or moisture--the less shaded cages would also be drier and warmer. 
Calcium

Since calcium is required for shell growth, it might be expected that shell size would be affected by the presence or absence of limestone at a site. However, results from field surveys generally do not support this hypothesis. Surveys of Helix pomatia (Agocsy, 1963), Cepaea hortensis in Iceland (Bengtson et al., 1979), Theba pisana (Sacchi, 1971) and a variety of other European and Mediterranean species (Rensch, 1932) show that shell size is independent of calcium carbonate abundance. Økland (1925, as discussed by Rensch, 1932) found that various helicid species tended to be smaller in limestone areas.

In an analysis of laboratory-reared Arianta arbustorum, Cook (1965) found that subsets of broods reared with chalk were often (but not always) smaller on the average than those raised without chalk. These inconsistencies might be due to genetic differences among the broods. Oldham (1929), working on the same species, found no size differences between individuals raised with and without chalk. But

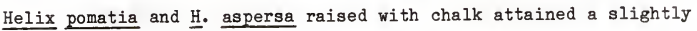
larger size than those raised without (0ldham, 1934). Frömming (1954) found no size differences between Bradybaena fruticum raised with soil and chalk and those raised without.

While these laboratory results indicate that in some species calcium scarcity may produce smaller shells, this would not seem to apply to field situations, since no such correlation has been found there. Snails may be able to get sufficient calcium to produce normal-sized shells by selective consumption of plants with higher calcium levels. 
Population Density

Adult size has been shown to be negatively correlated with population density in several European helicids. The relationship has been shown in field surveys of Cepaea nemoralis (Cook \& O'Donald, 1971; Williamson et al., 1976; Oosterhoff, 1977) and three other helicid species (Tattersfield, 1981). The significant change in shell size observed by Cook \& $0^{\prime}$ Donald over little more than one generation implies that the size changes were largely the result of environmental effects. Laboratory studies (Oosterhoff, 1977) and outdoor cage studies (Cook \& Cain, 1980) of Cepaea nemoralis raised at different densities have shown that size differences are caused by density differences. Oosterhoff (1977) has shown that higher densities decrease adult size by reducing the growth rate of juveniles.

In a series of outdoor cage experiments on adult Cepaea hortensis at high and low densities, Knights (1979) failed to find a consistent pattern of differential mortality with respect to size at different densities. Larger adults tended to be favored at both densities. However, significant heterogeneity among replicates was found, implying that other unidentified factors had an important influence on size.

The available evidence thus indicates that density has an important influence on adult size and that this effect is inductive rather than selective. Interactions between Related Species

Character displacement with respect to size might occur if size were involved in mate recognition or if size affected interspecific 
competition. Peake (1973) showed that the size frequency distributions of sympatric Diplommatina species in Malaya and in the Solomon Islands were non-overlapping and regularly spaced, except where the direction of coiling differed. Coiling direction could serve as an altenative reproductive isolation mechanism (see section on direction of coiling, below). However, without statistical tests comparing the size distributions of sympatric populations to randomly selected allopatric populations, the significance of this pattern is questionable (Connor \& Simberloff, 1979). The widespread dextral D. nevilli shows considerable geographic variation but allopatric populations are not smaller on average than sympatric populations that occur with larger dextral species. Thus there is no indication of character displacement with respect to size. Tillier (1981), studying diplommatinines in New Caledonia, gave one example which he claimed demonstrated character displacement. He illustrated the range of height and diameter of two sympatric populations and compared it to the range of all populations of the two species pooled. The sympatric populations showed less overlap in dimensions than the species as a whole, and this was taken as evidence of character displacement. This comparison is invalid because the morphometric ranges for the species includes both among-population variation as well as within-population variation and because of the larger sample size for the species than for the population (which would naturally increase the observed range of variation). Furthermore, the median height and diameter are morphologically considerably closer in the sympatric populations than in the species as a whole. If anything, convergent character 
displacement (Grant, 1972) is shown, although the statistical significance of this pattern cannot be evaluated from the data provided.

There are thus no data presently available that show that the size of land snails may be affected by interspecific competition or that it may serve as a species isolation mechanism.

Predation

In a few cases, predation has been found to have a selective effect on shell size. Oosterhoff (1977) noted that larger snails were preyed upon less frequently by beetles than smaller ones. In a field experiment on predation by the Song Thrush (Turdus ericetorum), Bantock \& Bayley (1973) found that in a mixed population of Cepaea

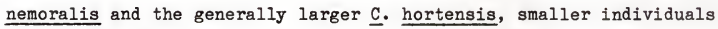
of $\underline{\mathrm{C}}$. hortensis and smaller $\underline{\mathrm{C}}$. nemoralis were preferentially preyed upon. These data suggest that the thrushes do not distinguish between the two species and that they preferentially prey upon snails of intermediate size, perhaps implying formation of a search image or greater efficiency of handling of snails of such size. A later study (Bantock et al., 1975) showed that selection for size by thrushes differs among the different morphs. Yellow five-banded $\underline{C}$ nemoralis were subject to disruptive selection with respect to size, whereas in yellow midbanded morphs, predation was random with respect to size. The cause of this pattern is not clear. While these findings show that thrushes do select snails with respect to size, there is no evidence that this selection is responsible for among-population size differences in nature. 


\section{$\underline{\text { Reproduction }}$}

Several studies show that reproductive output is positively correlated with size. In Cepaea nemoralis, larger individuals tend to lay larger clutches and more clutches per year (Wolda, 1963). A marginally significant positive correlation between adult size and clutch size was found by Oosterhoff (1977). In Achatina fulica, larger individuals lay a larger number of eggs per clutch; no difference in the number of clutches laid by small vs. large snails was found (Kekauoha, 1966).

Thus, all else being equal, larger snails will be favored by selection because of greater reproductive output. Clearly other selective factors must be counteracting this effect.

\section{Unexplained Patterns}

While in many cases the cause of variation in shell size is uncertain, there are several cases in which the cause is particularly baffling. Perhaps the most interesting of these is what constitutes the only predictable pattern of variation in Bahamian Cerion: on the inner (bank) side of islands, the snails are often small (and usually have weak, closely spaced ribs and a brown and white mottled shell), whereas on the outer (oceanic) side, a larger form (pale, with strong, widely spaced ribs) is more common (Woodruff \& Gould, 1980). These morphological differences are known to be largely due to genetic differences from the transplant experiments of Bartsch (Woodruff \& Gould, 1980). The occurrence of this pattern on a large number of islands argues strongly in favor of the adaptive value of the 
variation. Unfortunately, no environmental correlates of this pattern have been identified; the cause of the pattern remains unknown. Cook \& O'Donald (1971) observed differential mortality with respect to size in some dormant laboratory populations of Cepaea nemoralis over the winter. One population showed no differential mortality, whereas another showed significantly higher mortality of smaller snails. Replicates of a third group gave inconsistent results: one showed no differential mortality whereas two others showed higher mortality of smaller snails. In comparisons of mortality between populations, the population consisting of the largest snails showed significantly higher overall mortality than the population of the smallest snails, the opposite of the trend found in within-population mortality. These experiments show that conditions of the environment might select for size in land snails through differential mortality. However, the cause of mortality and the environmental factors involved (e. g., temperature, humidity, snail density) are unknown.

Wolda (1972) observed a progressive decrease in adult size in a series of captive outdoor populations of Cepaea nemoralis over several years. The decrease was due to recruitment of progressively smaller individuals to the adult population from the juvenile population. While the high density of the populations might account for an initial decrease following establishment of the populations, later decreases were not found to be correlated with density. Neither was the size of newly recruited adults in different populations found to be correlated with density. Possibly a temporal trend in some characteristic of the 
physical environment or some conditioning effect of the snails on the environmental medium might be involved.

\section{Whorl Number and Whorl Expansion Rate}

In a study of several land snail faunas (Cain, 1980), it was shown that whorl number is generally not related to size in comparisons among species within a region. However, two exceptions were noted. Very elongate shells generally have a larger number of whorls, presumably to increase shell strength, and very small shells tend to have a lower whorl number. Cain suggests that this might be adaptive in maintaining a sufficiently large whorl cross-sectional area for efficient circulation.

Snails with narrower whorls also have relatively small apertures, unless the aperture becomes expanded at maturation. Cameron (1981), studying British land snails, found that larger species had larger apertures than would be expected from isometry. This is a consequence of the higher whorl expansion rate and lower whorl number of large species. He proposed that selection was acting to maintain a lower loading on the aperture (total adult weight/surface area of aperture), which would tend to increase with size under isometry. This allometric increase would tend to reduce the risk of detachment of a larger snail from a substrate to which it is sealed while inactive. This would presumably reduce the risk of predation or desiccation. An experimental study by Gebhardt-Dunkel (1953) showed that water loss from inactive snails occurs predominantly through the aperture. 
Later experiments by Machin (1967) established that water loss rate through the aperture was positively correlated with aperture area, although the relationship was not linear. A survey by Gebhardt-Dunkel (1953) showed that xerophilous species tend to have relatively smaller apertures, apparently due primarily to narrower whorls rather than modification of the aperture at maturity. It seems likely that a lower whorl expansion rate, producing narrower whorls, is adaptive in a dry environment in that it may reduce water loss.

\section{Shell Shape}

Gould (1971) has pointed out that shell shape may not necessarily be adaptive per se but may be an inadvertant consequence of selection for other developmentally correlated shell features such as size. Most land snails show non-gnomonic growth, i. e., their shape changes as they grow (Goodfriend, 1983a). So, for example, selection for smaller size might produce an adult shell with fewer whorls. In a species in which the shell becomes progressively more domed during ontogeny, this selection would also produce a flatter shell, although the shape itself might have no particular adaptive significance.

Most of the literature on variation in shell shape concerns the relative width of the shell (height/diameter ratio). Several studies document correlations between shell shape and environmental factors. New Caledonian Diplommatina tend to be stouter in higher rainfall areas (Tillier, 1981), while Levantina tends to be more elongate (Heller, 1979). The Tahitian Partula otaheitana has a weak tendency 
to be relatively stouter in areas of higher insolation and higher rainfall (Emberton, 1982). The genetic basis of this variation is not known for any of these cases, and no hypotheses on the cause of these correlations have been proposed. Knipper (1939) found the relative height of various helicid species to be greater (i. e., the shell is more rounded) at higher elevations. He supposed that the lower surface area to volume ratio of such forms was adaptive in retarding heat loss. But the increased relative height might be a selectively neutral consequence of the larger whorl number observed for these forms. Furthermore, the significance of surface area to volume ratios in relation to temperature is questionable for ectotherms such as land snails.

Character displacement involving shell shape has been shown in fossil Poecilozonites (Schindel \& Gould, 1977). The nature of the interaction producing this effect is unknown. Competitive interactions or reproductive isolation might be involved. Heller (1979) documented an increase in the relative height of Levantina caesareana as it approaches a flatter parapatric Levantina species. The increase in relative height could be simply the result of the associated increase in size (discussed above). Ontogenetic analysis of the populations would be needed to determine the developmental interrelations of size and relative height.

Cain (1977, 1978a, 1978b) has shown that the statistical distribution of the relative height of land snail shells of many regions is bimodal--the shells tend to be either very elongate or slightly flattened, rarely globular or slightly elongate. Cain has 
proposed that this may be due to the mechanics of balancing the shell during locomotion (Cain, 1977) and/or to as yet unidentified properties of niches available to land snails (Cain, 1978b). The idea of the relation of shape to the mechanics of shell-carrying is quite interesting but an area of total ignorance at present. Considering the great weight of the shell and the visceral mass enclosed within it, differences in shape are likely to have a significant effect on the energy expended in holding the shell in a balanced position during locomotion. Downward reflection of the aperture upon maturation (in, e. g., helicids) might be related to improving the balance of the shell. An analysis of the mechanics of shell-carrying is badly needed.

In a study of the ontogeny of Poecilozonites, Gould (1968) showed that development of a domed shell may result from positive allometry of the relative height of the aperture. He interpreted this allometry as allowing maintenance of a relatively large volume for retraction of the foot, although no measurements of foot size were made. In larger snails, foot surface area could become limiting to locomotion, since, under isometry, the loading on the foot (weight per unit surface area) increases with increasing size. Allometric shell growth in larger snails could provide for accommodation of an allometrically increasing foot volume.

Rensch (1937) found that flat, keeled species of Sicilian Murella tended to occur in drier areas, whereas higher, rounded species were associated with wetter areas. The significance of these shape differences is not clear. Cook \& Pettitt (1979) have suggested that a 
keel increases the strength of a shell, thus decreasing predation. This hypothesis remains untested.

There is thus quite a variety of proposed explanations for variation in shell shape. However all are conjectural at present.

\section{Direction of Coiling}

Most land snail genera are composed exclusively of dextral species. However, a few genera contain both dextral and sinistral forms. In such genera, sympatric species often show opposite directions of coiling. Peake (1973) found that sympatric Diplommatina species of similar size always differed in the direction of coiling. Populations of Partula suturalis sympatric with other Partula on Moorea almost always differ from these other species in the direction of coiling (Murray \& Clarke, 1980). Coiling direction is known to be maternally inherited in Partula (Murray \& Clarke, 1966). Differences in direction of coiling may serve as a mechanism of partial reproductive isolation between species, since it serves as a partial barrier even within species (Lipton \& Murray, 1979). These coiling differences between sympatric populations might represent an initial response to selection for reproductive isolation when two species come in contact. Since many Partula are polymorphic for coiling direction, the variability on which selection could act may be present from the time of contact. Over time, other more effective mechanisms may evolve but the differences in coiling direction might still be retained due to fixation of alleles controlling coiling. 


\section{Apertural Modifications}

Shell maturation in land snails of many families frequently involves production of an aperture modified in shape or partially blocked by denticles. Nearly all hypotheses of the adaptive significance of these features have involved their function in reducing predation or water loss. Boettger (1921, 1935) has suggested that apertural narrowing and production of denticles in Otala in North Africa serve to reduce predation by carabid beetles. He found that the size of apertural denticles varied concordantly with the relative head length of a carabid beetle preying upon these snails. Beetles possessing longer, narrower heads occurred where the snails had larger denticles. Cook (1895) and Solem (1972) considered apertural denticles to function in reducing predation by arthropods. Paul (1974) found it difficult to interpret the function of the denticles of Azeca as providing protection against predation, since some of the denticles (up to nine are present) do not produce any restriction of the aperture. No tests of the effectiveness of apertural denticles against predation have been performed. However, the effectiveness of very large apertural denticles against predators seems self-evident. Boettger (1921, 1935) believed that denticles and apertural narrowing in adult Otala also serve to reduce water loss. He was not sure whether the denticles originated in response to moisture stress or predation. Paul (1974) supposed that water loss from a retracted snail should be a function of the exposed surface area of the mantle collar and that therefore apertural modifications, such as denticles, 
should have no effect on water loss. Machin's (1967) experiments showed a correlation between water loss rate and apertural cross-sectional area in several helicid species. However, apertural cross-sectional area is likely to be strongly positively correlated with the surface area of the mantle collar of the retracted snail, so these data cannot be used to distinguish between the significance of aperture area and mantle collar area in reducing water loss. The effectiveness of apertural denticles in reducing water loss has not been tested experimentally.

Clessin (1897) stated that denticle development in many pupillid species was dependent on calcium carbonate availability. This could be a direct effect of the environment. Or calcareous areas may be drier (they are better drained) or have higher predator populations, either of which might select for well-developed dentition.

In Galapagos Bulimulus, species occupying moister microhabitats tend to have small parietal and columellar denticles, while those in drier habitats do not (Coppois \& Glowacki, 1983). Similarly, development of a small parietal denticle in populations of Partula otaheitana is associated with areas of higher rainfall and higher insolation (Emberton, 1982). In neither case do the denticles seem large enough to have any effect on predation. The correlation is the opposite of that expected if the denticles served to reduce water loss. These denticles may serve some as yet unidentified function. Knipper (1939) found that adults of species or populations of helicids in drier areas tended to have a lip which was built out from the shell and which lies in one plane. He considered that this 
modification would permit more effective sealing to surfaces (such as rocks) during inactivity. Mazek-Fialla (1934) also associated a built-out lip with effectiveness of sealing to substrates and presumed that this would decrease water loss. The lip was found to be better developed in species living in relatively exposed microhabitats, where water loss would be a greater problem. Possibly these lip modifications for sealing might also decrease predation by making detachment of the snail more difficult (cf. Cameron (1981), discussed above).

\section{Shell Thickness}

Land snails display considerable variation in shell thickness among species, populations, and life history stages. It is known from laboratory studies that shell thickness is a function of the availability of calcium carbonate (Oldham, 1929, 1934; Voelker, 1959; Crowell, 1973; Oosterhoff, 1977). Pollard (1975) showed through laboratory breeding experiments that variation in shell thickness among populations of Helix pomatia in England is in large part heritable. Thus variation in shell thickness has been shown to have significant environmental and genetic components.

Gould (1969), studying fossil Poecilozonites, found a temporal and geographic correlation between shell thickness and the calcium carbonate abundance of the substrate. Shell thickness increases during ontogeny in Poecilozonites and the thinner-shelled forms have a number of other paedomorphic characteristics as well. Gould 
interpreted this paedomorphy representing an adaptation to low calcium environments. Helicids also tend to have thinner shells in non-limestone areas (Taylor, 1881; Hoff, 1923; Agocsy, 1963). Whether this represents the inductive effect of low calcium abundance (as seen in laboratory experiments) or genetic variation adapting the snails to a low calcium environment is not known.

Shell thickness in the helicids Helix pomatia (Pollard, 1975) and Theba pisana (Sacchi, 1971; Bar, 1978) is greater in areas with lower rainfall. Gebhardt-Dunkel (1953) noted that species that inhabit drier regions tend to have thicker shells. The significance of this variation can be seen from the studies of Machin (1967) which show that the rate of water loss through the shell decreases linearly with increasing shell thickness. While relatively little water loss occurs through the shell, this small amount may be critical to snails that aestivate for long periods of time.

\section{Discussion}

Despite the numerous studies involving geographic variation in land snail shell form, we remain rather ignorant of the causes of these patterns. Certain patterns occur frequently enough to suggest that they have some generality. For example, size is often positively correlated with moisture. However, we do not know to what degree this is a result of environmental induction or selection. The possible selective advantage of larger snails in wetter areas has not been explored. The positive correlation between shell thickness and 
calcium and its negative correlation with moisture have also been established in a variety of taxa. The former may represent the inductive effect of low calcium on shell thickness or it may be an adaptation to a low calcium environment; probably both apply in different taxa. The association of thicker-shelled snails with drier areas may represent an adaptation to moisture stress; but no study testing fitness in relation to shell thickness has been carried out. By comparison, the causes of geographic variation of color morph frequencies of land snails are much better understood, though many mysteries still remain (reviewed by Jones et al., 1977). A major reason for this better understanding of selection on shell color patterns is that their genetics are well documented (at least in helicids) and relatively simple, most characters being controlled by one or (rarely) two loci. Predation is the best documented factor controlling morph frequencies. This is because mortality due to predation can often be unambiguously established from shell remains. The roles of other environmental factors that affect mortality or fecundity are rather more difficult to establish in the field. According to the evidence presently available, predation is not an especially important selective force on land snail shell form (except perhaps on apertural dentition, but this is not established). This accounts in part for our poorer understanding of the causes of shell form variation as compared to morph frequency variation. 
THE SYSTEMATIC CONTEXT

The primary purposes of this section are to place the cline in Pleurodonte lucerna in western St. Ann Parish, Jamaica, in the systematic context of the genus $\underline{\text { Pleurodonte }}$ and the $\underline{P}$. lucerna complex and to show that this cline represents a single variable species. In doing so, I consider especially the variation and distribution of the P. lucerna complex in St. Ann Parish and, in less detail, in other parishes in central Jamaica. For convenience, I employ species names in my treatment of the systematics of the $\underline{P}$. lucerna complex. Then, in the following section on nomenclature, I show why these names have been selected for the forms to which I apply them.

\section{The Genus Pleurodonte}

Pleurodonte has a disjunct distribution which includes Jamaica and the Lesser Antilles but not the intervening islands of Hispaniola and Puerto Rico. Wurtz (1955) recognized three subgenera: two (both monotypic) in Jamaica and a third (Pleurodonte s. s.) with one section (Dentellaria) in Jamaica and another (Pleurodonte) in the Lesser Antilles (table 1). The Jamaican section Dentellaria is composed of of two groups, the $\underline{\mathrm{P}}$. Iucerna group ( $=\underline{\mathrm{P}}$. acuta group of Jarvis (1902)), and the $\underline{P}$. sinuata (Müller) group. The $\underline{P} \cdot \underline{\text { lucerna group }}$ contains four species in eastern Jamaica ( $\underline{P}$. carmelita (Fér.), $\underline{P}$. 
chemnitziana (Pfr.), $\underline{\text { P. }}$ ingens (C. B. Ads.), and $\underline{\text { P. subacuta }}$ (Pfr.)), one in the interior of central and western Jamaica ( $\underline{P}$. bainbridgei (Pfr.)), and an island-wide series of forms, the $\underline{P}$. lucerna complex.

A fossil member of the Pleurodonte lucerna complex from the Bowden Beds of southeastern Jamaica was described as $\underline{P}$. bowdenensis by Simpson (1894). While formerly considered Miocene in age (Woodring, 1928), these deposits are now considered to be of earliest Pliocene age (Bolli \& Bermudez, 1965). The $\underline{\text { P. }}$ lucerna complex is thus of ancient origin. A member of the $\underline{P}$. sinuata complex is also known from the Bowden Beds (Kimball, 1947), so the divergence of the two Dentellaria groups predates the Pleistocene.

\section{Systematics of the Pleurodonte lucerna Complex}

The Pleurodonte lucerna complex consists of an amazing array of forms, many of which have at some time been given species status. Pilsbry (1889) noted that

there is a surprising amount of variation in the species of this group. Specific distinctions seem to be indeed wholly artificial and the variation in some cases connects the most dissimilar forms into continuous series. [p. 97]

These forms are generally geographic variants. However in one area, two distinct forms ( $\underline{P}$. lucerna and $\underline{P}$. sublucerna) often occur together. These are considered semispecies, since in other areas where these taxa meet parapatrically, they introgress. 


\section{Materials and Methods}

Revision of the systematics of the Pleurodonte lucerna complex is based on extensive material collected by the author from 1974 to 1982 . The distribution and systematics of this complex in St. Ann and the immediately adjoining area (figure 1) were based on dissections of 465 specimens from 109 populations. Localities of 24 additional populations, whose species identity was based only on shell morphology, were also plotted. Since species identity is better indicated by anatomical characters (see below), records of populations represented only by shells were included only if the shells were indistinguishable from nearby populations whose identity was based on dissections. In no case were the distributional limits of species based on undissected material. Numerous populations in other areas of Jamaica (especially the parishes adjoining St. Ann) were also dissected in order to clarify the sysematics of the $\underline{P}$. lucerna complex. One sample of specimems at the Florida State Museum was also included in the analysis.

Live-collected specimens were drowned in water, then fixed and preserved in ethanol. Shell diameter was measured at the point behind the reflected lip at the point where the lip begins to grow outward. Height was measured from the apex to the point on the base in the center of the umbilical region. The size of the verge (terminal copulatory organ) was characterized by the verge size index (VSI). This was calculated as verge length times the square of the radius midway between the base and the tip of the verge, and is thus a function of verge volume (but not a direct estimator thereof). All 
measurements were made with a dial caliper accurate to $0.1 \mathrm{~mm}$. In most cases the measurements were later rounded off to the nearest millimeter.

Station numbers consist of two letters, indicating the parish, followed by a number, assigned chronologically. Parish abbreviations are: Cl (Clarendon), Ha (Hanover), Ma (Manchester), Po (Portland), SA (St. Andrew), SC (St. Catherine), SN (St. Ann), Tr (Trelawny), and We (Westmoreland).

Pleurodonte lucerna and P. sublucerna in Sympatry

In the region of sympatry in southeastern St. Ann and the adjoining part of St. Catherine (figure 1), $\underline{P}$. lucerna has a flat, strongly keeled shell (table 2, figure 2A). The shell of $\underline{P}$. sublucerna is relatively higher, smaller, and has a rounded to weakly angular periphery (figure $2 B$ ). The penis of $\underline{P}$. sublucerna is thicker than that of $\underline{P}$. lucerna (figure $3 A, B$ ). The verge of $\underline{P}$. sublucerna is large, with deep longitudinal grooves on the shaft, and both fine longitudinal grooves and two to four low (sometimes very weak) circular ridges on the tapered tip (figure $3 \mathrm{C}$ ). The verge of $\underline{p}$. lucerna is small and smooth (figure 3D). No intermediates between the two forms occur in the area. These sympatric forms differ in at least several characters which are unlikely to be developmentally correlated (viz., shell form, penis and verge size, and two characters of verge sculpture). Differences in diameter, relative height, and peripheral angle could be developmentally correlated, with the development of the keel also increasing the diameter and decreasing the relative height. 
These differences cannot definitely be interpreted as representing more than a single character. Because these differences between the two sympatric forms are consistent, the forms must be considered distinct species.

Within the region of sympatry, each species also occurs alone. No differences were observed between these populations and the sympatric populations.

Pleurodonte lucerna and P. sublucerna in Allopatry

Pleurodonte sublucerna extends east of its area of sympatry with P. Iucerna to Portland Parish (figure 4) and along the southern half of Jamaica from St. Thomas Parish west at least to southeastern Manchester Parish. In St. Ann, it extends from the southeast northward and westward to the upper part of the coastal slope (figure 1). Throughout these areas the form of the male genitalia is similar, except that the longitudinal grooves on the tip of the verge are weaker or absent and the circular ridges are stronger in the forms of southern Jamaica (e. g., ST-4, ST-Ea-4, SA-Ki-1, SC-7, C1-23, C1-27, $\mathrm{Cl}-40, \mathrm{Cl}-42, \mathrm{Ma}-7)$. No anatomical differences were observed between sympatric and allopatric populations of $\underline{P}$. sublucerna. $\underline{P}$. lucerna occurs throughout St. Ann except on the upper central part of the coastal slope (where it is replaced by $\underline{P}$. sublucerna) and perhaps the area in eastern St. Ann north of the area of sympatry. Few records of Pleurodonte in this latter area are available due in part to incomplete collecting but more to extensive clear-cutting. The male genitalia are consistent in form throughout St. Ann. However, in 
populations of especially small snails, the proportions of the genitalia are sometimes also smaller (e. g., sta. SN-37). No anatomical differences were observed between populations sympatric with $\underline{P}$. sublucerna and allopatric populations.

Pleurodonte lucerna and P. sublucerna in Parapatry: A Hybrid Zone

In several areas where Pleurodonte lucerna and $\underline{P}$. sublucerna are parapatric, the contact zone has been intensively sampled. At sta. $\mathrm{SN}-176$ (figure 5), $\underline{\mathrm{P}}$. lucerna (figure $6 \mathrm{~A}$ ) is similar to individuals from the area of sympatry but larger (table 3 ). The verge is small and generally smooth. At SN-178, the snails are smaller (figure 6B) but unusually variable in size. The shells are mostly keeled but some are only very weakly angular at the periphery. The verge is variable in size and sculpture. The population is thus unusually variable and intermediate between $\underline{P}$. lucerna and $\underline{P}$. sublucerna. Shells from SN-57 (figure 6C) are smaller and have a weakly angular periphery. The morphology and size of the verge is typical of $\underline{p}$. sublucerna but the grooves of the shaft are weak in some individuals. The specimens are thus very similar to specimens of $\underline{P}$. sublucerna from the area of sympatry. At SN-224, the population has the verge morphology typical of $\underline{P}$. sublucerna. However, the shells (figure 6D) are larger than the SN-57 specimens and are keeled but sometimes weakly so. Other populations of $\underline{P}$. sublucerna on the north coastal slope also have keeled shells (SN-51, SN-206, SN-208, SN-227, SN-232), as do some Portland populations (e. g., Po-21). 
Similar Pleurodonte lucerna-P. sublucerna transitions zones have also been sampled at $\mathrm{SN}-168$ to $\mathrm{SN}-58$ and $\mathrm{SN}-125$ to $\mathrm{SN}-163$ (figure 1).

All of these transition zones are notable for the fact that they involve all characters (shell, reproductive) that separate sympatric populations, for the unusually high variability of geographic intermediates, and for their narrowness. Because of the high variability of intermediate populations, the transition zones may be considered hybrid zones, according to the terminology of Woodruff (1973).

The Central Form and Transitions to Pleurodonte lucerna and P. sublucerna

In southwestern St. Ann another transition zone exists between typical Pleurodonte lucerna and what I term the central form of $\underline{P}$. lucerna. At SN-137 (figure 1), P. Iucerna shells (figure 11C, D) are similar in size and shape to those from the area of sympatry. The verge of these snails is generally smooth and small as in the sympatric populations (table 4). At SN-199, the snails are larger and the verge is small and smooth or with $1-3$ circular ridges on the tip. The snails at SN-129 are of similar or slightly larger size. The verge is generally larger and usually has circular ridges on the tip. The C1-43 snails are smaller and have larger verges which always have circular ridges. Snails with this verge form (medium size, tip with 1-3 circular ridges, shaft without longitudinal grooves) are referred to here as the central form. Since the transition from typical $\underline{P}$. lucerna to the central form is gradual, these forms must be considered conspecific. 
The central form occurs along the northern edge of eastern Clarendon and north into southernmost St. Ann. At the easternmost edge of northern Clarendon it appears to grade into Pleurodonte sublucerna. Intermediate specimens occur at $\mathrm{Cl}-12$ and $\mathrm{SN}-119$. These have shells with angular peripheries and have very weak grooves on the shaft of the verge. Sample sizes of populations in this area are not sufficient to fully document the transition. Because the relationship of the central form to $\underline{P}$. sublucerna is not fully understood, no formal name is proposed for this form.

The Central Form of Pleurodonte lucerna: Transitions to the West

Verge size increases westward from the central form at $\mathrm{Cl}-43$ into northwestern Clarendon (VSI 18-31, $n=6$, at C1-11) (figure 4) and the tip becomes more elongate and develops additional circular ridges (total of 4-6). The shells change from keeled and moderate in size (46-50 $\mathrm{mm}$ at $\mathrm{Cl}-11 ; 46-50 \mathrm{~mm}$ at $\mathrm{Ma}-30, \mathrm{n}=5$ ) to smaller and rounded further westward in eastern central Manchester (36-40 mm at Ma-2, $n=7$; 38-41 $\mathrm{mm}$ at Ma-13, $\mathrm{n}=12$ ). The verge is of similar or slightly larger size (VSI 17-43 at Ma-13, n=6) and develops a more elongate tip with more numerous (6-9) circular ridges. There must be a contact zone between these forms and Pleurodonte sublucerna (the semispecies inhabiting the south coast) somewhere in southern Manchester but its precise location has not been determined. Northward from Ma-13, the shells increase in size $(42-45 \mathrm{~mm}$ at sta. FGT2807, n=4) and develop an angular periphery. A further increase in verge size (VSI 42-63, $n=5$ ) is also seen. Further north, in eastern and central Trelawny, the 
shells are very large $(55-59 \mathrm{~mm}$ at $\mathrm{Tr}-34, \mathrm{n}=8 ; 50-54 \mathrm{~mm}$ at $\mathrm{Tr}-30$, $\mathrm{n}=8)$ and have a keeled $(\operatorname{Tr}-34)$ or angular $(\operatorname{Tr}-30)$ periphery. The verge is of similar size (VSI $38-73$ at Tr-34; VSI $32-78$ at $\mathrm{Tr}-30$ ) but the circular ridges are less numerous $(2-5)$ and weaker. They are absent in some individuals. A typical Trelawny form ( $\mathrm{Tr}-48$ ) has been found within $5 \mathrm{~km}$ of my easternmost record for typical $\underline{\mathrm{P}}$. lucerna at Tr-29. The snails at $\mathrm{Tr}-29$ have a verge that is smooth and small (VSI $8-9, n=3$ ) but at the upper size range of the St. Ann $\underline{P}$. lucerna forms. The intervening area has not been sampled, so the relationship between these forms is unknown. However, it appears that a transition zone is involved, since the Trelawny form converges toward the St. Ann form (in showing reduction or loss of circular ridges on the verge tip) and the St. Ann forms converge toward the Trelawny forms through the Tr-29 population (which has a larger than average verge). More sampling is needed before the relationships of these forms are fully understood. The Trelawny and St. Ann forms are, however, ultimately connected through the continuous and lengthy morphological series (through the central form) outlined above. Therefore these western forms, although

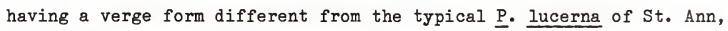
cannot be considered to represent a distinct species.

\section{Discussion}

Each of the characters that distinguishes Pleurodonte lucerna and P. sublucerna in the region of sympatry shows complete intergradation in other areas. Therefore, although the forms represent distinct species under sympatry, distinctions between them are necessarily 
somewhat arbitrary in other areas. They comprise a pair of semispecies, forming a Rassenkreis with overlapping ends. A similar situation is described by Murray \& Clarke (1980) in Partula suturalis and $\underline{P}$. olympia on Moorea.

My separation of the St. Ann forms of the Pleurodonte lucerna complex is based on the characteristics of the genitalia. This was preferred over shell characters for several reasons. The genitalia usually differ by several characters (size, presence or absence of longitudinal grooves on the shaft and circular ridges on the tip) that usually vary concordantly; transitions occur along only a single narrow band (and perhaps through the central form in northern Clarendon). Shell characters vary concordantly less often and they show numerous and broad transition zones. In fact the areas of transition predominate over areas of uniformity; this will be further documented below in the description of the cline transect. The parsimonious explanation of the broad geographic pattern of character variation is that differentiation involved first the genitalia and that these forms then attained something near their present distributions before geographic differentiation of shell form was completed. The hybrid zone would then represent a zone of secondary contact.

The north-south transect through western St. Ann (figure 9), which is the main subject of this paper, passes through a population of Pleurodonte lucerna at the coast. Southward, on the upper part of the coastal slope, it passes through populations of $\underline{P}$. sublucerna (SN-206 and SN-208, not included in the analysis), and then through 
numerous $\underline{P}$. lucerna populations on the interior plateau. Along the transect, no differences are seen in the reproductive anatomy except for the gradual transition to the cental form morphology. It will be shown below that despite the pronounced variation in shell form, these populations comprise a continuous morphological series and thus represent a single species.

\section{Nomenclature}

The Pleurodonte lucerna complex was last monographed by Pilsbry (1889) under Helix and was later (Pilsbry, 1894) transferred to Pleurodonte. On the basis of shell characters, he allocated the various forms to two species, $\underline{P}$. acuta and $\underline{P}$. lucerna, and gave the various shell morphs the status of variety or form. He distinguished $\underline{\text { P. lucerna }}$ from $\underline{P}$. acuta on the basis of its "flatter base, more compressed aperture, larger teeth, and especially the decidedly deeper, larger constriction or scrobiculation behind the peristome." (1889, p. 105). Under $\underline{P}$. lucerna he included the varieties julia Ferussac and fuscolabris C. B. Adams. The remainder of the forms were placed under $\underline{P}$. acuta. No data on comparative anatomy were presented or utilized in this classification. He also listed, but did not utilize, the names $\underline{P}$. abnormis (Pfeiffer) and $\underline{P}$. rhynchaena (A. D. Brown) (see below). Baker (1935) included all the forms of the $\underline{P}$. $\underline{\text { lucerna }}$ complex under $\underline{P}$. lucerna and recognized a number of subspecies and "races". He never collected material from the area where two forms occur sympatrically. Clearly, neither Pilsbry's nor Baker's 
classification is consistent with the picture of the systematics of the $\underline{P}$. lucerna complex as presented above.

The first available name for a member of the Pleurodonte lucerna complex is Helix lucerna Müller (1774, p. 13). The single type specimen (figure 7A, B), at the Zoologisk Museum der Universitets Copenhagen, measures $31.4 \mathrm{~mm}$ (diameter) X $13.5 \mathrm{~mm}$ (height), and has 4.6 whorls. The periphery is strongly keeled. The last whorl is weakly concave above the periphery and strongly convex below. The peristome bears two thick denticles of moderate size. The back of the outer denticle is weakly twisted toward the outside. The specimen is subfossil and is ivory to pale tan in color. The surface is worn and pitted and has been polished. The parietal callus has mostly flaked off, revealing the intact surface sculpture of the ventral side of the last part of the penultimate whorl. The sculpture consists of low tubercles, elongate in a radial direction.

Müller gave no locality data for his specimen and, of course, the anatomy is unknown. However, the form of the shell is sufficiently distinct that its geographic origin can be reliably inferred. The shell is most similar to subfossil specimens from SN-237 (figure 7C, D) at Buckfield Pen, near Ocho Rios, St. Ann. This area has been settled since the period of Spanish occupation in the 1500 's, so it is reasonable to suppose that Muller's specimens could have been collected there. The specimens from SN-237 differ from Müller's specimen in being larger ( $34-40 \mathrm{~mm}$ diameter, $n=4$ ) and in having larger denticles. Sampling has so far failed to reveal any living 
populations of the Pleurodonte lucerna complex at Buckfield Pen, although subfossils have been found at a second site (SN-234).

Living specimens belonging to the Pleurodonte lucerna complex are abundant $1.8 \mathrm{~km}$ south of SN-237 at SN-246 in Fern Gully. These shells are similar to the $\mathrm{SN}-237$ shells in size $(34-41 \mathrm{~mm}, \mathrm{n}=11)$ and dentition but are more weakly keeled. The similarity of these forms and their geographic proximity suggest they are likely conspecific. The verge of the SN-246 specimens is small (VSI 4-6) and has a smooth shaft. The tip is also smooth or may have one circular ridge ( 8 of 11 specimens). Thus the Fern Gully form is not distinct from populations consisting wholly of individuals with small, smooth verges. All of these forms, including the keeled, small-verged form of the region of sympatry, may be considered conspecific with Muller's $\underline{P}$. lucerna.

Helix heteroclites Lamarck (1822, p. 74) is a moderately large (47 mm diameter, according to Mermod, 1950) form with a very weakly angular periphery and two moderately developed denticles. The type was illustrated by Mermod (1950). Based on these photographs, the shell appears indistinguishable from specimens of Pleurodonte lucerna from SN-148 and SN-152. The shell is also similar to specimens from SN-117 (forms with a large, grooved verge) although these generally have a more angular periphery, smaller denticles, and larger diameter. Some of the St. James forms (e. g., SJ-6) are similar to $\underline{H}$. heteroclites in size and shape but these lack the inner denticles and the outer denticle is smaller. In the absence of locality data, anatomical data, or a larger series of types, the identity of $\underline{H}$. heteroclites remains uncertain. I consider it a nomen dubium. 
Helix acuta Lamarck (1822, p. 95; illustrated in Lamarck (1827), plate 462, figure 1) and Carocolla acutissima Lamarck (1822, p. 95) are absolute synonyms. The former name was preferred by Pilsbry (1889, p. 101). Lamarck's type specimen, at the Museum d'Histoire Naturelle de Geneve, was illustrated by Mermod (1951). It is very large ( $57 \mathrm{~mm}$ diameter, as measured from photos provided by Dr. Claude Vaucher and as given by Mermod), strongly keeled, and concave above and below the periphery. Such shells occur in the wetter areas of St. Ann: Chippenham Park (SN-213, 51-62 mm, VSI 2-6, $n=7$ ) east to Brittonville (SN-176, 51-60 mm, VSI 1-7, n=10) and south to Colliston (SN-102, 56-64 mm, VSI 2-4, n=7), Stepney (SN-216, 54-60 mm, VSI=1-3, $\mathrm{n}=4$ ), and Ballintoy ( $S N-143,52-60 \mathrm{~mm}$, VSI $2-3, n=5)$. Thus Pleurodonte acuta (Lam.) must be considered conspecific with $\underline{P}$. lucerna. The name is available to represent the large keeled form of P. lucerna. However, I prefer to withhold designation of subspecies until an island-wide revision of the $\underline{\mathrm{P}}$. lucerna complex can be carried out.

Helix julia Férussac (1822, p. 35) was listed by Ferussac but neither described nor figured. Pfeiffer (1867) assigned $\underline{H}$. julia Fer. to one of Ferussac's figures of $\underline{\mathrm{H}}$. lucerna and provided a description of the species. The shell is small (33 mm diameter) and relatively high, and has two large apertural denticles. This is the form of Pleurodonte lucerna found in the rain shadow south of Brown's Town, St. Ann (e. g., SN-76).

Helix lamarckii Férussac (1822, p. 35; figure in Ferussac \& Deshayes (1827), plate 57, figure 3) is a large, strongly keeled form 
with the last whorl concave above and below the periphery. This is the form of Pleurodonte lucerna in southern St. Ann and of larger specimens of the central form (e. g., Cl-43). It is thus a form of $\underline{P}$. lucerna.

Helix patina C. B. Adams (1849, p. 29) is a very large, strongly keeled form with the last whorl concave above and below the periphery. Jacobson \& Boss (1973) selected and illustrated the lectotype (plate 71 , figures 1-3) and gave its diameter as $58.3 \mathrm{~mm}$. The specimen closely resembles the type of Helix acuta Lam. and must have come from the same general area. Jarvis (1902) considered Adans' $\underline{H}$. patina to represent the forms from the Cave Valley-Aenon Town area. Populations from this area are nearly always smaller but one specimen of $57 \mathrm{~mm}$ diameter and with central form verge morphology has been collected at Cave Valley (SN-129). ․ㅡ. patina must be considered a synonym of Pleurodonte lucerna.

Helix fuscolabris C. B. Adams (1850, p. 106) is based on material from Westmoreland Parish (Jacobson \& Boss, 1973). The lectotype (Jacobson \& Boss (1973), plate 70, figures 10-12, $37.9 \mathrm{~mm}$ diameter) has a moderately high spire, rounded periphery, and large denticles. This form is typical of most populations of the Pleurodonte lucerna complex in Westmoreland, except in having relatively larger denticles. Specimens from We-25 are of similar size (37-40 mm, $n=6)$ and shape. The verge (VSI 7-32) has a smooth shaft and 6-9 circular ridges on the elongated tip. These forms show broad morphological overlap with the forms of central eastern Manchester, which grade through the central form into the keeled form of $\underline{P}$. lucerna. The name thus refers to a form of $\underline{P}$. lucerna. 
Type material of Helix nobilis C. B. Adams (1850, p. 106) was not located by Jacobson \& Boss (1973). The very large size (64 mm), keeled periphery, concave upper last $1 / 2$ whorl, and dark coloration below the periphery, as given in Adams' description, agree well with the form of Pleurodonte lucerna found around Colliston (SN-102, 56-64 $\mathrm{mm}, \mathrm{n}=7$ ).

Helix abnormis Pfeiffer (1854, p. 56) is based on an aberrant high-spired specimen. Pilsbry \& Brown (1910) referred this to the form of central Manchester, which they called Pleurodonte acuta goniasmos. It is also similar (except for the spire) to St. James forms (e. g., SJ-6), in that both have a rounded periphery and a single small outer denticle. Because of its aberrant character, the identity of this form must remain uncertain.

Helix rhynchaena A. D. Brown (1870, p. 392) refers to a large keeled form (diameter $52 \mathrm{~mm}$ ), probably Pleurodonte lucerna from southern St. Ann. Pilsbry (1889, p. 106) indicates that "Mr. Brown seems to have abandoned the name; for in his collection there are no specimens--not even the type--marked rhychaena."

Helix acuta var. sublucerna Pilsbry (1889, p. 102) was described without locality but clearly applies to a south coast form. The accompanying illustration (from Pfeiffer, 1846) was of a specimen not seen by Pilsbry. The lectotype (figure 6E, F) and three paralectotypes (selected by Baker, 1963) are very small (28-32 mm diameter) and have an off-white color, narrow brown subperipheral band, and brown-tinged peristome. The denticles are of moderate height and the outer one is flattened laterally. The umbilicus of 
three specimens is not fully closed over, but the specimens are mature. The shells superficially resemble those of Pleurodonte lucerna from SN-37 (figure 10A, B) on the north coast but the latter differ in having 1) a significantly narrower last half whorl, 2) the denticles larger and broader, with the back part of the outer denticle twisted toward the outside, 3) conspicuous concavities (on the outside of the shell behind the lip) which correspond to the positions of the denticles, 4) darker color, with the subperipheral band paler or absent, and 5) a thicker lip. The types are similar to specimens from Cl-31 on the south coast of Clarendon. The latter are usually larger, with a thicker and paler (usually white) lip, paler subperipheral band, and more angular periphery. However, the two samples overlap with respect to each of these characters. While Pilsbry's types probably did not come from this same locality, they may have come from some nearby population along the south central coast. Similar forms (small, flat, with relatively small denticles and rounded periphery) occur along the south coast (e. g., SC-11, SC-12, Cl-23, Cl-27, Cl-30, $\mathrm{Ma-5)}$. Jarvis (1902) also applied the name sublucerna to forms of this area (southern St. Catherine east to southwestern St. Thomas, according to his distribution map).

The single preserved specimen from $\mathrm{Cl}-31$ has a large, longitudinally grooved verge with circular ridges on the tip, as do snails from nearby populations of the Pleurodonte lucerna complex in southern Clarendon ( $\mathrm{Cl}-23, \mathrm{Cl}-27, \mathrm{Cl}-40$, and $\mathrm{Cl}-42)$. As discussed above, the verge form is similar to forms in central and eastern Jamaica, including the large-verged form (with rounded shell 
periphery) that occurs in the region of sympatry. The name $\underline{P}$. sublucerna may therefore be applied correctly to all these forms. Later names for members of the Pleurodonte lucerna complex include Helix acuta var. oxytenes A. D. Brown in Pilsbry (1889), Helix goniasmos A. D. Brown in Pilsbry (1889), Helix nannodonta A. D. Brown in Pilsbry (1889), and Pleurodonte acuta semperfluens Pilsbry \& A. P. Brown (1911). All represent forms of either $\underline{P}$. lucerna or $\underline{P}$. sublucerna but are available for subspecific taxa should these be designated in the future. 
|

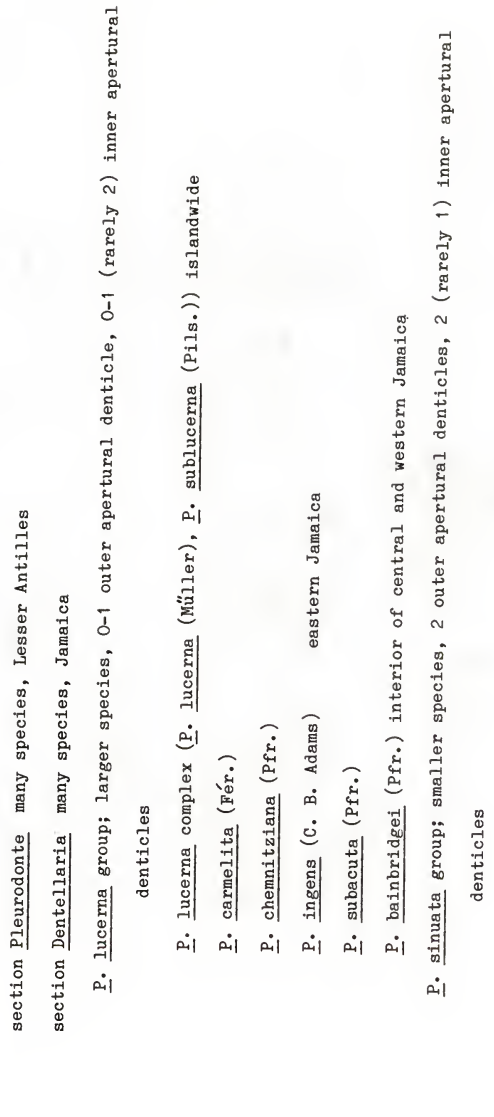


Table 2. Comparison of morphology of Pleurodonte lucerna and $\mathrm{P}$. sublucerna under sympatry (sta. SC-16, SC-17, and SN-27). For sheli characters, $n=21$ and 22 , respectively. For anatomical characters, $n=8$ and 11 , respectively.

\begin{tabular}{|c|c|c|}
\hline Character & $\underline{P}$. Iucerna & P. sublucerna \\
\hline $\begin{array}{l}\text { mean (range) shell } \\
\text { diameter (mm) }\end{array}$ & $50(46-56)$ & $43(39-46)$ \\
\hline $\begin{array}{l}\text { mean (range) relative shell } \\
\text { height (height/diameter) }\end{array}$ & $0.40(0.35-0.47)$ & $0.47(0.42-0.51)$ \\
\hline peripheral angle & keeled & rounded to weakly angular \\
\hline penis & thin & thick \\
\hline $\begin{array}{l}\text { mean (range) verge size } \\
\text { index }\end{array}$ & $7(4-9)$ & $31(14-44)$ \\
\hline shaft of verge & smooth & longitudinal grooves \\
\hline tip of verge & smooth & $\begin{array}{l}\text { 2-4 circular ridges } \\
\text { (sometimes weak), fine } \\
\text { longitudinal grooves }\end{array}$ \\
\hline
\end{tabular}




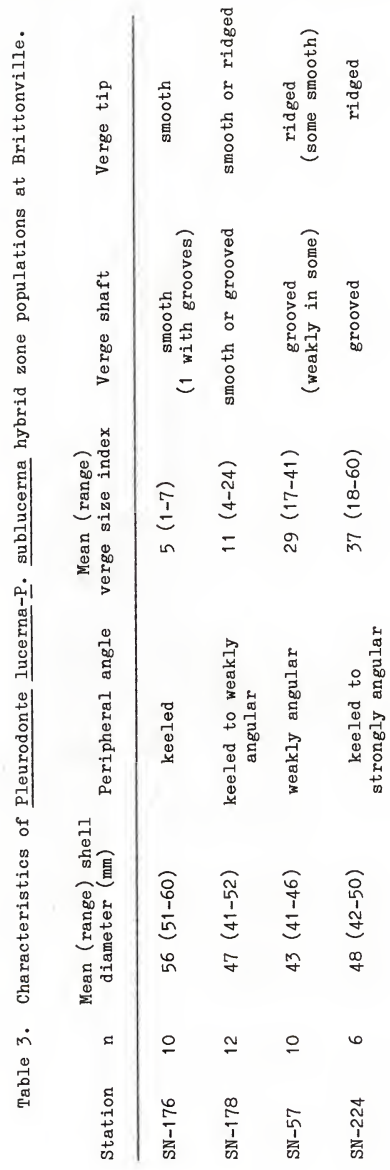




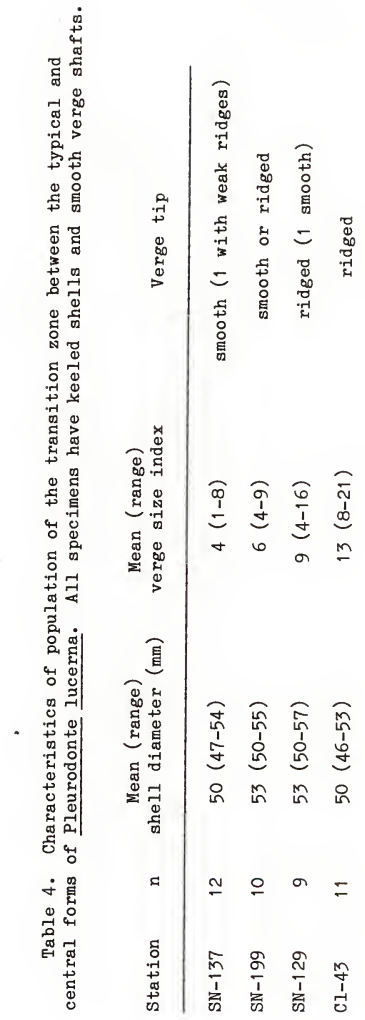




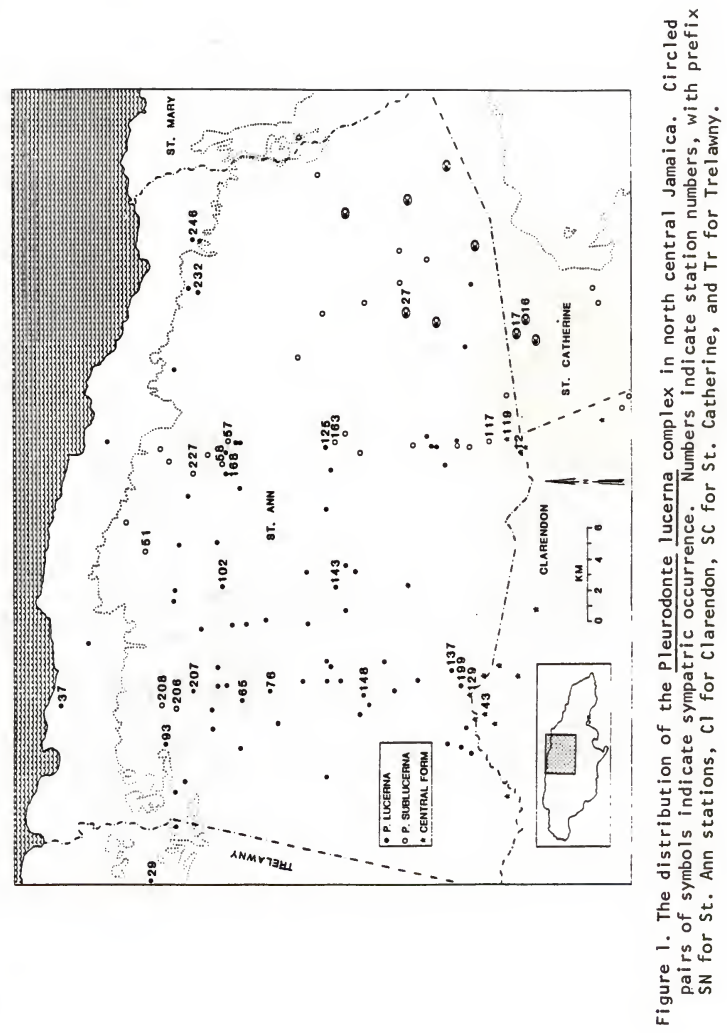



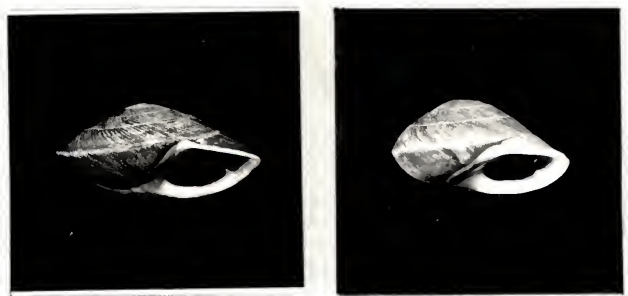

Figure 2. Shells from sympatric populations (station SC-17) of A. Pleurodonte lucerna; B. P. sublucerna. $0.87 \times$. 


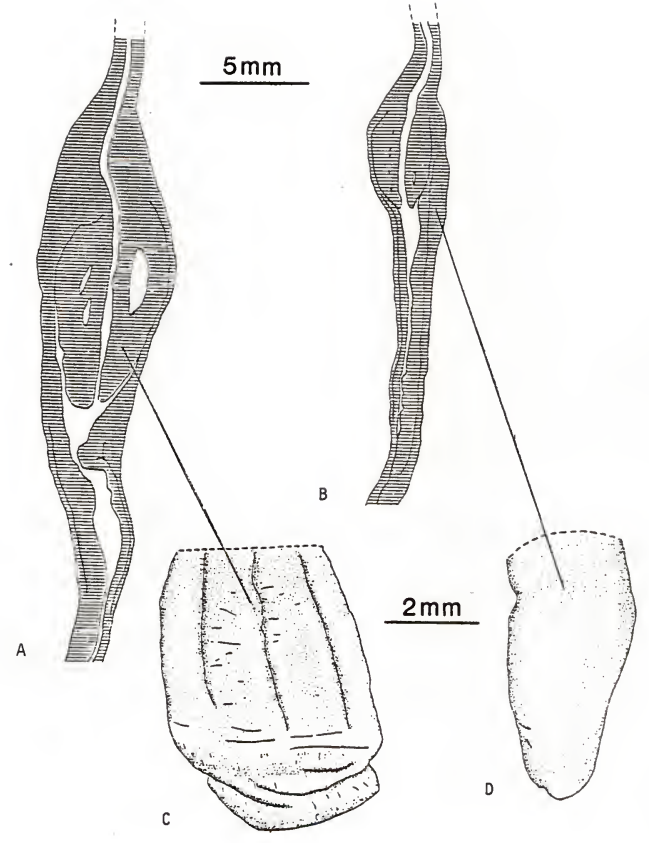

Figure 3. Male reproductive organs of Pleurodonte from station SC-17.

A. $P$. sublucerna, longitudinal section of penis; B. P. lucerna, longitudinal section of penis; C. $\underline{P}$. sublucerna, verge; D. $\underline{P}$. lucerna, verge. 


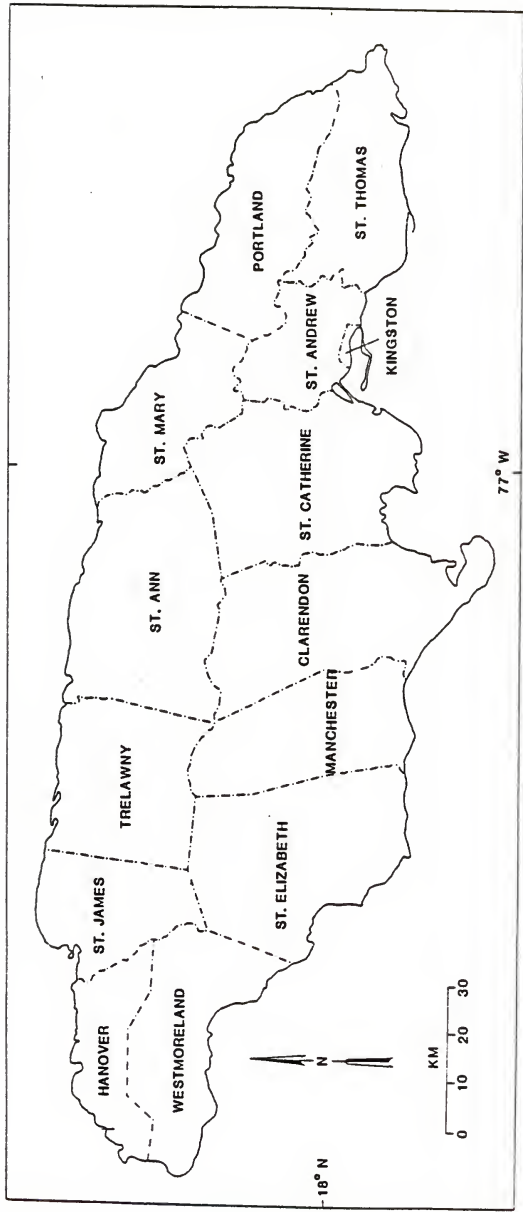

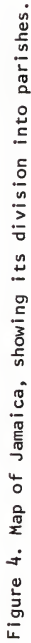




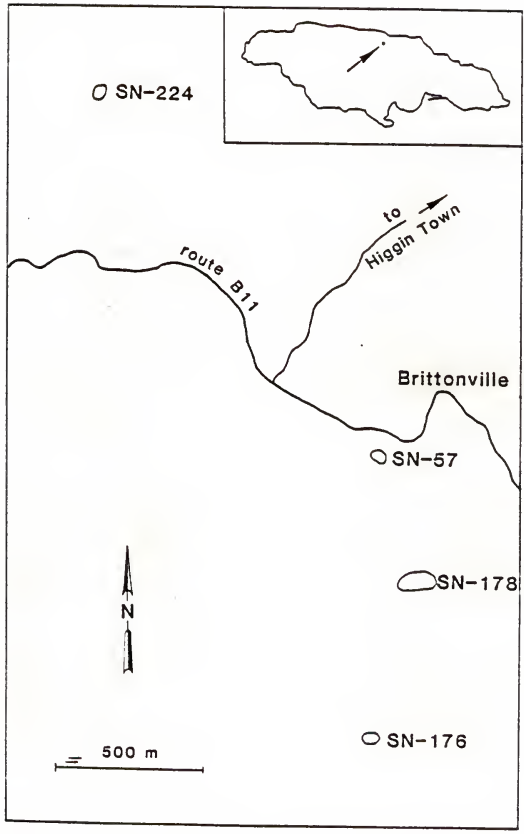

Figure 5. Map of the Pleurodonte lucerna - $\underline{P}$. sublucerna hybrid zone at Brittonville. 

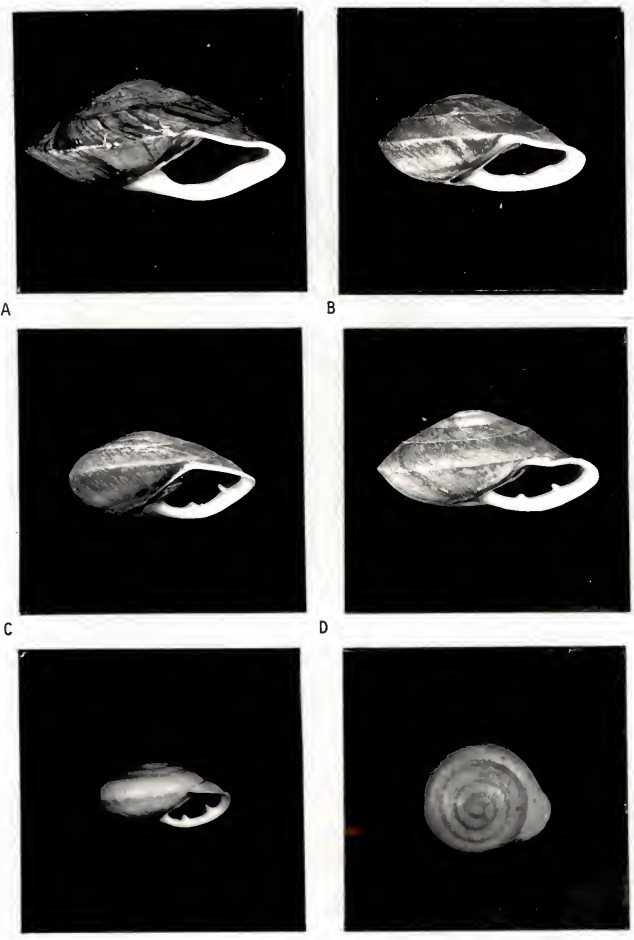

E

F

Figure 6. A-D. Shells from the hybrid zone at Brittonville.
A. $\mathrm{SN}-176 ;$ B. $\mathrm{SN}-178$;
C. $\mathrm{SN}-57$;
D. $\mathrm{SN}-224$.

E-F. Lectotype of Helix sublucerna.

All shells $0.87 \times$ 


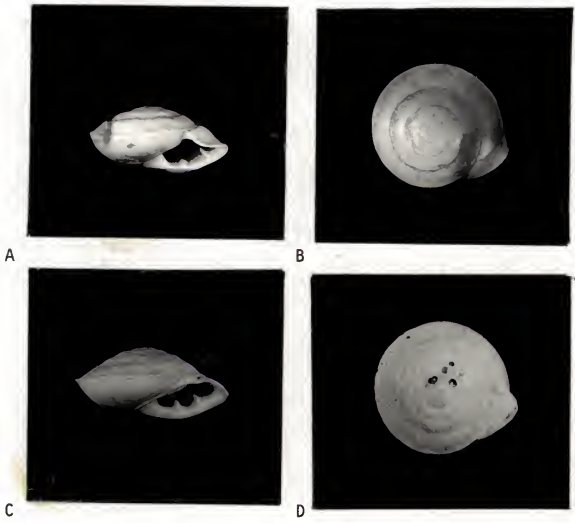

Figure 7. A, B. Type of Helix lucerna;

C, D. Subfossil Pleurodonte lucerna from SN-237.

All shells $0.87 \bar{X}$. 
THE NATURAL HISTORY OF PLEURODONTE LUCERNA

To assist in interpreting the cline in Pleurodonte lucerna in western St. Ann and its relationship to environmental variation, a brief review of the natural history of this species is presented here. Pleurodonte lucerna is a hermaphroditic pulmonate land snail in the family Camaenidae. Juveniles hatch from eggs laid in humus or leaf litter. They have very thin shells and a sharp, unmodified lip. At some point in the ontogeny of the snails, the lip of the shell becomes reflected outward and no further increase in shell size occurs. Such individuals are referred to as subadults. Maturation to the adult stage consists of a considerable thickening of the shell (especially the reflected lip) and development of the reproductive organs. The life history of $\underline{P}$. Iucerna is covered in detail in the section on the proximate cause of variation, below.

Pleurodonte lucerna is an inhabitant of forests but also occurs in banana plantations in which leaf litter is allowed to accumulate. Over most of Jamaica, $\underline{P}$. Iucerna occurs on small limestone hills; the narrow valleys between the hills have been cleared nearly everywhere. Consequently most of the hill populations are now isolated from each other.

Inactive Pleurodonte Iucerna generally occur on the ground, among leaf litter or rocks, or on soil under rocks. However, in summer, 
some juveniles in some populations climb to ca. 0.2-1 m onto tree trunks or vertical rock faces and pass their diel period of inactivity there. Activity in both adults and juveniles is closely related to moisture conditions. Adults are nocturnal, whereas juveniles are diurnal. Juveniles are dormant for ca. half the year, centered around the winter dry season. They secrete several thin, brittle calcareous epiphragms. Adults in most populations are active throughout the year, as moisture conditions permit. But in populations where the snails are small (e. g., sta. SN-65), some or most of the adults are dormant over the winter dry season. Such individuals secrete a single thin, brittle calcareous epiphragm across the aperture, outside the apertural denticles.

Pleurodonte lucerna feed on fallen plant debris, primarily leaf litter, but also fruits and flowers. Most of the food they consume is freshly fallen. They are rather selective feeders, consuming less than $10 \%$ of the available plant species. 


\section{THE ENVIRONMENTAL SETTING}

In this section I establish the ecological context in which variation along the cline transect is to be viewed. I emphasize primarily the area of St. Ann Parish, especially the western half, through which the transect was made.

\section{Summary of Geological History}

In the Cretaceous, the area presently occupied by Jamaica consisted of scattered volcanoes, ringed by reefs (Robinson et al., 1971). During most of the early Tertiary, Jamaica was a shallow bank covered with reefs. These reefs deposited hundreds to thousands of meters of calcareous sediments which became compacted to form the limestone that now covers most of the island. The Middle Miocene saw the emergence of the island. In the Middle to Late Miocene, volcanic ash fell on Jamaica. This ash is thought to be the parent material of the present-day bauxites which have accumulated between the hills of the interior (Comer, 1974). The uplift initiated in the Miocene continued through the Cenozoic and was accompanied by a buckling-up along the major (east-west) axis of the island. This produced an elevated interior plateau with a relatively steep north coastal slope. The Quaternary saw dramatic fluctuations of sea level which, combined with the continued uplift of the north side of the island, left a 
series of reef terraces along the base of the north coastal slope (Cant, 1972).

\section{Topography and Descriptive Geology}

The coastal plain of St. Ann is narrow, usually $0.5-1 \mathrm{~km}$. It consists of Quaternary alluvial deposits and/or a flat limestone bench--the reef terrace of the previous interglacial. At the base of the coastal slope there occur either low limestone hills (20-35 m) or limestone reef terraces of Pleistocene age. The limestones of the lower coastal slope (ㄷ‥ $300 \mathrm{~m}$ ) are of Miocene age and tend to be relatively impure. The residuum produced from their dissolution forms a rather thick layer of mineral soil which mostly covers the limestone. The topography is a doline karst (Sweeting, 1958), consisting of low elongate hills (muning perpendicular to the coast) separated by wide, shallow depressions. This rolling landscape is occasionally cut by stream gullies.

In western St. Ann, the coastal slope rises to ca. $450 \mathrm{~m}$ over 6 $\mathrm{km}$ and then more gradually to the interior plateau at ca. $600 \mathrm{~m}$. In central St. Ann, the coastal slope rises up abruptly to ca. $650 \mathrm{~m}$ (at Chippenham Park). The upper coastal slope and interior plateau consist of limestone of Eocene to Oligocene age. Like the lower coastal slope, the upper coastal slope is a doline karst but is cut by few streams. The interior plateau has a cockpit karst topography consisting of small, closely-spaced, round or slightly elongate hills, $60-120 \mathrm{~m}$ in height. 


\section{Wind}

The major winds are the northeasterly to east-northeasterly trade winds (Jamaican Meteorological Service, 1973). During the winter, cold air masses occasionally pass down from the north. During the summer, tropical disturbances come from the south or east. Land-sea breezes occur along the coast.

\section{Rainfa11}

Rainfall in Jamaica is predominantly orographic--the result of the interaction of topography with air masses. Throughout Jamaica rainfall is distinctly seasonal. A major dry season occurs during the winter and a minor one during the summer (Jamaican Meteorological Service, 1973). The coast of St. Ann is generally dry (1.21 m mean annual rainfall at Discovery Bay, 1931-1960; $0.98 \mathrm{~m}$ at Runaway Bay) but becomes wetter to the east (ca. $1.53 \mathrm{~m}$ at St. Anns Bay and Ocho Rios)(figures 1 and 9)(Jamaican Meteorological Service, ms). At Discovery Bay (figure 8), a moderately moist May is followed by a rather dry summer and a long autumn wet season (October to January). At Brown's Town, at the top of the coastal slope above Discovery Bay, conditions are wetter $(1.69 \mathrm{~m} / \mathrm{yr})$ due to orographic effects. The seasonal pattern is similar to Discovery Bay but rainfall is slightly higher at all seasons. At Chippenham Park, to the east where the top of the coastal slope is somewhat higher, the rainfall is especially heavy $(2.30 \mathrm{~m} / \mathrm{yr}$ ). Downwind (west-southwest) from this wet spot there is a rain shadow, which extends from south of Brown's Town to 
Alexandria $(1.32 \mathrm{~m} / \mathrm{yr})$ and west to Watt Town $(1.36 \mathrm{~m} / \mathrm{yr})$. As compared to Brown's Town, the summer dry season at Alexandria is somewhat less pronounced and the autumn wet season is shorter (September to November). Further south, mean annual rainfall increases, so that at Cave Valley mean annual rainfall $(1.57 \mathrm{~m})$ is similar to that of Brown's Town. However the seasonal distribution of rainfall differs from the latter in that the autumn wet season is shorter, the winter is especially dry, and the summer is wetter. The decreased winter rainfall is due to a decrease in the frequency of cold fronts reaching inland from the north. Higher summer rainfall is due to penetration of summer storm systems from the south; these typically penetrate only as far north as Alexandria (personal observation). Rainfall shows considerable annual variation. Annual rainfall totals at Brown's Town varied from $1.17 \mathrm{~m}$ to $2.33 \mathrm{~m}$ over 20 years between 1956 and 1978. At Cave Valley, totals varied from $1.15 \mathrm{~m}$ to 2.11 m over 16 years between 1958 and 1977. Very wet years are the result of hurricanes or tropical storms. Annual rainfall variations are strongly correlated among stations.

\section{Temperature}

No temperature data from St. Ann weather stations are available. However, it is expected that mean annual temperature should be largely a function of elevation and, perhaps to a lesser extent, mean annual rainfall. A simple multiple linear regression of mean annual temperature on elevation and mean annual rainfall (with interaction 
term) was performed on data from the 16 island-wide weather stations for which data were available (Jamaican Meteorological Service, 1973). The overall regression was highly significant $\left(F_{3,12}=43.2\right.$, $\left.\mathrm{p}<0.0001 ; \mathrm{R}^{2}=0.915\right)$. But the interaction term was non-significant $\left(F_{1,12}=0.61, p=0.45\right)$ and was therefore dropped from the model. The model without the interaction term gives $R^{2}=0.911$ $\left(F_{2,13}=66.43, p<0.0001\right)$. Rainfall was found to make a non-significant contribution to this regression $\left(F_{1,13}=2.50\right.$, $\mathrm{p}=0.14$ ) and so was excluded from the model. This permitted inclusion of data from five additional weather stations for which only temperature and elevation data are available. The final model of mean annual temperature $(\mathrm{T})$ in ${ }^{\circ} \mathrm{C}$ as a function of elevation ( $E$ ) in kilometers is: $\mathrm{T}=-5 \cdot 20 \mathrm{E}+25 \cdot 54$. This relationship is highly significant $\left(F_{1,14}=201.6, p<0.0001 ; R^{2}=0.914\right)$. The estimated slope indicates that a mean temperature decrease of $5.2^{\circ} \mathrm{C} / \mathrm{km}$ elevation, which is very close to the wet adiabatic lapse rate (rate of cooling of rising saturated air) of $6^{\circ} \mathrm{c} / \mathrm{km}$. The slight deviation of certain stations from the regression line fall into two categories:

1. Local topographic effects. At Worthy Park, which lies at 380 $m$ elevation in an interior valley surrounded on all sides by higher ground $(450-900 \mathrm{~m})$, the observed mean annual temperature is $1.0^{\circ} \mathrm{C}$ cooler than predicted from its elevation. The difference is probably due to the drainage of cooler air into the valley.

2. Differences between coasts. North coast stations are an average of ca. $1^{\circ} \mathrm{C}$ cooler than south coast stations. The reason for this difference is not known. 
Neither of these situations would produce variation in temperature independent of elevation in the area covered by the cline transect.

Seasonal temperature range at weather stations is relatively small. At Montego Bay, St. James ( $1 \mathrm{~m}$ elevation), mean monthly temperature ranges from $23.5^{\circ} \mathrm{C}$ (January) to $26.7^{\circ} \mathrm{C}$ (July and August). At Worthy Park, St. Catherine, the range is $20.1^{\circ} \mathrm{C}$ (January) to $24.1^{\circ} \mathrm{C}$ (September).

The temperature experienced by snails on the ground will differ from weather station temperatures due to several factors: direction of exposure of the slope (whether north, south, etc.), degree of horizon obstruction (angle to horizon; see Geiger, 1973), ground moisture, and shading by vegetation. The first two factors should vary predominantly within hills, rather than among hills, the base of the south side of a hill being coolest and the top of the north side of a hill being warmest. All else being equal, the ground should be slightly cooler on average at wetter localities.

\section{Vegetation}

The north coast of St. Ann was originally covered with forest--the Dry Limestone Forest of Asprey \& Robbins (1953). Here, as on the coastal slope, the forest has been largely cleared and exists now only in small isolated patches. The forest (as seen at sta. $\mathrm{SN}-37$ and the Discovery Bay Marine Laboratory, $2 \mathrm{~km}$ west of Discovery Bay) consists of small trees (8-15 m high) forming a slightly incomplete canopy. The flora is a mixture of evergreen and deciduous 
species. Epiphytes are moderately abundant; the understory is relatively dense and ground layer is sparse.

The vegetation of the interior plateau (the Wet Limestone Forest of Asprey \& Robbins, 1953) is similar in both wetter and drier areas of St. Ann. The forest consists of slender trees (generally $6-30 \mathrm{~cm}$ diameter at breast height), forming a mostly closed canopy at 12-20 m. Nearly all trees are evergreen. Epiphytes are moderately abundant. The understory is moderately dense and consists primarily of small trees. The ground layer is very sparse ( $<5 \%$ cover). On the plateau, forest occurs on most hills but all valleys are cleared. Most of the forest is probably original but has been selectively cut to varying degrees.

\section{Ground Structure}

Coastal forests occur on deeply honeycombed limestone benches. A thin rendzina soil accumulates in hollows in the limestone. Leaf litter is generally sparse but may accumulate $4-5 \mathrm{~cm}$ deep in hollows.

The degree of rockiness of the upper coastal slope and interior plateau forests is very variable. Typically, honeycombed limestone rubble (5-70 cm maximum dimension and piled up to $80 \mathrm{~cm}$ deep) mostly or completely covers the ground. At the other extreme, there may be only occasional loose rocks (5\% cover). At all sites a loose mull humus layer (ca. $3-20 \mathrm{~cm}$ thick) is present. This layer is held together by a root mat. It may cover or surround the limestone rubble or occur directly on top of the mineral soil where rubble is scarce. 
Mineral soils on the hills are light brown to reddish and very clayey. The A horizon is generally lacking or poorly developed. Both humus and mineral soil are weakly alkaline ( $\mathrm{pH} 7.6-7.7$ at sta. SN-137; $7 \cdot 3-7.7$ at sta. SN-65).

\section{Environmental Variation along the Cline Transect}

The snails at the coastal station (SN-37, figure 9) are living in a relatively hotter and drier environment than the other populations on the interior plateau. The environmental extremes at the coast are exaggerated during the winter dry season by the semi-deciduous characer of the vegetation there, which causes more insolation to reach the ground. On the plateau, the forests are evergreen. Temperature is probably relatively uniform along the transect on the plateau, although local variation may be produced by different degrees of exposure. Mean annual rainfall at the edge of the plateau (SN-207) is relatively high and decreases southward, due to a rain shadow effect. Further into the interior, the rainfall increases again, such that at Cave Valley $(\mathrm{SN}-129)$ at the end of the transect, the mean annual rainfall is similar to that at the edge of the plateau. Considerable variation exists in the degree of rockiness of the substrate but no geographic trends are apparent. 


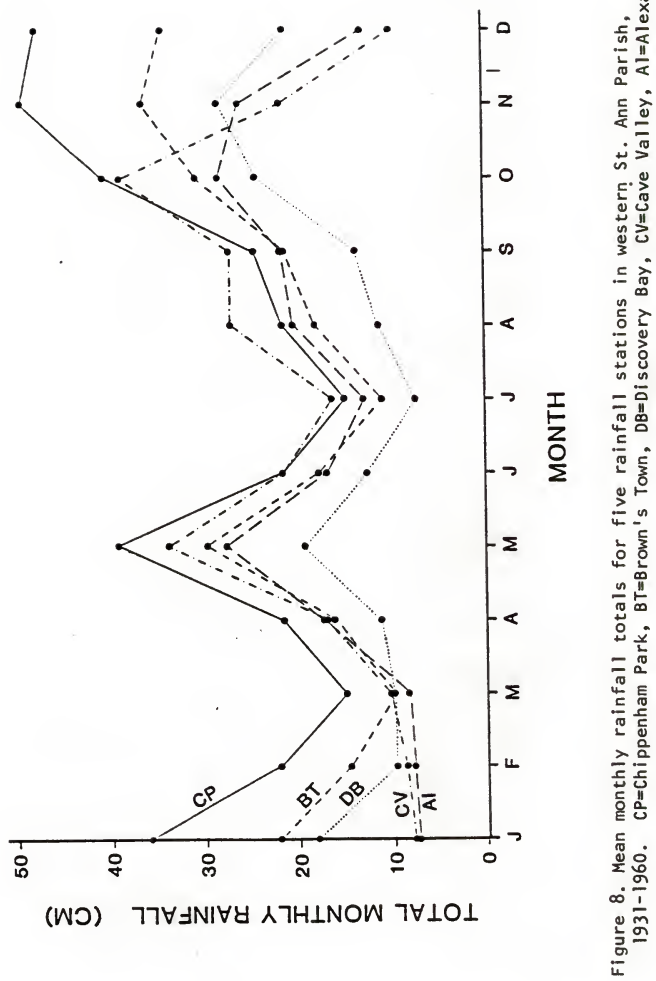


THE CLINE

Geographic variation in Pleurodonte lucerna was sampled along a north-south transect from near Discovery Bay to Cave Valley (figure 9). Fifteen populations were studied. No populations on the coastal slope were found along the transect, although a population of $\underline{P}$. lucerna (sta. SN-93) occurs on the coastal slope $2.2 \mathrm{~km}$ west of the transect.

The following characters were measured: shell diameter, shell height, relative height of shell, height and relative height of the inner and outer denticles, and peripheral angle. Diameter and height are general indicators of shell size, whereas relative height (height/diameter) is a measure of shell shape (Cain, 1977). Relative denticle height (denticle height/diameter) was calculated in addition to absolute height measurements for two reasons. First, it is perhaps more directly functionally interpretable, since, by taking size into account (as measured by diameter), it is an indicator of the degree to which the denticles block the aperture. Secondly, it is a convenient measure of the deviation of dimensional relationships from isometry, since relative denticle height would be constant under a null hypothesis of isometric relations of shell dimensions among individuals and populations. Peripheral angle provides a quantitative 
characterization of the degree of roundness (high peripheral angle) or angularity (low peripheral angle) of the shell periphery.

\section{Materials and Methods}

All populations were sampled within forests, from areas less than ca. $50 \mathrm{~m} \mathrm{X} 50 \mathrm{~m}$. For each population, 21 individuals were measured. Specimens analyzed were either live-collected or fresh dead, i. e., with periostracum still present. There was no possibility that the latter may have been transported from neighboring hills since terrestrial hermit crabs do not utilize the shells of $\underline{P}$. lucerna and, in any case, are found only as far inland as the top of the coastal slope.

Shell diameter and height were measured as above. Denticle height was measured at $6.6 \mathrm{X}$ using a microscope ocular micrometer with a cross hair attached to it, with one axis of the cross hair parallel to the micrometer scale. The shell was placed so that the line of the cross hair perpendicular to the micrometer scale was tangential to the inside of the lip of the shell on both sides of the denticle to be measured. Denticle height was then read off the micrometer scale and converted to millimeters. This method permitted measurement to the nearest $0.15 \mathrm{~mm}$ (the width of one micrometer unit). Peripheral angle was measured at a point $45^{\circ}$ ( $1 / 8$ whorl) behind the lip by the method of Goodfriend (1983a). 


\section{Univariate Analysis of Variation}

\section{Population Means}

Pleurodonte lucerna has a very small mean diameter at the coastal station SN-37 (figures 10 and 11A, B). The diameter is large in snails at the top of the coastal slope (SN-207; figure 11C, D), then decreases rapidly to SN-65 (figure 11E, F). South of SN-65, there is a regular and gradual increase in mean diameter to SN-68. From there to Cave Valley (SN-129), the shells remain large (e. g., SN-137. figure $12 \mathrm{C}, \mathrm{D})$, although some variation is seen. Variation in other characters generally follows an approximately parallel trend. Peripheral angle is high in the small SN-37 snails, low in the large SN-207 snails, and then increases rapidly with decreasing snail size to $\mathrm{SN}-65$. To the south there is little change in peripheral angle until SN-152 (cf. SN-148, figure 12A, B), where it becomes angular (low angle) and then gradually keeled (very low angle) further south. Absolute shell height follows the trend for diameter, but relative shell height shows the opposite trend, with relative height decreasing with increasing diameter. The coastal population (SN-37) has relatively large denticles and the large shells at $\mathrm{SN}-207$ have relatively smaller denticles. Relative denticle size increases rapidly as shell size decreases to $\mathrm{SN}-65$, then continues to increase more gradually to $\mathrm{SN}-203$. Further south there is a rapid diminution of relative tooth height as the shells become larger and more keeled. The trend of absolute denticle height (not shown) is quite similar. 
Shell thickness was measured in several representative populations: the small rounded shells of the coast (SN-37) and interior (SN-76), and large keeled (SN-137) and angular (SN-152) shells of the interior. A small disc (ca. 3-4 mm in diameter) was removed from the base of each shell ca. $225^{\circ}$ behind the aperture by a high-speed pneumatic drill. The thickness of the disc was measured to $0.01 \mathrm{~mm}$ using a ball and anvil-tipped dial micrometer. Relatively little variation was found in absolute shell thickness (table 5) as compared to shell size. Shell thickness is not proportional to size, as measured by diameter, but rather, populations with smaller shells have relatively thicker shells. The relatively thinnest shells (SN-137) are also the largest. Thus shell thickness appears to vary concordantly with the other shell characters described above. Spatial Autocorrelation

In order to test whether the observed spatial patterns are non-random, a spatial autocorrelation analysis was carried out on one selected variable, mean shell diameter, using Moran's coefficient I as the test statistic (Cliff \& Ord, 1973). The test was set up to evaluate whether adjacent stations are less or more similar than would be expected if mean diameter were randomly distributed along the transect. This was done by taking the connectivity values as 1 for adjacent stations and 0 for non-adjacent stations. The coastal station was not included in the analysis because of the large gap between it and the other stations. Because of the small sample size (14 stations), the distribution of the test statistic I under the null hypothesis of random geographic variation in mean shell diameter was 
derived empirically through a Monte Carlo simulation. A SAS (Statistical Analysis System) program was written to produce 500 random sequences of the 14 stations and to calculate I for mean shell diameter for each of these sequences. The derived distribution of I is shown in figure 13. The value of I calculated for the true sequence of stations was 1.64, which is higher than any of the 500 random values that were generated (highest=1.37). Therefore the null hypothesis of a random geographical pattern is rejected with $p<<0.002$ (1-tailed test). The positive value of I indicates that mean diameters of snails at adjacent stations are more similar to each other than to those at more distant stations. Thus clinal variation is indicated.

\section{Bivariate Analysis of Variation}

Correlations between character means were apparent from the univariate geographic trends considered above. In this section I examine these correlations between population means and consider also correlations between characters within populations.

Selection of a statistic for assessing correlations depends on the frequency distributions of the variables. Since all population samples are relatively small $(n=21)$, the distribution of the variables within a population cannot be determined. To circumvent this problem, I have, for each variable, combined measurements from the three populations whose means are most similar for that particular variable. Frequency histograms (with $n=63$ ) for each of the variables were 
produced from these data. In most cases these histograms take the form of bell-shaped curves and are therefore considered approximately normal. The distribution of the height of the outer denticle and the peripheral angle appear to be skewed to the right, but only weakly so. Given these results, I have selected a parametric statistic, the correlation coefficient, to evaluate character correlations. Tests of significance using this statistic assume approximate normality.

Under the assumption of isometric relations of shell form among individuals and populations, all linear measurements should be positively correlated, whereas ratios (relative height, relative denticle height, and peripheral angle) should be independent of linear measurements. Deviations from this pattern indicate allometric relationships among variables.

Because of the large number of comparisons involved (especially within populations), the criteria for accepting the significance of a particular correlation must be more stringent than usual. Correlations between Population Means

From table 6 it can be seen that in populations with larger diameter shells, the shells tend to be absolutely higher but relatively flatter. The denticles of populations with larger shells are relatively smaller and also absolutely smaller in the case of the inner denticle. The absolute and relative heights of the inner denticle are so highly correlated that the measurements are almost completely redundant. The absolute and relative heights of the outer denticle are also strongly correlated but less so. Peripheral angle is strongly negatively correlated with diameter and positively 
correlated with relative height. Its correlation with absolute height is not significant. The overall pattern of correlations is thus as follows: populations with large shells tend to have absolutely higher but relatively flatter shells, with relatively smaller denticles and a more keeled periphery; populations with smaller shells tend to have absolutely flatter but relatively higher shells with relatively large denticles and a rounded periphery.

Correlations within Populations

Correlations between characters among individuals of a population (table 7) show a different pattern from correlations among population means. Despite a larger sample size (21 vs. 15), relatively few of the correlations are significant at the 0.01 level. As in comparisons among populations, the correlation between height and diameter within populations tends to be positive, although significantly so only in some populations. Height and relative height are very strongly positively correlated within populations. This, in combination with the tendency for a positive height-diameter correlation, indicates that shell height increases somewhat faster than diameter. This pattern is the opposite of the strongly negative among-population correlation between height and relative height, which indicates that height increases slower than diameter. The within population trend can be interpreted as the result of the pattern of shell ontogeny; this is considered in the following section. The trend among populations must be due to among-population differences in shell ontogeny. 
Denticle height is independent of or positively correlated with diameter within populations, not negatively correlated as among-populations. Again, differences among populations in shell ontogeny are indicated. All measures of denticle height tend to be positively correlated with each other or independent of each other within populations. The relationship is in the same direction among populations but it is stronger. A possible common ontogenetic control of both denticles is suggested. Peripheral angle is sometimes negatively correlated with diameter within populations and strongly negatively correlated among populations. This correlation is to a certain extent a purely geometric consequence of doming--relatively higher shells have steeper sides. Other characters that are correlated among populations (peripheral angle with measures of denticle height, relative height with measures of denticle height) are independent within populations. There do not seem to be any developmental dependences between these characters; correlations among populations are due to other factors.

\section{Shell Ontogeny}

Size differences among populations can be caused by variation in a number of different ontogenetic variables. Adult shell diameter can be seen as the sum of the width contributions of the whorls of the shell. As such, it is affected by the number of whorls, the widths of the individual whorls (suture to periphery), and the angle of descent of the whorls. The analysis presented below employs the method of 
Goodfriend (1983a) to characterize the ontogenetic basis of differences in adult diameter. In this method the contribution of a whorl to diameter (the whorl radius, measured perpendicular to the axis of coiling) is geometrically analyzed into whorl width (measured radially from suture to periphery, which is also the suture with the following whorl for all but the last whorl) times a factor ( $\leq 1)$ which measures the amount by which the downward component of the whorl width reduces its contribution to whorl radius. This factor is a function $(\sin \alpha)$ of the angle of descent of the whorl $(\alpha)$, which is measured as the angle between the whorl width and a line perpendicular to the axis of coiling. Whorl width and radius are plotted on a log scale, so that isometric trends will appear as straight lines. The differences between whorl width and radius is a function of the angle of descent.

Whorl characteristics were measured every $180^{\circ}$, starting from the point where the lip begins to flare out and working back. Dimensions at standard whorl numbers $(2.0,2.5$, etc.) were obtained by interpolation. This permitted the means of each population to be estimated at each of these points. Five specimens were analyzed from each of four populations chosen to represent the full range of shell size and form along the transect: small rounded shells ( $\mathrm{SN}-37)$, larger rounded shells (SN-76), medium-sized angular shells (SN-148), and large keeled shells (SN-137).

Whorl ontogeny of $\mathrm{SN}-37$ and $\mathrm{SN}-76$ shells is similar (figure 14). The major difference seen is that the SN-37 shells start out significantly smaller at whorl 1. Both show an approximately 
isometric increase in whorl width and radius from whorl 1 to whorl 2 . From whorls 2 to 3.5 , the SN-76 and SN-37 shells show an approximately isometric increase but at a slower rate than in the earlier whorls. The angle of descent increases gradually, so that whorl width increases faster than whorl radius. In the final 1.5 whorls of the SN-76 shells, whorl width continues to increase isometrically until the last ca. $1 / 2$ whorl, where it shows a slight decrease. The angle of descent increases steadily and causes a decreasing contribution of the whorl width to the whorl radius. In the SN-37 shells, whorl width increases slightly faster than after whorl 3.5 , but, as in the $\mathrm{SN}-76$ shells, the last ca. $1 / 2$ whorl shows a decrease in whorl width. The angle of descent shows a sharp increasse later in the SN-37 shells than in the SN-76 shells, so that the whorl radius decreases only after whorl 4.5. SN-37 shells generally have more whorls than the SN-76 shells. The smaller adult diameter of the SN-37 shells is thus due to the smaller initial size, which counteracts the effects of a slightly greater rate of whorl expansion in the later whorls and the greater number of whorls.

SN-137 and SN-148 shells start out with the same size at whorl 1 (figure 14B). They show a similar, nearly isometric trend up to whorl 2.5. The SN-137 shells show a gradual negative allometric increase in both whorl width and radius and a gradual increase in the angle of descent up to the last $1 / 2$ whorl. But in the SN-148 shells, whorl width shows a noticeable negative allometry between whorls 2.5 and 3 . The relatively narrower whorl width is maintained in later whorls, although whorl width continues to increase more or less in parallel 
with the SN-137 shells. The last $1 / 2$ whorl of the SN-137 shells shows a slight decrease in whorl width but the trend in the angle of descent continues as in earlier whorls. In the SN-148 shells, the angle of descent increases significantly between whorls 4 and 4.5 and then remains constant to the termination of growth. No narrowing of whorl width is seen. The SN-148 shells generally have more whorls than the $\mathrm{SN}-137$ shells. SN-137 shells tend to have a larger diameter than SN-148 shells due to a higher rate of whorl expansion of the later whorls and a smaller angle of descent of the last whorl, despite a slightly smaller number of whorls.

Whorl 1 of the SN-76 shells is similar to the SN-148 shells. But whorl width increases less rapidly in the SN-76 shells after whorl 2. There is also a much greater increase in the angle of descent in the SN-76 shells, beginning at whorl 2 and eventually (after whorl 3.5) producing a diminishing contribution of whorl width to whorl diameter. Thus the SN-76 shells have a smaller diameter than the SN-148 shells due to a slower rate of whorl expansion and a higher angle of descent of the later whorls.

One ontogenetic pattern common to all populations is that of an increasing angle of descent over the course of development. This pattern is much more pronounced in populations of snails that reach a smaller adult size and is responsible for the negative correlation between relative height and diameter observed among populations. Within populations, this ontogenetic pattern (doming) is responsible for the strong positive correlation between height and relative height. 
The relation of whorl number to adult shell diameter was studied in more detail in four populations chosen to represent the range of shell diameter along the transect. Measurements were made on 15 specimens from each population. A tendency for populations with smaller shell diameter to have more whorls was found (figure 15). However, this pattern is not fully consistent, since SN-187 shells tend to have more whorls than the smaller SN-76 shells. Within populations, diameter and whorl number are usually independent (SN-37 with $\mathrm{r}=0.14, \mathrm{p}=0.61$; $\mathrm{SN}-76$ with $\mathrm{r}=0.01, \mathrm{p}=0.98$; $\mathrm{SN}-137$ with $\mathrm{r}=0.15$, $\mathrm{p}=0.60$ ); but they are positively correlated in the $\mathrm{SN}-187$ snails $(\mathrm{r}=0.61, \mathrm{p}=0.02)$. Even in the $\mathrm{SN}-187$ snails, variation in whor 1 number accounts for only about $1 / 3$ of the variation in shell diameter. Size differences both among and within populations are the result of ontogenetic differences other than whorl number.

These results indicate that there is no one consistent ontogenetic cause for differences among populations with respect to shell diameter. Variation among populations is caused by differences in initial whorl size, in whorl expansion rate in different stages of ontogeny, in the angle of descent in later whorls, and in whorl number.

\section{Multivariate Analysis of Variation}

A principal component analysis was carried out on the correlation matrix of population means to determine whether any patterns not noticed in the univariate or bivariate analyses might be revealed by 
consideration of all variables simultaneously. Relative measures of shell height and denticle height were used in order to eliminate isometric size-correlated variation. The analysis thus examines the "residual" allometric patterns of variation.

The first principal component (table 8) accounts for $89 \%$ of the variance and give approximately equal weight to each of the five characters. It distinguishes smaller, relatively high shells with relatively large denticles and rounded periphery from large, relatively flat shells with relatively small denticles and a keeled periphery, as indicated by the loadings of the transect population means on this axis (figure 16). This is the same pattern noted in the univariate and bivariate analyses. The clinal aspect of the variation among populations shows itself in the fact that the stations plot out in geographic sequence along this axis.

The second principal component accounts for ca. $2 / 3$ of the $11 \%$ residual variance. It is independent of diameter and compares peripheral angle to denticle size (table 8). From the south end of the cline transect north to sta. SN-148 and SN-152, populations show increasing loading on the second principal component axis, indicating that peripheral angle increases faster than relative denticle size. From SN-152 north to SN-203, the trend reverses and peripheral angle increases slower than denticle size, producing a decreasing loading on axis two. This axis identifies the fact that the change from keeled to rounded shells (around $\mathrm{SN}-148$ ) is shifted south relative to the change from small to large denticles (around SN-187). 
The remaining three principal component axes together account for only $3 \%$ of the total variation of the data and are therefore disregarded.

\section{Coefficient of Variation}

In order to examine geographic trends in the variability of the transect populations, the coefficient of variation (standard deviation/mean) was calculated for each character in each population. Variability of shell diameter (figure 17) shows no consistent trend along the transect. Height tends to be less variable in the middle of the transect (from the large, angular forms of SN-68 to the small rounded forms of $\mathrm{SN}-76$ ). Relative height is most variable in the keeled to angular forms to the south, least variable in the small to medium-sized SN-203 and SN-187 populations, and intermediate in variability in the small rounded to large keeled forms (SN-207) of the north end of the transect. Variability of the relative height of the inner denticles is very high in the small-denticled forms at the south end of the transect. The populations with large denticles show considerably less variability. Examination of the relationship of the mean height (relative and absolute) to the standard deviation shows that they are independent for both denticles ( $p>0.60$ for all four tests). The coefficient of variation is therefore not an appropriate measure of variability for denticles, since this is size-independent. The standard deviation of denticle height shows no geographic trends. Variability of the peripheral angle shows a regular pattern, with 
keeled forms having high variability and rounded forms having low variability. Standard deviations of more keeled shells are consistently larger than those of rounded shells, so this pattern is not an artefact of the independence of standard deviation and mean, as in the denticles.

The major pattern that emerges from this analysis is that no particular section(s) of the transect shows a generally greater level of variability. The lowest variability tends to occur in the SN-187 and SN-203 populations, which are morphologically intermediate between the smaller, more rounded forms to the north and the larger, more angular forms to the south. The significance of this pattern in understanding the evolution of the cline will be discussed in the last section.

\section{Summary of Geographic Trends}

Character variation in Pleurdonte lucerna along the cline transect shows a regular pattern of clinal variation and strong correlations between characters. The snails are small at the coast and large at the top of the coastal slope. They decrease rapidly in size further into the interior and then gradually become large again. Populations of large snails have keeled, relatively flat shells, with relatively small apertural denticles, whereas populations of small snails have rounded, relatively high shells with relatively large apertural denticles. Characters tend to be weakly correlated within populations, implying a lack of developmental dependence. No regular trends in the variability of characters are seen along the transect. 
Table 5. Shell thickness in four populations of Pleurodonte lucerna. $n=12$ for each population.

\begin{tabular}{lcc} 
Station & $\begin{array}{c}\text { Mean }(+ \text { S. E. }) \text { shell } \\
\text { thickness }(\mathrm{mm})\end{array}$ & $\begin{array}{l}\text { Shell thickness } \\
\text { as \% of diameter }\end{array}$ \\
\hline SN-37 & $0.57 \pm 0.03$ & 2.0 \\
SN-76 & $0.68+0.04$ & 1.9 \\
SN-152 & $0.66 \pm 0.04$ & 1.5 \\
SN-137 & $0.60 \pm 0.03$ & 1.2
\end{tabular}




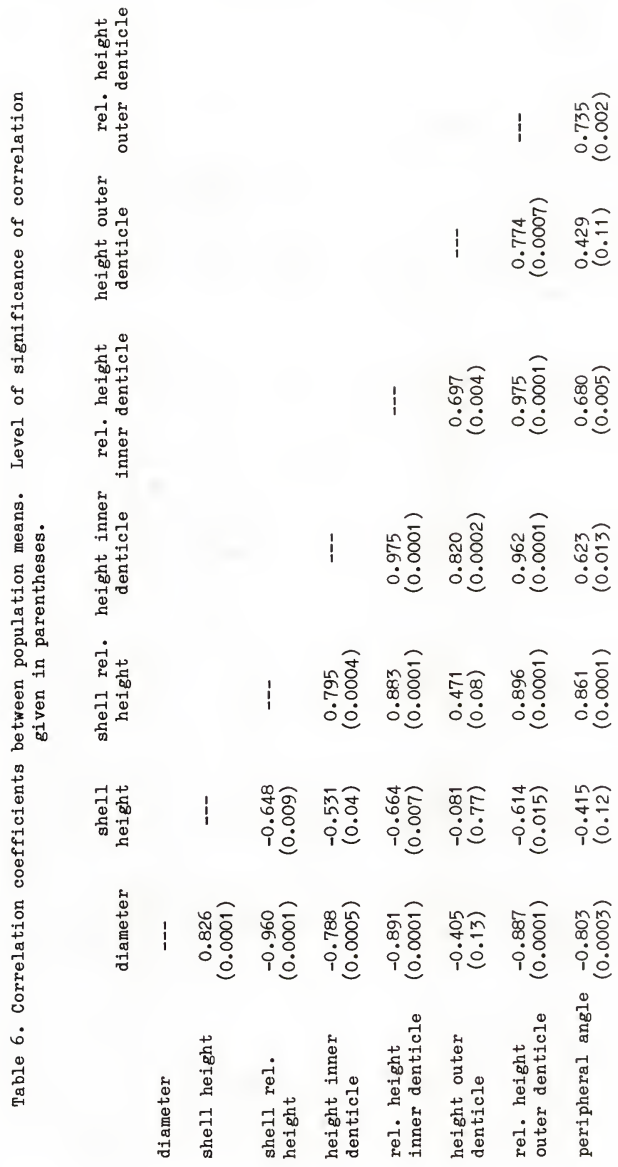




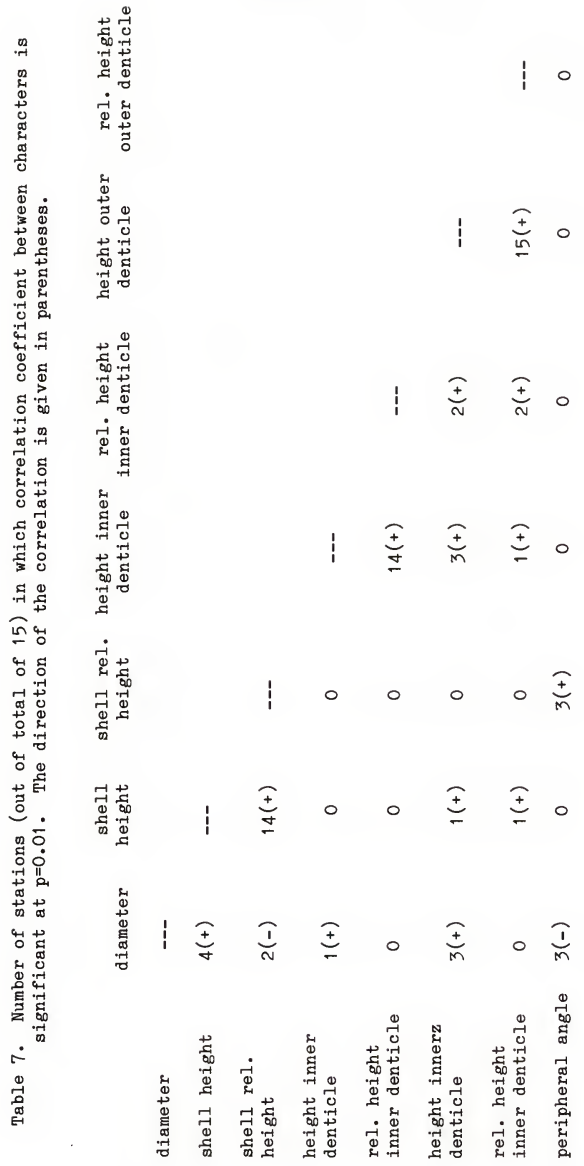


Table 8. First two axes of principal components analysis of correlation matrix of transect population means

principal component axis

1

2

diameter

$-0.459$

$-0.009$

rel. height

0.464

0.140

height inner

0.448

$-0.492$

denticle

height outer

denticle

0.454

$-0.368$

peripheral

angle

0.409

0.777

$\%$ of variance

89.2

7.7 


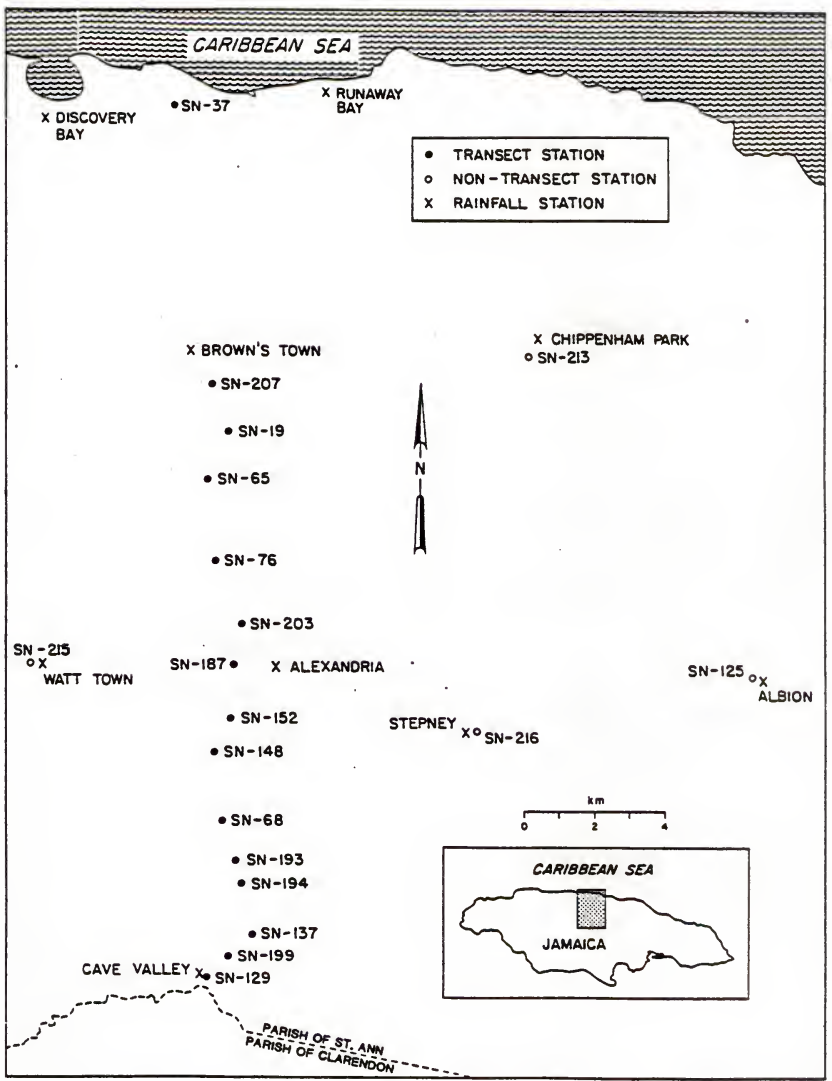

Figure 9. The cline transect stations and rainfall stations in western St. Ann Parish. 


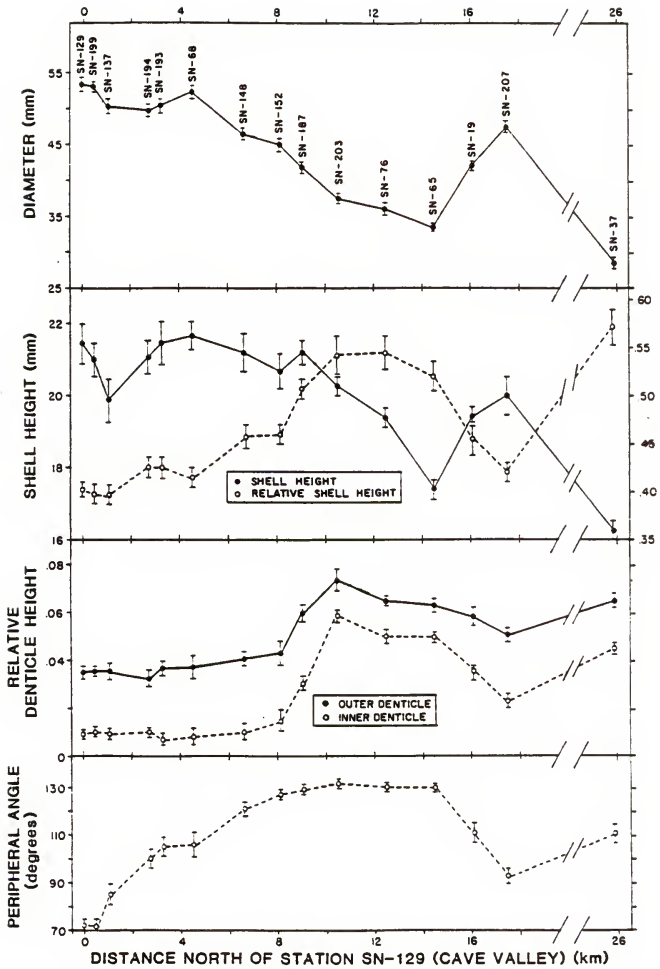

Figure 10. Variation in shell form in Pleurodonte lucerna along the cline transect. 
A
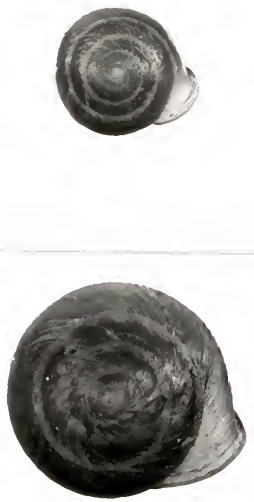

C

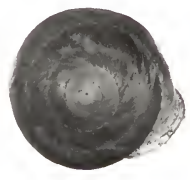

E
B
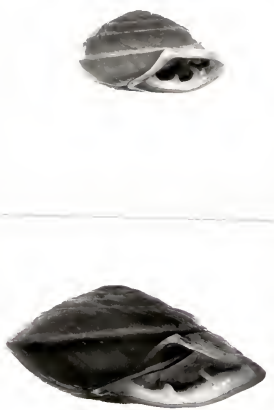

D

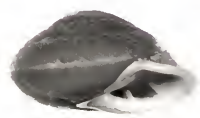

$\mathbf{F}$

Figure 11. Shells from populations along the cline transect. A, B. SN-37; C, D. SN-207; E, F. SN-65. All shells $0.9 \times$. 

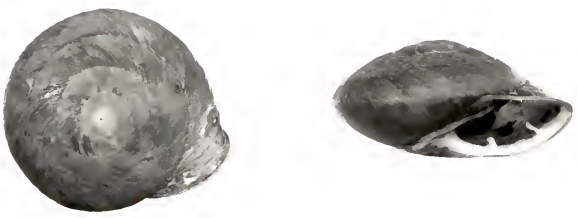

A

B
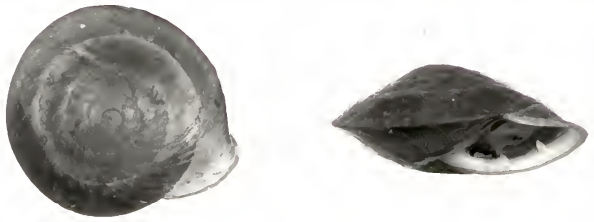

C

D

Figure 12. Shells from populations along the cline transect. A, B. SN-148; C, D. SN-137. All shells 0.9 X. 


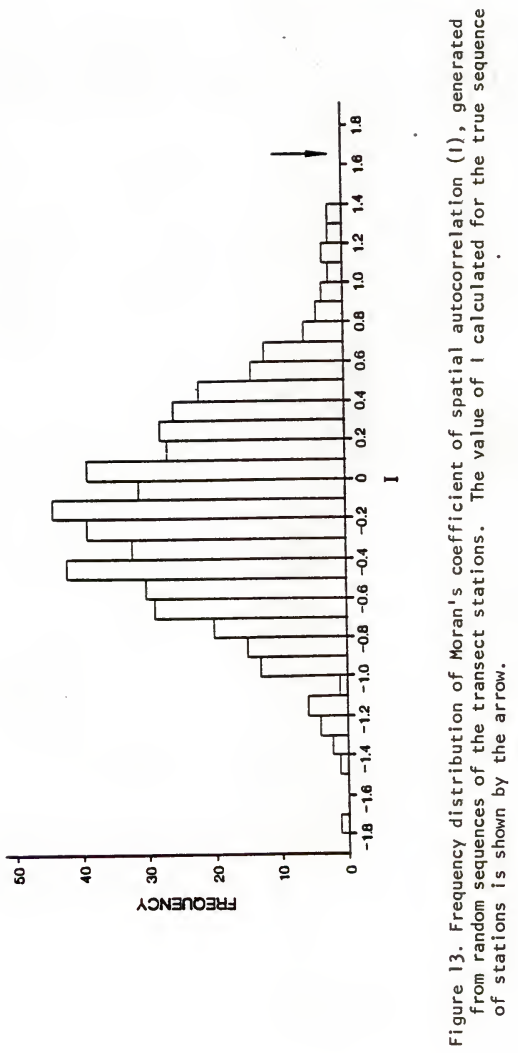




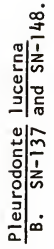

40

논

万人

뭉 뭉

믐

- $\frac{1}{2}$

ए

4

4

눈

동

ฯ

난

高

$\because \frac{n}{n}$

$\frac{\pi}{\pi}$

등

ט

-

॥

뜨으

윰

등

立

흔흔 


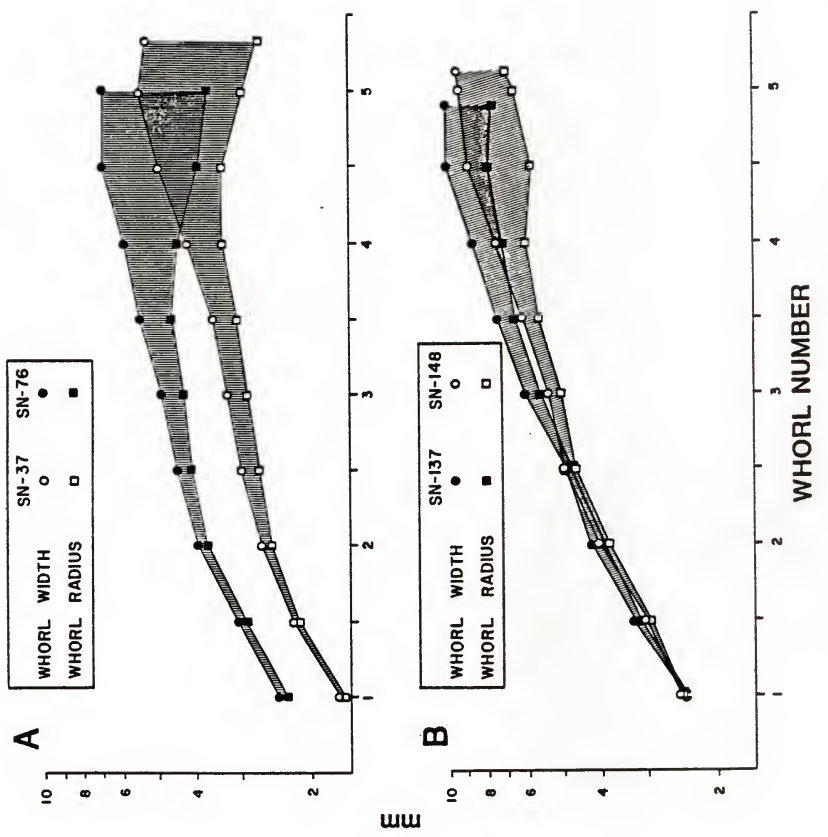




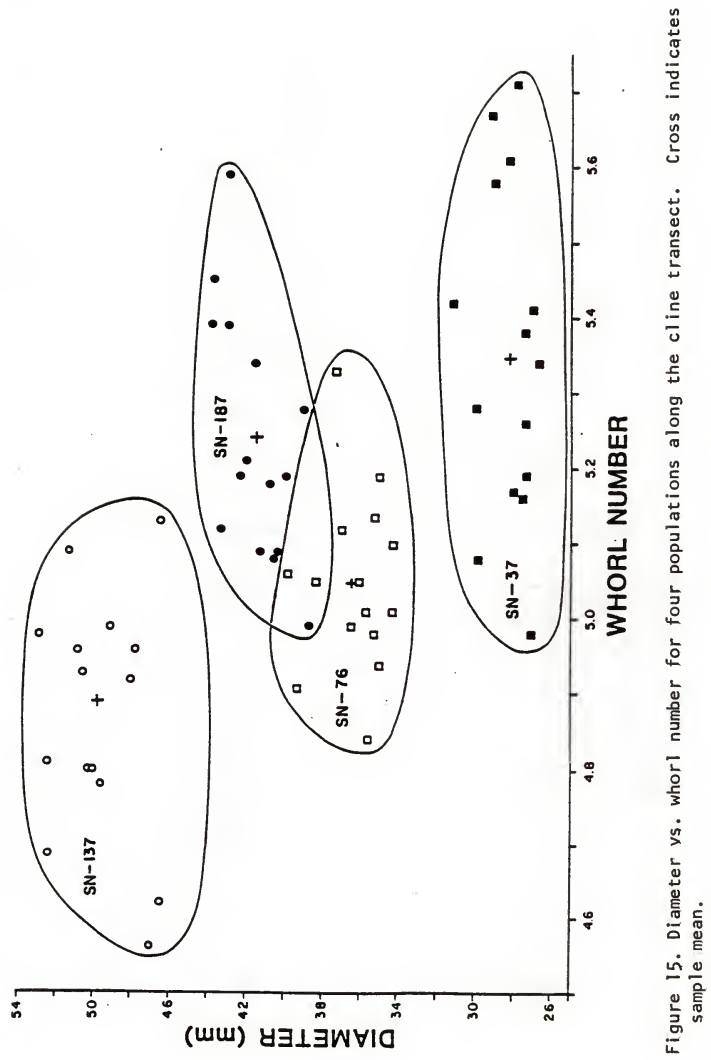




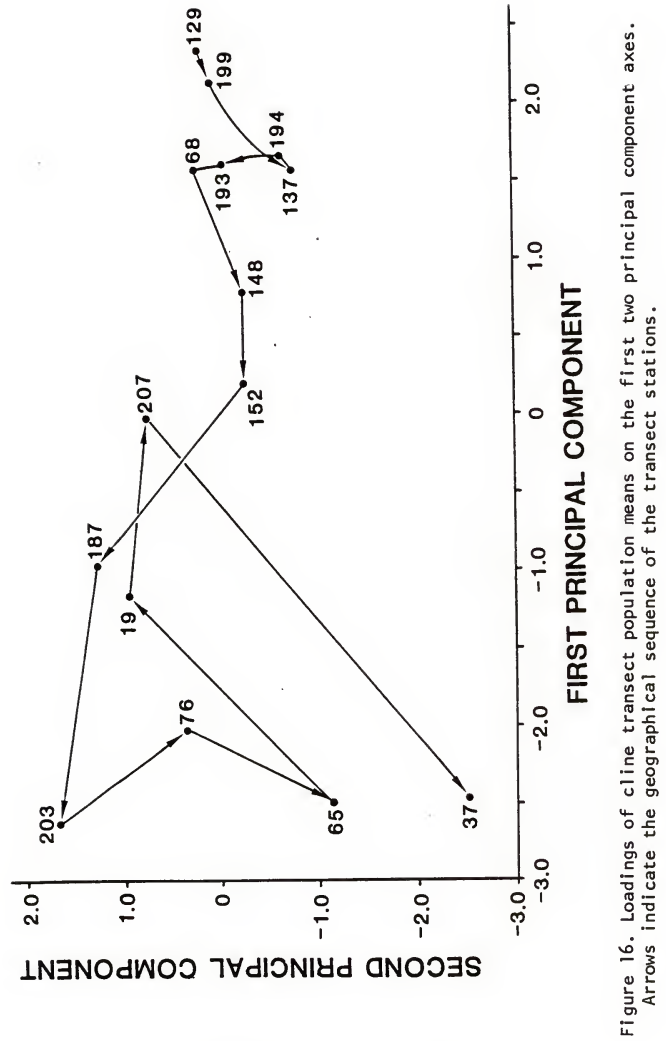


Figure 17. Variation in the coefficient of variation along the cline transect. 


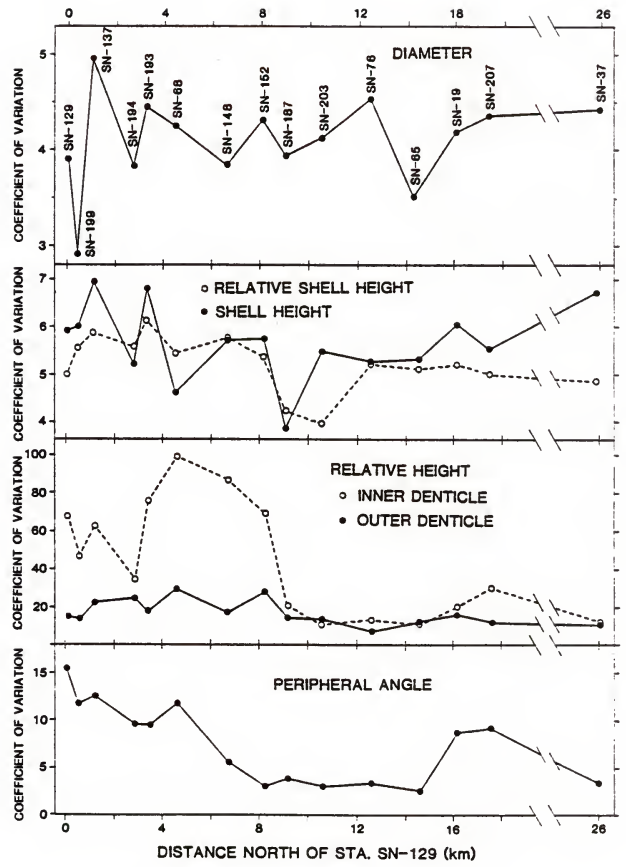




\section{RELATION OF CLINAL VARIATION TO ENVIRONMENTAL VARIATION}

It has been shown above that Pleurodonte lucerna shows regular geographic trends in shell morphology. In this section I examine the relationship between this variation and geographic patterns of environmental variation.

\section{Rainfal1}

In the course of sampling populations, it was noted that the snails in wetter areas tended to be larger than the snails in drier areas. To test this apparent relationship, the mean shell diameter of the Pleurodonte lucerna populations nearest each of the four rainfall stations along the cline transect was compared to mean annual rainfall. For sta. SN-37, which lies between the Discovery Bay and Runaway Bay rainfall stations, the mean of these two rainfall stations was taken as representing the rainfall at the site. Populations near each of four additional rainfall stations in St. Ann (figure 9) were also sampled and the diameters of their shells measured ( $n=15$ to 21 ). Mean shell diameter shows a strong positive correlation with mean annual rainfall $(r=0.84, p=0.009)$. The relationship was found to be curvilinear. A $\log _{10}$ transformation of mean annual rainfall was performed and this yielded a more linear relationship (figure 18) with a higher correlation coefficient $(r=0.89, p=0.004)$. Mean diameter (D) 
of a population can be predicted from mean annual rainfall (R) by the relationship $D=86.23\left(\log _{10} R\right)+29.70$, where $D$ is measured in millimeters and $\mathrm{R}$ in meters. Rainfall accounts for $78 \%$ of the variation in mean shell diameter.

The smallest snails of the transect are found at the dry coastal site SN-37. At the top of the coastal slope (SN-207) conditions are wetter and the snails are larger. To the south, in the rain shadow, the snails become smaller. At the south end of the cline, conditions are wetter again and the snails are correpondingly larger (SN-129). The wettest area of St. Ann, around Chippenham Park, has the largest snails $(\mathrm{SN}-216)$.

The morphology of fossil Pleurodonte lucerna from SN-37 is consistent with the present relationship of morphology to rainfall. Two Wisconsinan soil deposits containing land snails have been collected from solution holes in a recently blasted cliff face in the Pleistocene terrace at this site (Goodfriend, 1983b). The three complete specimens of $\underline{P}$. lucerna found in the deposits range from 25.6 to $26.6 \mathrm{~mm}$ in diameter, or from 1.43 to 2.22 standard deviations smaller than the mean diameter of the extant population. Denticle sizes are similar to the extant population. Two incomplete specimens (including the aperture and most of the last whorl) are similar to the complete specimens. Two of the complete specimens have a greater relative height ( 1.46 and 2.07 standard deviations above the mean) and greater peripheral angle ( 1.43 and 1.92 standard deviations above the mean) than the extant population while the third is similar to the extant population. Two lines of evidence indicate that Wisconsinan 
conditions were drier than at present in the Caribbean. It was shown by Pregill \& Olson (1981) that many West Indian vertebrates inhabiting arid environments presently occupy more restricted ranges than in the Late Pleistocene, indicating a shrinkage of arid environments since the Pleistocene. Variation in the abundances of kaolinite and quartz in Caribbean deep sea sediments was used by Bonatti \& Gartner (1973) as evidence that conditions on Caribbean islands were drier during Pleistocene glacial periods than during interglacials (including the present interglacial). Drier conditions were also present in lowland areas of the neotropical mainland during glacials, as evidenced by lower lake levels (Bradbury et al., 1981; Deevey et al., in press), pollen analyses (van der Hammen, 1974; Bradbury et al., 1981; Vaughn et al., in press), and geomorphological and biogeographical analyses (Colinvaux, 1979; Prance, 1982). The smaller size of $\underline{P}$. lucerna from dry Wisconsinan times is consistent with the present correlation between size and rainfall.

\section{Temperature}

From the consideration of temperature above, it is clear that the small snails at the coast are living in the warmest environment. The other populations, which live on the plateau at approximately the same elevation as each other (550-600 m), would experience cooler temperatures than the coastal snails. Since rainier sites on the plateau may also be slightly cooler (at least on the ground), it is not possible to independently assess the relationship of either to 
shell morphology by comparing geographic variants. However, the morphology of Wisconsinan Pleurodonte lucerna at SN-37 is inconsistent with the hypothesis that morphological variation is related to temperature. Sea surface temperatures near Jamaica were significantly cooler in the Wisconsin than at present. ${ }^{18} 0$ analysis of the tests of surface-dwelling foraminifera indicates a lowering of average temperature of $4^{\circ} \mathrm{C}$ (Emiliani \& Schackleton, 1974), while faunal analysis of foraminiferan assemblages gives an estimate of 2 to $3^{\circ} \mathrm{C}$ lower (Imbrie \& Kipp, 1971; Prell \& Hays, 1976). Evidence of Pleistocene glaciations at high elevations in the Dominican Republic also indicate formerly cooler temperatures in the Caribbean (Schubert \& Medina, 1982). If size (and correlated morphological characteristics) were causally associated with temperature and only coincidently with rainfall, then the shells of Pleistocene glacial snails should be larger than their modern counterparts. In fact they are somewhat smaller.

\section{Conspecific Density}

Several studies (reviewed above) have shown that in land snails, population density may affect adult size. In order to evaluate the possibility that this could control variation in shell size in Pleurodonte lucerna, data on population density from two populations were considered: the small snails at SN-65 and the large snails at $\mathrm{SN}-137$. Only the density of adults was estimated, since there are many problems associated with estimation of juvenile density 
(difficulty of refinding individuals and large temporal variation in abundance). Subjective impressions of density differences among sites are also discussed.

Methods

Density estimates were obtained by estimating the mean number of adults observed per unit area and dividing this by an estimate of the proportion of the total adult population that was observed (search efficiency). A grid of stakes $2 \mathrm{~m}$ apart was installed at each of the two sites ( $18 \times 14 \mathrm{~m}$ area at SN-65; $20 \times 14 \mathrm{~m}$ area at $\mathrm{SN}-137)$. The placement of the grids was determined on the basis of the relatively high density of snails observed in the selected areas. The surface of the forest floor within the grid area was searched with the aid of a calcium carbide miner's lamp on wet nights starting two hours after sunset. The position of each adult observed was characterized by 1) the quadrat it was in, if in the outer $4 \mathrm{~m}$ of the grid (figures 19 and 20), or 2) the exact position to the nearest centimeter if in the central area (CU plus CL at SN-65; CL, CC, CR at SN-137). Subsequently, this central area was divided into quadrats and the snails were characterized by the quadrat in which they were found. Counts were made on 9 wet nights (April-December) at SN-65 and 19 wet nights at $\mathrm{SN}-137$ (throughout the year). No seasonal trends in numbers observed on wet nights were noted, except that during the winter at $\mathrm{SN}-65$, most snails remain inactive despite occasional rains. Counts on such nights were not used to estimate density.

To estimate the proportion of the total population that was observed on these night searches, a thorough daytime search was made 
through all the leaf litter and under loose rocks in the central areas at each site on eight days when the leaf litter was wet. The individual numbers of the snails found were recorded (the snails had been numbered previously by notching the shell margins). On the night following the daytime search, a surface search was made of the central area and the $4 \mathrm{~m}$ border area around it, as above. The individual numbers of the snails encountered were recorded. Assuming that the probability of recapturing at night any particular individual recorded during the day is the same as the probability of capturing any particular unrecorded individual, then the ratio of the number of individuals recaptured at night to the number of snails recorded during the day gives an estimate of the proportion of the total population that is encountered during the night searches. Since the estimated total population density is the ratio of two estimates, the observed density and search efficiency, its statistical distribution cannot readily be determined for purposes of testing. Therefore a Monte Carlo simulation was run under MINITAB to empirically derive the distribution of this estimate. For each population, the mean and standard deviation were calculated for the observed density and, using these parameters, 500 random Normal variates $\left(N_{1}, \ldots, N_{500}\right)$ were generated. For search efficiency, the binomial expectation $(\hat{p})$ and number of observations were used to generate 500 random binomial variates $\left(\hat{p}_{1}, \ldots, \hat{p}_{500}\right)$. The ratios of the members of the two sequences $\left(\mathbb{N}_{1} / \hat{p}_{1}, \ldots, N_{500} / \hat{p}_{500}\right)$ were then calculated and their frequency distribution plotted. The distribution proved to be a symmetrical bell-shaped curve, except for a slightly longer lower 
tail. Approximate Normality was assumed and the mean and standard deviation of the ratios were calculated and employed in a t-test comparing mean population densities.

\section{Spatial Variation within Sites}

Figures 19 and 20 show the among-quadrat variation in density of adults observed during the night searches. No statistical comparisons have been made since densities cannot be assumed to be independent among quadrats. Nevertheless, differences among the estimated mean densities of some quadrats are several times larger than the standard error, so some differences are significant. The distribution of adults within the study plots is therefore patchy. Density Differences between Sites

In order to compare population densities between the two sites, possible differences in search efficiency must be taken into account. Temporal trends in search efficiency were not apparent at either site, so data for the eight day-night searches were pooled to give an overall estimate for each population.

Differences in the densities of observed adults were found, with more snails per $\mathrm{m}^{2}$ being seen at SN-137 (table 9). However, this difference is partially offset by the higher estimated seach efficiency at that site--a greater proportion of the actual population was found. The estimates of observed density and search efficiency were combined as described above to obtain estimates of actual population density. The difference between populations was found to be non-significant (table 9). However, because the $\mathrm{SN}-137$ snails have on average twice the dry mass (exclusive of shell) of the SN-65 
snails, the standing crop is considerably greater for the SN-137 snails. Adult size at these two sites is therefore independent of population density but positively correlated with standing crop. These results are not consistent with control of shell size by differences in population density. Subjective Assessment of Population Density Variation

Pleurodonte lucerna is characteristically patchily distributed. This was shown above at the scale of meters to tens of meters but is also true at the scale of tens to hundreds of meters. For example, at SN-65, snails are very scarce uphill from and to the sides of the study plot. For a stretch of several hundred meters northeast of the plot (on the northwest side of the hill), $\underline{P}$. lucerna is absent or extremely scarce, as indicated by surface searches on wet nights. Another high-density patch occurs near the northeast end of the hill. At SN-137, $\underline{\text { P. Iucerna }}$ is abundant on the east side of the plot but scarce above and to the west. Variation in density is also seen among sites. SN-65, SN-76, SN-187, and SN-137 have particularly dense populations, whereas SN-19, SN-148, and SN-193 have relatively sparse populations. No relationship is seen between these subjective density assessments and the morphology of the snails at these sites. Spatial variation within and among sites appears to be closely related to the distribution of certain species of plants whose fallen leaves are eaten by the snails. 


\section{Presence of other Pleurodonte Species}

Although it has not been convincingly demonstrated in any studies of land snails (see review section), character displacement with respect to size is examined here as a possible cause of variation in Pleurodonte lucerna. If size is controlled by this mechanism, then $\underline{P}$. lucerna should be smaller where it occurs with larger Pleurodonte species and larger where it occurs with smaller Pleurodonte species. Four other species of Pleurodonte occur at stations along the cline transect. $\underline{P}$. jamaicensis is $\dot{a}$ very large uncommon species (larger than all but the largest $\underline{P}$. lucerna). It has been found alive only at SN-137 and SN-76. Empty, slightly bleached shells have been found at SN-187, SN-193, SN-194, and SN-129. $\underline{\text { P. }}$ sinuata is a small common species (smaller than the smallest $\underline{P}$. lucerna) which has been found alive or freshly dead at all stations except SN-207, SN-152, SN-68, SN-193 (subfossil only), SN-194, and SN-129. It may also occur at

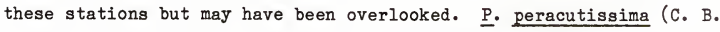
Adams) is a rare, small, very flat, rock-dwelling member of the $\underline{P}$. sinuata group. It has been collected alive only at SN-65 (two specimens found) and is known from empty shells (not fresh) from SN-148. $\underline{P}$. bainbridgei is a large species belonging to the $\underline{P}$. lucerna group. It has not been found alive at any of the transect stations. P. aspera is a large arboreal species widely distributed in Jamaica. Along the cline transect, it has been collected alive only at SN-129, but shells have been found at SN-137, SN-194, SN-68, SN-148, and SN-76. No relation is seen between the presence or absence of any of 
these species and the morphology of $\underline{P}$. lucerna shells. Along the transect, the small $\underline{P}$. sinuata is most abundant at $\mathrm{SN}-37$, where $\underline{P}$. lucerna is small. The very large $\underline{P}$. jamaicensis is common only at $\mathrm{SN}-137$, where $\underline{P}$. lucerna is also large. These observations are the opposite of what would be expected if character displacement were operating on shell size.

\section{Predators and Potential Predators}

Geographic variation in abundance or prey preferences of predators could have a significant effect on variation in shell morphology in Pleurodonte lucerna. There is direct or indirect evidence of predation on Pleurdonte lucerna by several different organisms. In addition to this evidence, I review other potential predators for whose activity no evidence is available.

Unidentified firefly larvae (Coleoptera: Lampyridae) are common predators on juvenile Pleurodonte lucerna at SN-65, SN-137, and other sites. Over 20 observations of predation on these and other small land snails have been made. Adult Pleurodonte have never been seen to be attacked. The lampyrids are so small (typically ca. 2 X $12 \mathrm{~mm}$ ) that the large denticles of small adults would present no barrier to them.

Freshly dead juvenile (never adult) Pleurodonte lucerna lying on top of the leaf litter are often found with an irregular hole punched in the dorsum of the shell, usually at the beginning of the last whorl, next to the aperture). The ventral side of such shells is 
usually undamaged except that the dorsal damage may extend over the periphery of the shell to the outer edge of the ventral side. Juveniles of the $\underline{P}$. lucerna complex damaged in this way have been found throughout Jamaica. One specimen at SN-65 is known to have been preyed upon during the daytime. The numbered specimen was found alive in the morning. In the early afternoon of the same day, its empty shell, with characteristic damage, was found on top of the leaf litter in same place. Unlike European snails preyed upon by thrushes, the damaged $\underline{P}$. Iucerna shells are not found accumulated in piles, nor are they found associated with anvil rocks (Morris, 1954). Pilsbry (1929) observed similar damage in adult Cuban camaenids of the genus Zachrysia. The damage in these globose shells is peripheral rather than dorsal and is usually ca. $180^{\circ}$ behind the aperture. Pilsbry assumed the damage was caused by birds, although no direct observations of predation were made. The predator of the $\underline{P}$. lucerna shells has never been observed but undoubtedly some species of bird is involved--the damage is the result of a peck, not a bite. Attempts at catching potential predatory birds with mist nets at $\mathrm{SN}-65$ were unsuccessful. Several species of birds have been observed foraging in the leaf litter at both SN-65 and SN-137: the Hopping Dick (Turdus aurantius), White-bellied Dove (Leptotila jamaicensis), and Ground Dove (Columbina passerina). White-bellied Doves are known to feed on land snails, but they swallow them whole (Downer, 1978). The Hopping Dick is also known to feed on snails but its method of attack and consumption is unknown (Lack, 1976). The Jamaican Woodpecker (Melanerpes radioletus) is known to consume land snails but only 
arboreal species (Cruz, 1977). The Ovenbird (Seiurus aurocapillus), a ground-foraging bird, preys on land snails in North America (Bent, 1953). This species occurs in Jamaica during the winter (Lack, 1976). It has not been observed at any of the cline transect stations and could not account for the numerous summer observations of freshly predated shells. The Hopping Dick seems the most likely candidate for the role of predator. Other Turdus species prey on land snails in England (Morris, 1954). All of the potential predator species have wide distributions within Jamaica, from the coast to the interior. No data on geographic variation in abundance are available. However, the frequency of predation has been estimated from collections of fresh, empty juvenile shells at six stations along the transect. In the study plots at SN-65 and SN-137, the leaf litter and loose rocks were searched every two weeks from February 1977 to February 1978 and all empty shells found were collected. In October 1983, collections of empty juvenile shells were made at SN-37, SN-207, SN-76, and SN-187. In general it was found (table 10) that juveniles in populations of snails that reach a small adult size (and associated morphological characters) showed a higher frequency of predated shells than populations of snails that attain a large adult size.

Shell damage is occasionally observed in adult Pleurodonte lucerna in populations at the southern end of the transect, where adults are relatively large and have small denticles. (e. g., SN-148, SN-68, SN-194, SN-137, and SN-129). This damage consists of a large hole (ca. $1 \times 2 \mathrm{~cm}$ ) on the base of the penultimate whorl, just inside the aperture. The shell here is thinner here than elsewhere on the 
outer surface. A bird, perhaps the Hopping Dick, must be responsible for such damage.

Another type of shell damage due to predation is seen in juveniles and rarely adults: the shell periphery is broken away, usually over the entire last whorl of the shell). The broken edges are very irregular. This type of damage is found in members of the $\underline{P}$. lucerna complex all over the island but is relatively uncommon. Similar damage is caused by rats in helicids (Sacchi, 1961). Introduced rats are abundant all over Jamaica. No other Jamaican animal would seem capable of causing this type of damage, except perhaps for the Jamaican Hutia, Geocampromys brownii (Fischer). However, the hutia is apparently extinct over much of this island and is not known from St. Ann (Anderson et al., 1983). Another Jamaican rodent, the Jamaican Rice Rat Oryzomys antillarum Thomas has been extinct since the late $1800^{\prime} \mathrm{s}$ (Allen, 1942). The Indian Mongoose (Herpestes auropunctatus) was introduced into Jamaica and is now widespread and abundant. This species is known to prey on land snails by forcefully throwing the snails backwards (underneath itself) against a rock to break the shell (Hinton \& Dunn, 1967). No shells damaged in this manner have been observed in Jamaica.

Larvae of the sarcophagid fly Euboettcheria nicasia Lopez (identified by P. J. Gagne, Insect Identification and Beneficial Insect Introduction Institute, U. S. Department of Agriculture) prey on Pleurodonte lucerna. Living snails with larvae of this fly have been found retracted and upside down on the leaf litter at SN-65. The snails were later found dead and covered with fly larvae. The larvae 
have been identified from specimens reared to adulthood in the laboratory. Both adult and juvenile snails have been observed to be consumed by this species. Similar fly larvae have also been found at SN-137, but these have not been reared to adulthood, so their identity is not certain.

Terrestrial crabs (probably a Sesarma species) are common on the plateau of St. Ann. However, they are always small ( $<20 \mathrm{~mm}$ in carapace width) and have small claws incapable of damaging a snail. Larger crabs occur only along the coast.

Carabid beetles of the subfamily Cychrinae, known to be major predators of land snails, do not occur in Jamaica. No beetles other than lampyrid larvae have been found to prey on land snails in Jamaica

Thus, of the known or potential predators, only birds would seem to have the potential to select for geographic variation in shell morphology

\section{Conclusions}

Geographic variation in Pleurodonte lucerna in western St. Ann is closely related to mean annual rainfall. It appears to be independent of temperature, population density, and presence or absence of congeners. No relationship to presence or absence of predators is apparent but there is a possible relationship to bird predation on juveniles--predation is higher at a site with relatively small adult snails. 


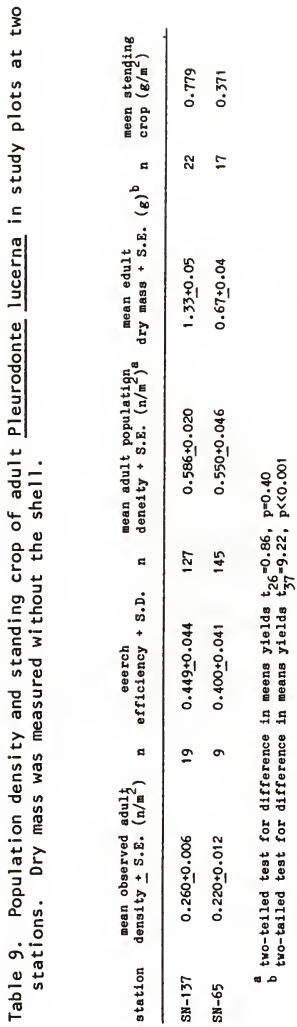




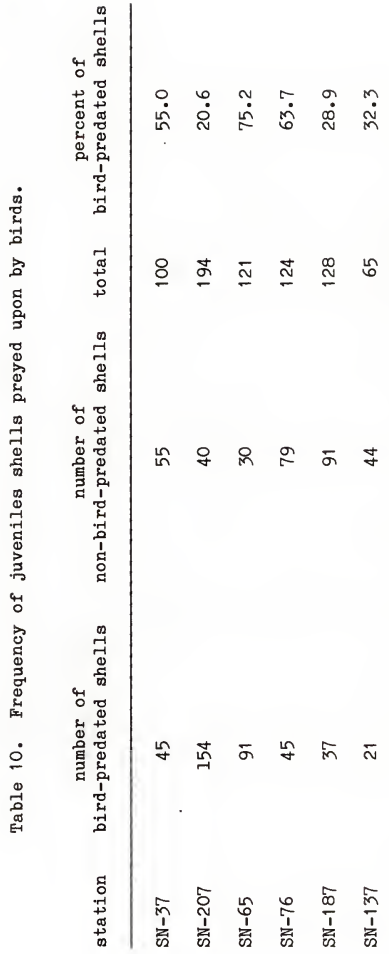




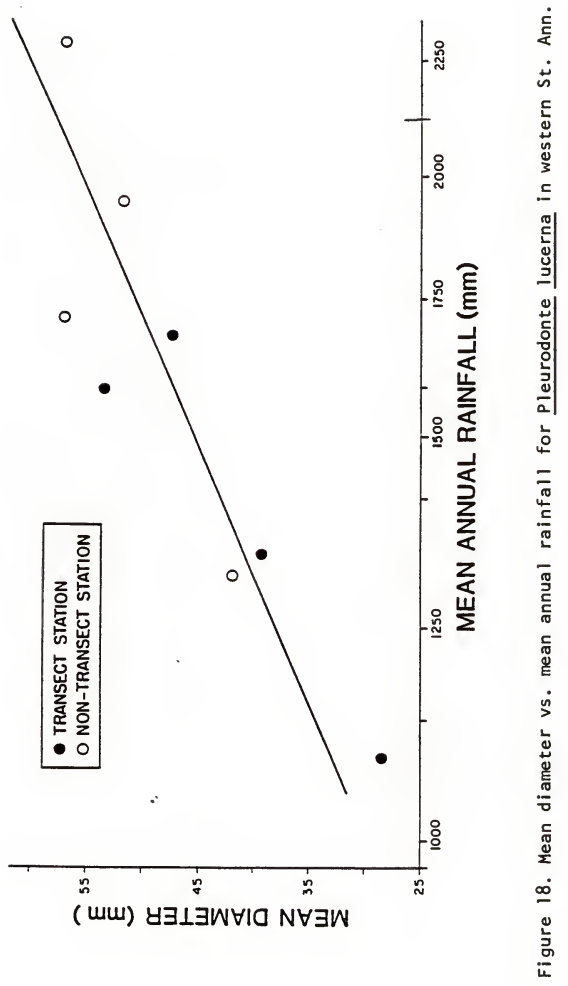




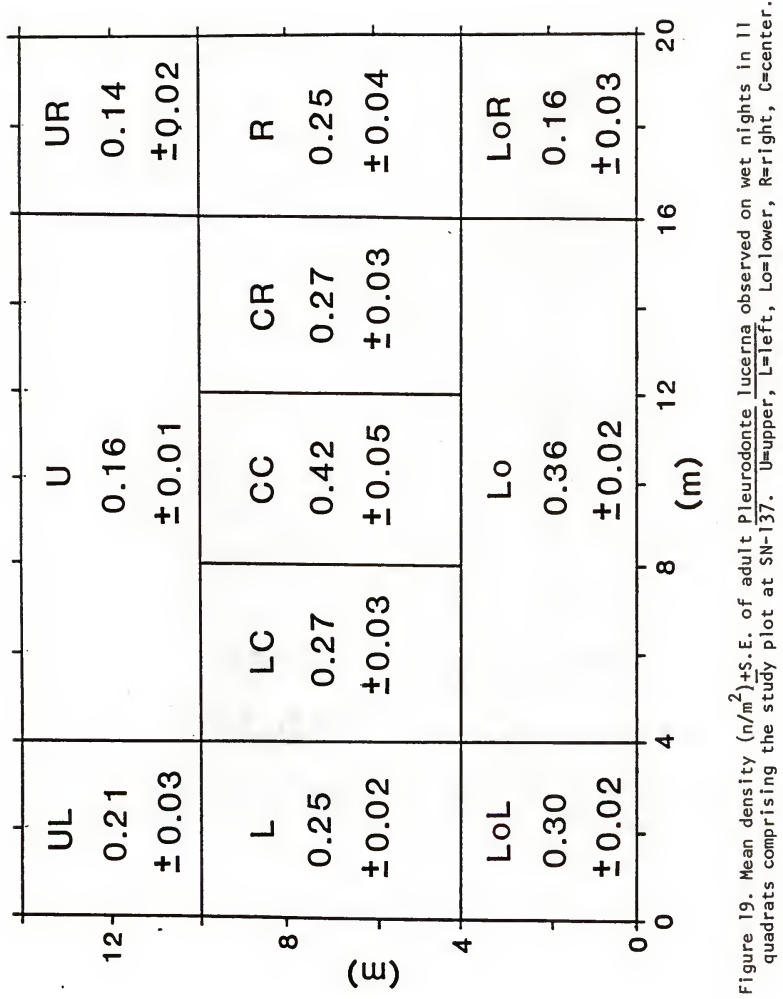




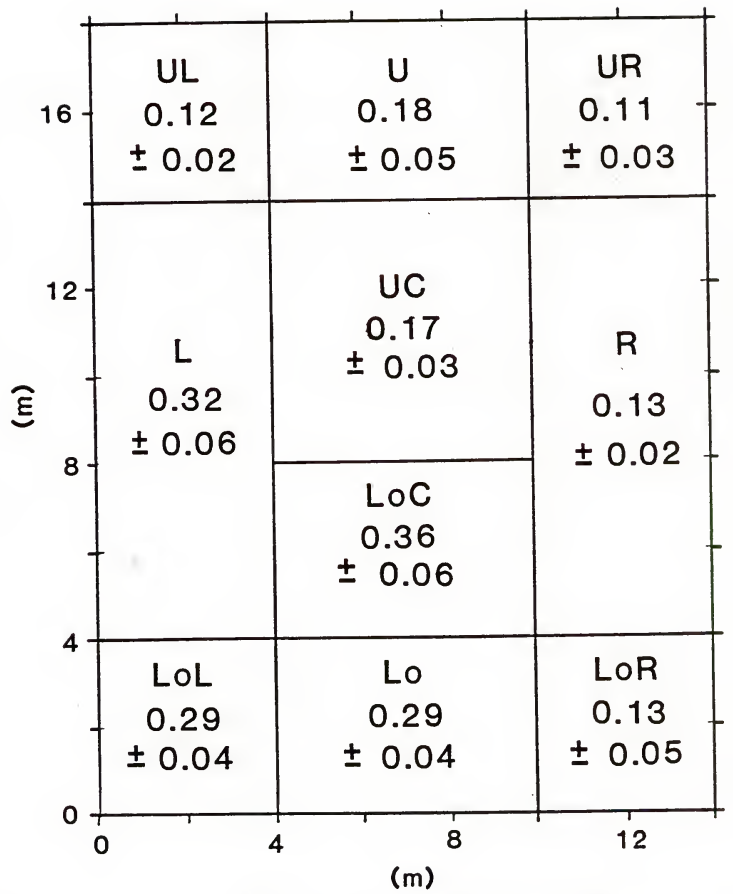

Figure 20. Mean density $\left(\mathrm{n} / \mathrm{m}^{2}\right) \pm S$. E. of adult Pleurodonte lucerna observed on wet nights in 10 quadrats comprising the study plot at SN-65. Abbreviations as in figure 19. 
MORPHOLOGICAL VARIATION :

ROLES OF ENVIRONMENTAL AND GENETIC INFLUENCES

Differences among populations in size and correlated morphological characters may be closely related to rainfall (or correlated factors) because these characters are environmentally influenced and/or because they are genetic variants. It is of particular importance to know whether there is a significant genetic component to among-population variation, since this would indicate that differences among populations result from natural selection. Two methods are commonly used to assess the effects of environment and genotype on phenotype. Reciprocal field transplant experiments and laboratory rearing studies permit different populations to be raised under identical environmental conditions; persisting phenotypic differences in the offspring would be due to genetic differences between the populations. Unfortunately, field transplant experiments are not practical for Pleurudonte lucerna since rates of recapture of marked juveniles are very low. Laboratory rearing experiments were attempted but were mostly unsuccessful. These results are briefly discussed below.

Because direct evidence for the genetic basis of variation in shell form and size is weak, an alternative approach is taken to elucidating the relative roles of environmental and genetic variation. I set up several hypotheses as to how differences in adult size and 
form among populations might be produced. I then evaluate these hypotheses based on evidence of differences in life-history patterns among populations, differences in the patterns of shell ontogeny, and temporal relationships between rainfall variation and morphological variation. Each line of evidence points to genetic control of adult size.

\section{Laboratory Rearing Study}

Juveniles collected from four sites representing relative minima $(\mathrm{SN}-37, \mathrm{SN}-65)$ and maxima $(\mathrm{SN}-207, \mathrm{SN}-137)$ of size along the cline were raised in the $1 \mathrm{ab}$ in $33 \times 21 \times 6 \mathrm{~cm}$ plastic containers, with 15 individuals (some from each population) per container. A layer of Jamaican leaf litter was put in each container and kept moist almost continuously. The snails were fed rehydrated leaf litter of preferred Jamaican species, which was provided in excess. Pieces of chalk were also put in each container to provide a source of calcium.

Initial growth was rapid but ceased within a few weeks in most specimens. Heavy mortality set in shortly thereafter. Only four specimens, all from SN-37, survived to reach the subadult stage. The cause of these poor results is almost certainly due to overcrowding (Dr.R. H. Cowie, personal communication).

The four SN-37 specimens attained an adult morphology typical of the natural population except that the snails are on average flatter and smaller, despite the fact that the conditions were wetter than they experience in nature. Their diameters ranged from 25.9 to 27.4 
mm ( 0.8 to 2.0 standard deviations smaller than the mean of the natural population) and relative height ranged from 0.507 to 0.544 ( 1.0 to 2.3 standard deviations below the mean). Whorl number was in the lower range of the natural population (4.9 to 5.3 ; cf. figure 15). This diminution of size in laboratory reared snails is a common observation and is almost certainly associated with the abnormally high density of snails (see review section on size and density, especially Cook \& Cain, 1980, above). Such densities do not occur in nature. Since the specimens did not become fully mature before they died, full denticle size was not attained. However, the denticles are indented on the outside of the shell to the same strong degree as in the natural population. Despite some differences from the natural population, the laboratory-reared snails can unambiguously be identified as having come from the SN-37 population.

\section{Possible Controls of Adult Shell Size and Form}

There are several different mechanisms that could produce the observed geographic variation in shell size and correlation with rainfall.

1. Differences in growth rate may affect the size attained at the termination of shell growth, if the the age at termination of shell growth or the time of maturation does not differ among populations. In wetter areas, snails may grow faster due to more frequent opportunities for activity and thus attain a larger size. 
2. Differences in the duration of juvenile growth may affect the size attained at the time of termination of growth. Snails that are genetically programmed to have a longer juvenile stage would tend to attain a larger size. Or, alternatively, environmental differences among sites may cause termination of growth to occur later at sites where snails attain a larger size.

3. Adult size variation may be affected by variation in a genetic program that causes termination of growth at different sizes in different populations. Juveniles grow for however long it takes to reach that size, then they terminate shell growth.

These hypothesized mechanisms are not necessarily mutually exclusive.

Vermeif (1980) has stressed the importance of growth rate as a determinant of adult size and shape variation among populations and individuals of various species of mollusks (predominantly marine taxa). Slower growing snails may produce narrower whorls and reach a smaller adult size. Thus growth rate could affect shell form as well as size in Pleurodonte lucerna.

\section{Life History}

In order to evaluate the applicability of these hypotheses to size and form variation in Pleurodonte lucerna, information on variation in several life history characteristics is required: age at termination of shell growth, growth rate, and time of termination of shell growth. In this section, I evaluate and compare data on these 
life history characteristics from two populations on the plateau: the small SN-65 snails and the large $\mathrm{SN}-137$ snails.

\section{Age at Termination of Shell Growth}

The age of individuals reaching the subadult stage was deteremined by analysis of growth lines (growth stops) laid down over the period of winter aestivation.

Sta. SN-137. In 1977, active juveniles first appeared in 1977 after the first major spring rain in mid-April. The new growth appeared brighter in color and was clearly demarcated from the duller color of the previous year's growth by a growth line. The bright color of the new growth remained until mid-July, at which time the initial section of the new growth had faded in some specimens to the color of the previous year's growth. Nine egg clutches were found at SN-137, from 14 May to 30 August 1977 (the latter hatched on 3 September). Hatchlings were 10 to $13 \mathrm{~mm}$ in diameter. Active, recently hatched snails were first seen on 28 June (none seen on 16 June) and as late as 11 October (none seen on 25 October). Juvenile activity decreased through September and October. A very few juveniles were found in November. Juveniles with epiphragms were first found in late October and no more active juveniles were observed after early December until the next spring. Thus reproduction is apparently limited to the summer, while juvenile activity occurs over about half the year, centered around the summer.

The juveniles observed and marked in spring 1977 (before the 1977 juvenile year class appeared) were very variable in diameter at the winter growth stop (16.1 to $39.8 \mathrm{~mm}$ in specimens measured in May; 
$n=14$ ). Of these, six were observed later that activity season (September and October) as subadults, whereas eight were observed the next year (February to May 1978) still in the juvenile stage. The latter had overwintered in 1978 with diameters of 31.6 to $42.8 \mathrm{~mm}$. of the juveniles hatched in 1977, only two were later observed after termination of seasonal activity (diameters 16.6 and $32.8 \mathrm{~mm}$ over the winter). However, other 1977 year class juveniles that were observed near the end of the activity season (mid-October and later) had a diameter range of 17.2 to $35.6 \mathrm{~mm}(n=8)$. These are minimum estimates of the final diameter reached that year since the individuals may have grown further after they were observed. Thus the minimum size range of 1977 year class juveniles at the end of seasonal activity is 16.6 to 35.6. Many other probable 1977 year class juveniles were also observed late in the year but only data for specimens also seen soon after hatching (shell consisting entirely of bright new growth) are included here.

The size range of the 1977 year class juveniles at the end of the 1977 activity season was greater than that of the spring 1977 juveniles whose life history stage at the end of the season was known. All of these spring 1977 specimens thus probably represent 1976 year class juveniles. Those that reached the subadult stage in 1977 terminated shell growth in their second season of activity (ca. one year later), whereas those that were still juveniles at the end of the 1977 activity season must require an additional activity season (or longer) to reach the subadult stage (total of ca. two years or more). Some of the spring 1977 juveniles whose later fate was unknown were 
significantly larger over the 1977 winter than the largest 1977 year class juveniles were over their first winter. Some of these spring 1977 juveniles may therefore represent pre-1976 year classes. This is further supported by the usual presence in these larger specimens of one or two growth lines previous to the winter 1977 growth line. These specimens also could not have reached the subadult stage earlier than their third activity season (ca. two years).

The year of transition to the subadult stage is only weakly predictable from the size of an individual at the beginning of seasonal activity. Of the fourteen 1976 year class juveniles whose life history stage the next year was known, the largest three individuals (25.6 to $33.4 \mathrm{~mm}$ diameter) became subadults in 1977 , whereas the smallest three $(14.9$ to $16.8 \mathrm{~mm}$ ) remained as juveniles. of the individuals of intermediate size (16.9 to $23.4 \mathrm{~mm})$, three became subadults in 1977 and five remained juveniles. Thus juveniles that are larger at the beginning of the activity season appear to be more likely to reach the subadult stage in the same year.

Sta. SN-65. In 1977, active juveniles first appeared in mid-April, following the first major spring rain, as at SN-137. Few juveniles were active over the dry summer but activity continued later than at SN-137 in the autumn. Activity decreased from mid to late November, such that by early December no juveniles were found active. Juveniles of the 1977 year class, 14 to $19 \mathrm{~mm}$ diameter $(n=5)$, first appeared in early August, following moderate rains. These were larger than hatching size ( 8 to $11 \mathrm{~mm}, n=6$, in the one clutch of eggs found in early November), implying that the juveniles may have hatched 
earlier. Juveniles barely larger than hatching size (11 to $12 \mathrm{~mm}$ ) were found as late as late November. Reproduction at SN-65 therefore probably occurs from mid or late summer to late autumn.

Of the SN-65 juveniles of the 1977 year class which were marked in 1977, 14 were recaptured in spring 1978. Diameter at the 1978 winter growth stop ranged from 13.1 to $24.6 \mathrm{~mm}$. No 1976 year class juveniles were found in 1978. In 1977, ten juveniles were observed later that year as subadults. The 1977 winter growth stop for these individuals ranged from 14.4 to $24.0 \mathrm{~mm}$ ( $n=9$; one not recorded). This is almost exactly the same size range as the winter growth stop of 1977 year class juveniles over the winter of 1978. Therefore the specimens that became subadults in 1977 were probably 1976 year class juveniles. At SN-65, then, attainment of the subadult stage occurs in the season following hatching (ca. 1 year later). Time of Termination of Shell Growth

At $\mathrm{SN}-137$, the transition from juvenile to subadult occurred as early as early July in 1977 but more commonly in August to September. The latest transition observed was in mid-October (specimens with lip becoming reflexed). At SN-65, the earliest observed transition from juvenile to subadult was in late June. The last observation of a juvenile seen later that season as a subadult was in mid-0ctober.

Thus termination of shell growth does not occur at a restricted time of year, nor does it occur simultaneously among individuals of a population. No difference is seen between the two sites with respect to the time of termination of shell growth. 
Growth rate

Methods. To evaluate the role of growth rate in determining shell form and size, both long term (seasonal) and short term $(1 / 2$ to 1 month) growth rates were estimated in the field for juveniles at SN-65 and SN-137. Juveniles in the study plots at the two sites were individually numbered on the dorsal side of the shell with India ink covered with a thin layer of clear acrylic coating thinned in toluene and applied with a cotton swab. The study sites were searched approximately every two weeks from February 1977 to February 1978. The diameter of each juvenile found was measured in situ with a dial caliper, to the nearest $0.1 \mathrm{~mm}$. Growth rate estimates were based on changes in the shell diameter or diameter at the winter growth stop of recaptured individuals. From analysis of juveniles sampled at the two sites (but outside the study plots) over the activity season, the relationship between shell diameter and snail dry mass (without shell) was determined. After measurement of shell diameter, the shell was removed and the bodies dried to constant weight at ca. $150^{\circ} \mathrm{C}$. and weighed to four significant digits. A natural logarithm transformation of dry mass produced a linear relationship between dry mass and diameter in SN-65 snails and in SN-137 snails less than $40 \mathrm{~mm}$ in diameter (figures 21A, 22). For larger SN-137 snails, the untransformed dry mass was found to be linearly related to diameter (figure 21B). For SN-65 juveniles, dry mass (M, in grams) is related to diameter ( $D$, in millimeters) by the following equation: In $\mathrm{M}=$ $0.149 \mathrm{D}-6.12$. $\mathrm{D}$ and $\mathrm{In} \mathrm{M}$ are correlated, with $\mathrm{r}=0.966\left(\mathrm{R}^{2}=0.934\right)$. For the smaller SN-137 juveniles, In M $=0.113 \mathrm{D}-5.48$, with $r=0.971$ 
$\left(\mathrm{R}^{2}=0.942\right)$. For $\mathrm{SN}-137$ juveniles over $40 \mathrm{~mm}$ in diameter, $\mathrm{M}=0.029 \mathrm{D}$ - 0.761 , with $r=0.854$ and $R^{2}=0.730$. Data on the shell diameter observed in the field were converted to estimated dry mass on the basis of these equations. Laboratory and field observations indicate that growth occurs in small increments $(<1-2 \mathrm{~mm})$. Growth over a time interval was calculated as the difference between the initial and final estimated dry masses. Mean daily growth was calculated by dividing the estimated increase in dry mass by the number of days of the growth interval. Williamson (1976) used a similar method to measure growth rates of Cepaea nemoralis in the field; however, his snails were taken to the laboratory for marking and later released. At SN-65, short-term growth rates were measured over intervals of 13 to 15 days, from 5 May 1977 to 27 October 1977. At SN-137, the intervals between measurements were 14 to 28 days, from 17 May 1977 to 25 October 1977. Estimates from different time intervals generally represent different individuals, except for one individual at SN-65 and two individuals at $\mathrm{SN}-137$, whose short-term growth rates were estimated for two time intervals.

Short-term Growth Rates. Since individual growth rates are likely to be size-dependent, these rates were plotted against snail dry mass (without shell) at the beginning of the growth interval (figure 23). In the SN-65 juveniles, growth rate was found to be positively correlated with dry mass ( $r=0.90, p<0.001)$, but the $\mathrm{SN}-137$ snails showed highly variable growth rates negatively correlated with dry mass $(r=-0.54, p=0.01)$. Data on $\mathrm{SN}-137$ snails $>0.3 \mathrm{~g}$ dry mass were not included, since no comparison with SN-65 snails in that size 
range could be made. But these larger individuals showed growth rates varying from $\mathrm{O}(\mathrm{n}=3)$ to $9 \mathrm{mg} /$ day (one individual with an estimated dry mass of $0.505 \mathrm{~g}$ ). This last observation would have changed the correlation from negative to positive. The relationship between size and short-term growth rate in the $\mathrm{SN}-137$ juveniles is certainly a weak one. Growth rates of the two populations show very broad overlap, although the larger SN-137 snails tend to grow more slowly.

Annual growth. For juveniles passing their first winter aestivation period, the estimated dry mass at the winter growth stop gives the total growth during the first year (including the mass at hatching, which is actually a maternal contribution). For juveniles that had passed two winter aestivation periods, growth during the second year was estimated by subtracting the estimate of dry mass at the end of the first activity season from the estimate of dry mass at the end of the second activity season. This was possible only for juveniles found in the spring of both 1977 and 1978 and which showed clearly demarcated new growth. For individuals reaching the subadult stage, seasonal growth was estimated by subtracting the estimated dry mass over the previous winter from the estimated dry mass at the transition to the subadult stage. Subsequent increase in dry mass of the snail body that season is therefore not included in these estimates.

The results for the two sites are given in tables 11 and 12 . The growth rate of juveniles at SN-137 during their first year was on average much greater in 1977 (a very wet year; data presented below) than in 1976, although growth was very variable and overlapped broadly 
between years. First year juveniles at SN-65 showed very similar growth in both 1976 and 1977. The average growth was similar to 1976 first year juveniles at SN-137. Second year class juveniles at SN-137 which did not reach the subadult stage in 1977 showed much greater growth than first year juveniles, as would be expected from their longer period of growth (the full activity season). Evaluation of life-history patterns in relation to shell size and form

The three hypotheses for the control of adult shell size set out at the beginning of this section can now be evaluated on the basis of the life-history patterns of the snails. Hypothesis 1 (faster-growing snails attain a larger size; no differences among populations with respect to the duration of the juvenile stage) is not supported by the data on growth rates: consistent differences between populations with respect to annual growth were not found. This relationship between annual growth and adult size is examined below in greater detail, in relation to temporal variation in rainfall. Neither does hypothesis 2 (snails growing for a longer period of time attain larger size) appear to apply to Pleurodonte lucerna, since both SN-65 and SN-137 juveniles may terminate growth during their second activity season. The larger snails do not terminate growth later in the season than the smaller snails. However, all life-history observations are consistent with hypothesis 3 (growth terminates at a genetically controlled size). The SN-137 snails, which have a higher whorl expansion rate than the SN-65 snails, tend to grow more slowly on a coshort-term basis. This is the opposite of the expected relationship if growth rate affected whorl width (Vermeij, 1980). Variation in this aspect of 
shell form is probably also due primarily to genotypic differences among population.

\section{Evidence from Shell Ontogeny}

Indirect evidence for the genetic control of morphological differences among populations comes from the comparative analysis of shell ontogeny presented above. If size differences among populations were the result of differences in the rate of growth (hypothesis 1) or the duration of growth (hypothesis 2), then all shells should show a similar pattern of shell ontogeny, except that larger shells should have more whorls. In fact, the populations were found to show significant differences in ontogeny. One population (SN-37) differed from the others in initial whorl width. The other three populations had the same initial whorl width but differed in whorl expansion rate and angle of descent, both quantitatively and in the whorl number at which changes in these characters occurred. In comparisons among populations, larger snails have fewer whorls than smaller snails,

In all populations, the underside of the shell (which is flat in juveniles) becomes rounded and convex toward the end of the penultimate whorl (where the adult aperture will form at the end of the last whorl), although this occurs only at the center of the base in individuals that become keeled as adults. In shells that are rounded as adults, the peripheral angle changes from keeled to angular to rounded at around this point. Thus the point at which growth stops is predictable from earlier in the ontogeny of the shell. 
These ontogenetic observations indicate that final adult size and form is not simply a matter of cessation of growth at some arbitrary point in development. From the consideration of life histories above, it is clear that particular phases in shell ontogeny are not asociated with any particular time of year. Juvenile year classes are very variable in size and maturation to the subadult stage may occur over a wide period of time. The control of ontogenetic changes is thus not obviously linked with environmental conditions, but rather must be due predominantly to genotypic differences among populations.

\section{$\underline{\text { Rainfall }}$ and size}

If size were environmentally influenced, then rainfall would be the most likely inductive agent, since it is highly correlated with size among sites. In areas of higher rainfall, increased activity might permit greater annual growth and thus larger adult size (hypothesis 1). If spatial variation in rainfall were responsible for inducing size differences among populations, then temporal variation in rainfall should produce temporal variation in adult size within populations. However, evaluation of temporal relationships of size and rainfall within sites reveals no correlation between these variables.

A comparison was made between $\mathrm{SN}-137$ snails reaching the subadult stage in especially wet years and the general population of adults. The adult population is an appropriate basis of comparison for subadults of a particular year because it represents a large number of 
year classes. Subadults (which become adult by the following year) comprised 10 to $15 \%$ of the adult-subadult population in the fall of 1977. If this ratio is typical, and if population size is stable from year to year, then adults would live for some 7 to 10 years on average. A number of individually marked adults have been observed five years after they were marked (by notching the shell margin with a code).

The years 1977 and 1981 were unusually wet from April to September, the period during which juvenile growth occurs and the subadult stage may be reached. Cave Valley $(1.8 \mathrm{~km}$ southwest of $\mathrm{SN}-137)$ received $1.64 \mathrm{~m}$ of rainfall during this period in 1977, as compared with a median annual rainfall of 0.89 m from 1970 to 1977. Cave Valley data for 1981 are not available. At Bog Hole, Clarendon (2.4 km south of SN-137), 1.94 m of rain fell from April to September in 1977, and $1.35 \mathrm{~m}$ in 1981, as compared to a median of $1.04 \mathrm{~m}$ for 1970 to 1981.

Snails reaching the subadult stage in 1977 were no different in size from the general adult population in 1977 (figure 24; $t_{63}=0.37, p=0.70$, two-tailed test). Neither did the mean of snails maturing in 1981 differ from the general population of 1977 adults $\left(t_{46}=1.02, p=0.31\right)$. These results show that rainfall in the last year of shell growth is unrelated to the adult size attained by the snails.

However, it is still possible that rainfall could affect the size of snails at the beginning of the growth season and that this in turn may be correlated with the final size attained by snails reaching the 
subadult stage that season. Assessment of the relationship between overwintering juvenile diameter and the subadult diameter is based on six individuals whose overwintering (1977) diameters were known from measurement in spring when new growth was apparent and which were found later that season as subadults. Data were also included for a large number of other 1977 subadults which were not previously found or not found sufficiently early in the year to be able to definitely identify the winter growth stop based on observation of the new growth-old growth transition (figure 25). In most of these individuals, the winter growth stop is probably correctly identified but in some specimens it may have been confused with a summer growth pause line. That these identifications are usually correct is shown by the records of the 1977 winter growth stop measured in spring 1978 juveniles that had also been found in spring 1977. In four out of six cases, the 1978 measurements of the presumed 1977 growth stop agreed with the known 1977 growth stop, as measured in spring 1977. The results show that subadult diameter of an individual is independent of its diameter as a juvenile at the beginning of the activity season. This is true both for the six individuals for which the overwintering juvenile diameter is definitely known and for the other snails for which it is not definitely known. Rainfall might affect the size attained by overwintering juveniles (juveniles hatched in the wet year of 1977 were larger during their first winter than were 1976 year class juveniles), but this size has no relation to the subadult diameter attained during the following activity season. Since the final size attained by $\mathrm{SN}-137$ snails is not dependent on rainfall in 
the final year nor on the size at the beginning of the last activity season, size variation is not directly influenced by rainfall. If individuals within a population are not responsive to rainfall in this way, the differences in diameter among sites also cannot be due to the inductive effects of rainfall.

A second line of evidence indicating that the correlation of size and form with rainfall cannot be the result of induction by rainfall (or other temporally correlated factors, such as perhaps temperature) comes from data on annual rainfall variability. If size or form differences among populations were due to differences in the rainfall regimes that the snails at each site experienced, then the consistent differences among sites could only be produced by consistent differences in rainfall among sites. Since most snails reach the subadult stage in ca. one to two years, the variation in mean annual rainfall for two consecutive years is a conservative estimate of the differences in rainfall experienced by snails of different year classes. Figure 26 shows two-year moving means of annual rainfall for three rainfall stations along the cline transect. It is readily apparent that there is broad overlap between the driest station (Discovery Bay, near SN-37) and the wetter stations at Brown's Town (near SN-207) and Cave Valley (near SN-129). Thus a snail growing up at SN-37 during certain years may experience a wetter moisture regime than snails at SN-207 or SN-129 experience during other years. Since shell morphology at SN-37 is absolutely consistently different from the other sites, rainfall could not have a direct influence on size. 


\section{Conclusions}

The various lines of evidence reviewed above agree in showing that environmental influence on growth rate or duration of growth does not play a significant role in determining differences in shell morphology among populations. Instead, it appears that adult shell form is the result of a genetically controlled onotogenetic program that is little modified by the environment. Juvenile development proceeds at a highly variable rate until final adult size is reached at the subadult stage. Environmental circumstances probably have a strong effect on this rate and consequently on the time required to reach the subadult stage, but not on the final morphology produced. 


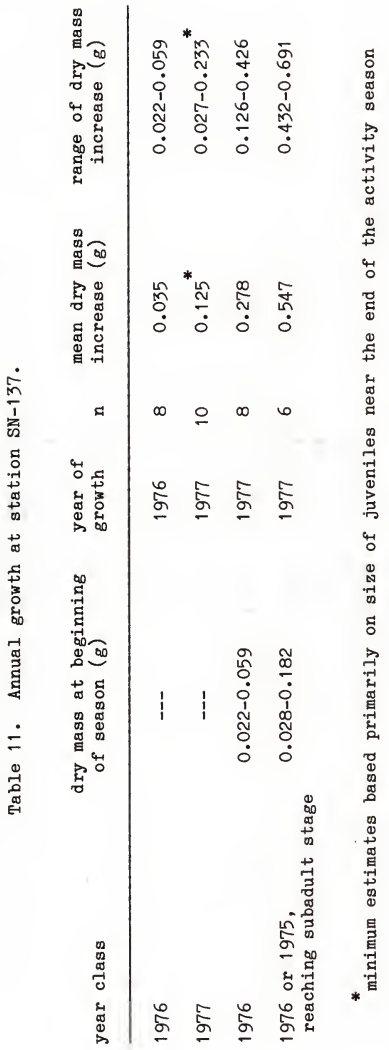




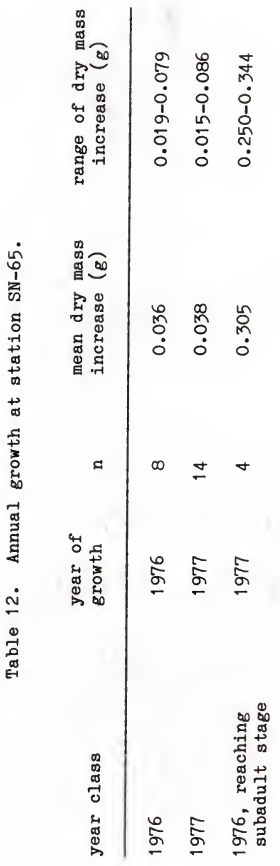



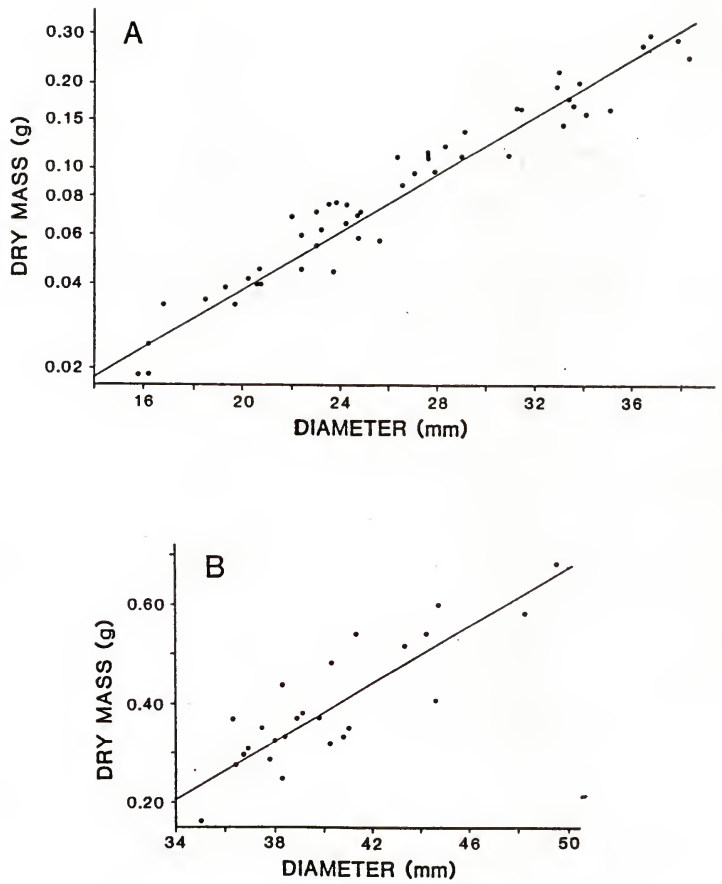

Figure 21. Dry mass (without shell) vs. shell diameter for juveniles from SN-137. A. Smaller juveniles (semilog plot); B. Larger juveniles (linear plot). 


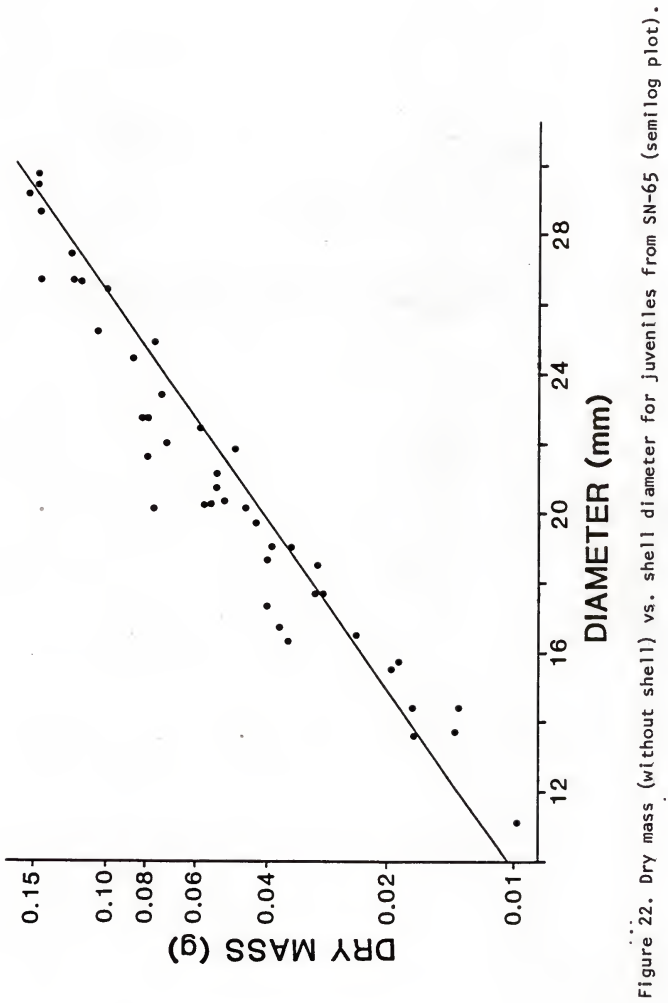




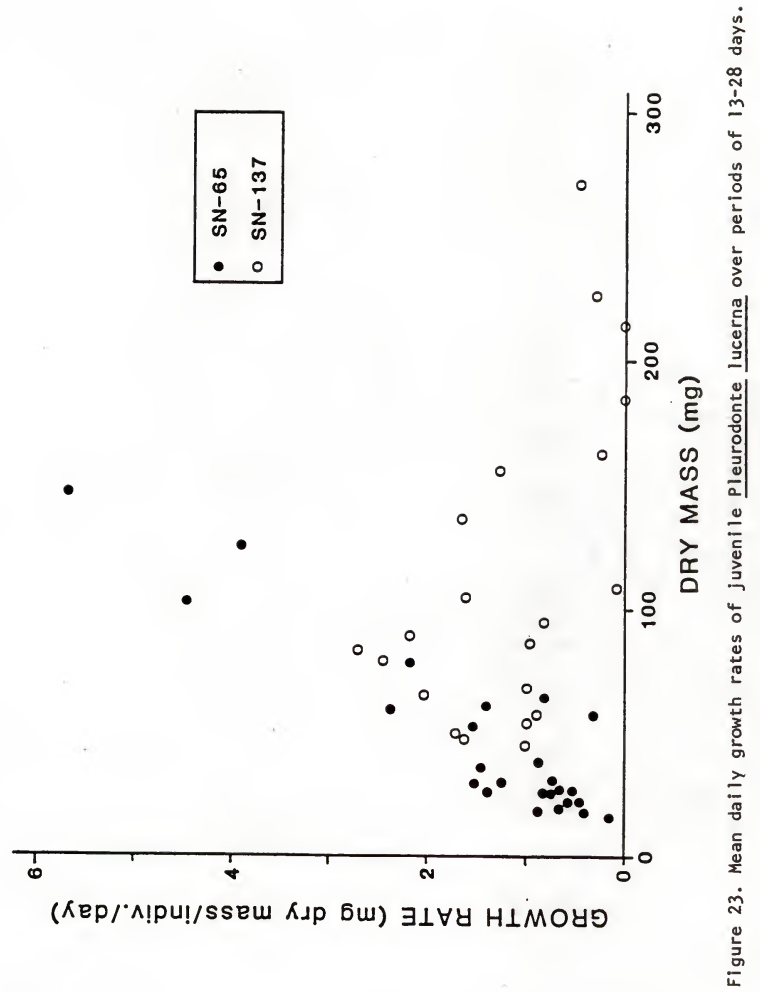



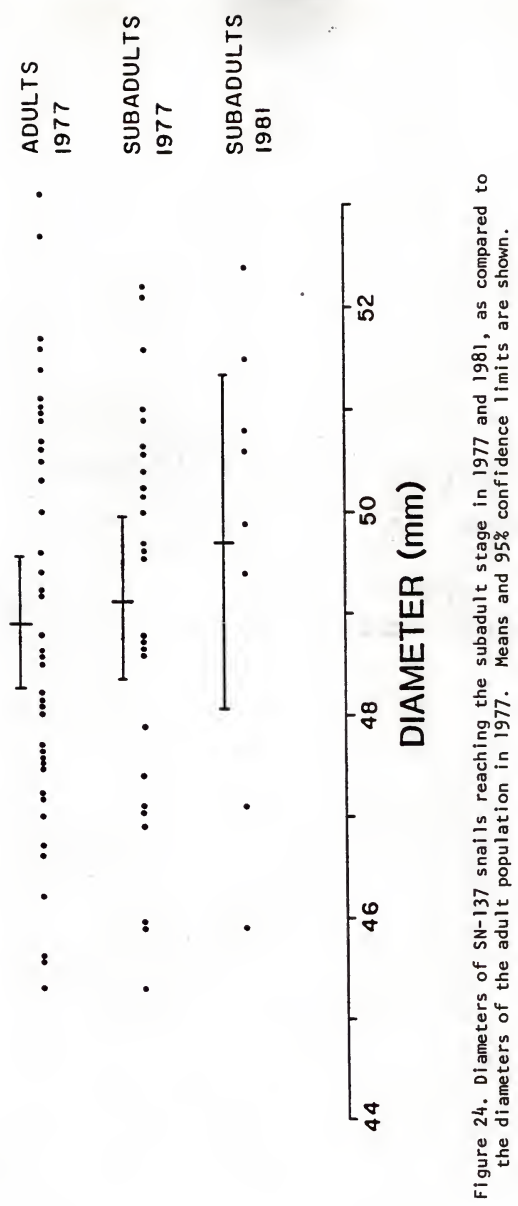


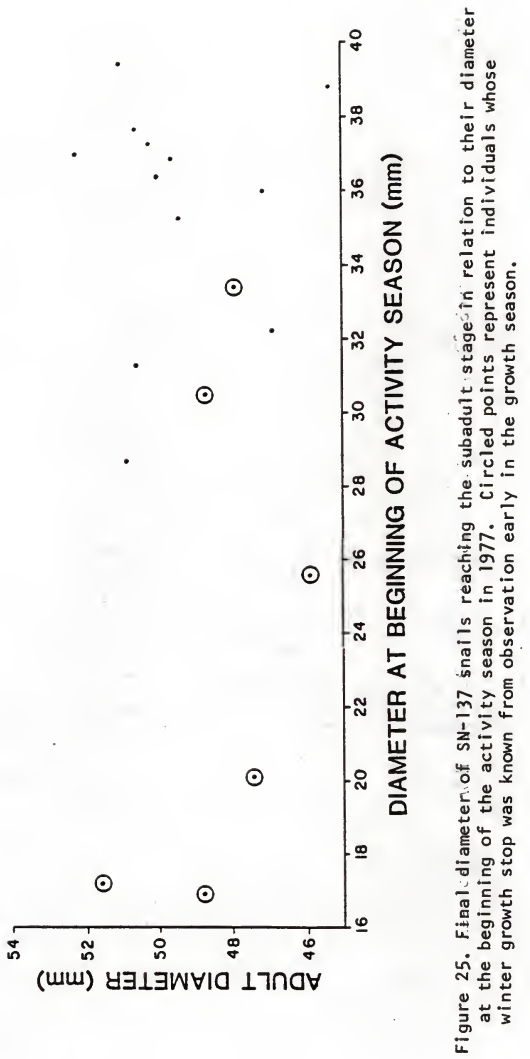




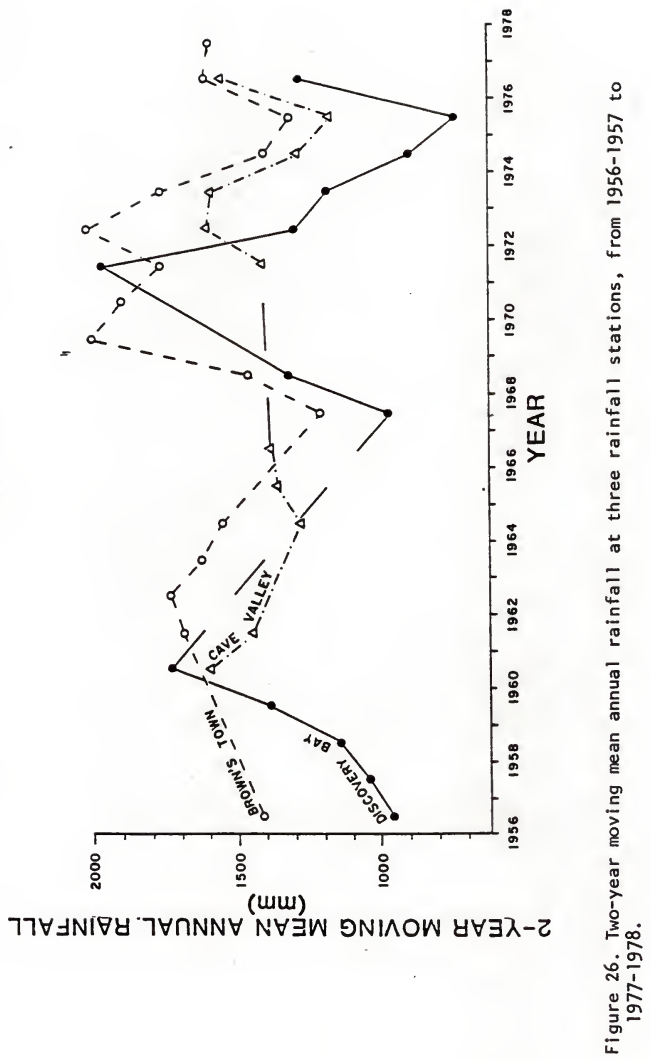




\section{SHELL MORPHOLOGY AND NATURAL SELECTION}

Since among-population variation in shell morphology is primarily due to genotypic differences, natural selection must be responsible for the correlation between morphology and rainfall. Rainfall, or a geographic correlate of rainfall, must be selecting for different morphologies in different areas. In this section I explore some hypotheses as to how selection may act to produce the observed morphologies.

I propose below that dry conditions select for a relatively small aperture area (resulting from a low whorl expansion rate), which reduces the rate of water loss from an inactive snail. This low whorl expansion rate imposes constraints on the morphology of the soft parts of the snail: only a relatively small foot can be accomodated when the animal is retracted. Because adhesion is a function of surface area, larger snails require a relatively larger foot volume in order that mass/foot surface area be in the same proportion as in smaller snails. Thus snails with low whorl expansion rates must also be small snails. These hypotheses are evaluated on the basis of evidence of water loss rates in relation to shell morphology and the relationship between foot surface area and snail mass. The possible role of apertural denticles in reducing water loss is also evaluated experimentally; the evidence for such a role is negative. Intensity 
of predatory activity of birds is higher in drier areas. This predation would tend to select for many of the same shell characters as would drought--small aperture area, resulting from small snail size and low whorl expansion rate--as well as for large apertural denticles and a thicker shell. Lower peripheral angle in larger snails is interpreted as an adaptation to provide sufficient lung surface area, which would otherwise tend to decrease (in relation to mass) with increasing snail size. No particular adaptive significance is attached to the variation in relative height of the shell; it may be a consequence of selection for different whorl expansion rates.

\section{Water Loss and Shell Morphology}

Water is especially critical to land snails since they have a wet body surface, from which water readily evaporates, and since they lose considerable amounts of water (in the form of mucus) during locomotion. The shell is the organ that is primarily responsible for reducing water loss over most of the body surface. It is not surprising, then, that shell morphology should be responsive to selection by moisture regimes.

Several hypotheses have been proposed relating shell morphology to water loss rate. Boettger (1921) proposed that apertural denticles reduce water loss. Machin (1967) showed that aperture cross-sectional area was correlated with water loss rate, whereas Nopp (1974) and Paul (1974) proposed that mantle collar surface area, rather than aperture area, should control water loss rate in retracted snails. In order to 
determine which aspects of shell morphology have a significant effect on water loss rate, an experiment with water-filled Pleurodonte lucerna shells was carried out. Water loss rate from intact shells was compared to loss rates from shells with the denticles removed in order to assess the role of apertural denticles. Water loss rates of shells with the aperture and last $45^{\circ}$ of the last whorl (0.12 whorl) removed were compared to intact shells. If evaporative surface area alone were controlling water loss independent of aperture form, then removal of the aperture should have no effect on water loss rate. The surface area/volume ratios of small and large Pleurodonte lucerna shells is estimated and compared to water loss rates in order to assess whether the morphology of smaller shells is effective in reducing water loss.

Measurement of water loss rates

Three shells from $\mathrm{SN}-76$ and three from $\mathrm{SN}-137$ were used in the experiments. The shells were coated on the outside with a thin layer of canning wax dissolved in toluene in order to eliminate water loss through the shells as a factor. The shells were mounted on perforated plexiglas bases $(3 \times 3 \mathrm{~cm})$ with warm wax. The specimens were mounted in a position such that when the specimens were filled with water, the water surface was in the same position as the mantle collar surface of a snail withdrawn $45^{\circ}$ into its shell. This was accomplished by positioning the shell so that 1) the axis of coiling was parallel with the base, and 2) a mark on the periphery $45^{\circ}$ behind the point where the lip begins to flare out was the same height above the base as the axis of coiling (i. e., the aperture was turned upward $45^{\circ}$ about the 
axis of coiling). The shells were filled to the $45^{\circ}$ mark by submergence in a solution of distilled water with $1 \mathrm{ml} / \mathrm{l}$ saturated mercuric chloride solution (to prevent bacterial growth) and $1.4 \mathrm{ml} / \mathrm{l}$ Acationox (a detergent added to reduce the meniscus). The shells were rotated while submerged so as to remove all air from the shell. The filling of the shell simulates the position of the mantle collar surface of a snail withdrawn $45^{\circ}$ into its shell. The shell surface was allowed to dry for $24 \mathrm{hr}$ after filling. The level of the water solution was then adjusted to the level of the $45^{\circ}$ mark with a syringe (solution added and/or removed) before running the experiment. In order to maintain standard humidity conditions and saturation deficit conditions, the water loss experiments were run within a 2.61 glass desiccator kept at $22-24^{\circ} \mathrm{C}$. The bottom of the desiccator was filled with a saturated solution of ammonium chloride with excess crystalline ammonium chloride present. This maintains a relative humidity of $78 \%$ at $23^{\circ} \mathrm{C}$ at equilibrium (Winston \& Bates, 1960). The desiccator shelf consisted of a $6-\mathrm{mm}$ wire mesh screen with a 3 volt DC electric motor attached centrally to the underside. A $14 \mathrm{~cm}$ plastic propellor blade was attached to the motor to provide circulation. The wires to the motor ran between the top of the desiccator and the lid to an AC-DC adaptor plugged into an AC outlet. A ring of fibreboard with a groove cut for each wire was placed on the top edge of the desiccator and the lid rested on top of this ring. Petroleum jelly was used to seal the desiccator. The fan was run for $24 \mathrm{hr}$ to bring the system to equilibrium before each experiment. Then the shells, filled with the water solution and preweighed to $0.1 \mathrm{mg}$ on a Mettler 
H54AR balance, were quickly placed on the desiccator shelf and the lid sealed. The fan was run for $1 \mathrm{~min}$ to $\mathrm{mix}$ the air. The shells were left in the desiccator for $24 \mathrm{kr}$, then removed and weighed. The water loss was calculated as the difference between the original and final weights of the shells. The 24-hour experiments alternated between 24-hour periods of equilibrating the system with the fan running. These conditions simulated water loss in still air, as would be experienced by a snail resting in the leaf litter or humus or under rocks.

Apertural denticles were removed with a high-speed pneumatic drilling tool. In the SN-76 shells, this removal left holes in the shells since the denticles are hollow basally. The holes were filled with warm wax, smoothed interiorly with a warm knife to give a surface flush with the inner surface of the shell. Removal of the aperture and the last $45^{\circ}$ of the shell was carried out using a carbide grinding wheel. The shells were actually ground to $1 \mathrm{~mm}$ from the $45^{\circ}$ mark so as to retain water at the $45^{\circ}$ level.

The volume of the shell (exclusive of the last $45^{\circ}$ ) was measured by filling the shells as in the experiments, except that pure distilled water was used. The fully dried shell was weighed before filling. After the outside had dried out, the water level was adjusted and the specimen was weighed. The difference in weights gave the weight of the water filling the shell to $45^{\circ}$ behind the aperture. The weight of the water was converted to volume.

Aperture area was measured by tracing the outline of the aperture onto paper at $6 \mathrm{X}$ using a camera lucida on a Wild stereo microscope. 
The outlines were then cut out and their areas measured to the nearest $0.1 \mathrm{~mm}^{2}$ using a Li-Cor area meter (model 3100). These measurements were converted to aperture area by dividing by 36 . The procedure was repeated after the denticles were removed. The cross-sectional area at $45^{\circ}$ behind the aperture (representing the evaporative surface area) was measured after the last $45^{\circ}$ of the shell was removed. Nine replicates were run for the intact shells, for shells with denticles removed, and for shells with the last $45^{\circ}$ removed. Results

Effect of denticles on water loss. The results were analyzed using analysis of variance models with water loss as the dependent variable and treatment, replicate number, temperature, aperture area (without denticles), and cross-sectional area at $45^{\circ}$ as independent variables. Significant heterogeneity was found among replicates $\left(F_{16,84}=7.29, p<0.0001\right)$ but this accounted for only $3 \%$ of the total variance. This factor was not included in subsequent models. In an ANOVA model of water loss in relation to evaporative surface area, treatment (with vs. without denticles), and an interaction term, treatment had no significant effect $\left(F_{1,104}=2.14, p=0.15\right)$, nor was the interaction term significant $\left(F_{1,104}=3.01, p=0.09\right)$. The same model but with aperture area substituted for evaporative surface area also showed no significant effect of denticle removal $\left(F_{1,104}=2.25, p=0.14\right)$ or interaction effect $\left(F_{1,104}=0.00\right.$, $\mathrm{p}=0.98$ ). Thus denticles have no demonstrable effect on water loss rate, nor did denticle removal have any differential effect according to aperture area or evaporative surface area. Consequently, the data 
for specimens with and without denticles were pooled. Both evaporative surface area and aperture area are excellent predictors of water loss rate. Evaporative surface area accounts for $91.2 \%$ of the variation in water loss $\left(F_{1,106}=1099.8, p<<0.0001\right)$, whereas aperture area accounts for $90.5 \%$ of the variation $\left(F_{1,106}=1015.5\right.$, $\mathrm{p}<<0.0001)$. The two measures are so highly correlated $(r=0.98)$ that they are almost completely redundant.

Effect of aperture and last $45^{\circ}$ of shell on water loss. Removal of the aperture and last $45^{\circ}$ of the shell produced a tremendous increase in the water loss rate, as compared to shells with the aperture intact $\left(F_{1,159}=434.11, p<<0.001 ;\right.$ table 13). Thus the presence of a "skirt" of shell (the last $45^{\circ}$ ) around the evaporating surface has a major inhibitory effect on water loss. This implies that a deeper retraction into the shell by the snail would reduce the rate of water loss. The ratio of the mean rates of water loss for each individual without:with the aperture removed is strongly correlated with the area of the evaporating surface ( $r=-0.96$, $\mathrm{p}(0.001)$. In the experimental shells with the last $45^{\circ}$ intact, the humidity gradient from the water surface to the environment of the desiccator would be perpendicular to the water surface. However, removal of the shell "skirt" also allows development of a lateral humidity gradient (parallel to the water surface), thus producing the observed increase in water loss rate. The effective surface area of this lateral gradient is proportional to the perimeter of the evaporating surface, which is relatively greater (in relation to surface area) in smaller surface areas. This accounts for the greater 
effect of the removal of the last $45^{\circ}$ of the shell in smaller shells as compared to larger shells.

Water loss in relation to surface area/volume and size. For shells filled to $45^{\circ}$ behind the aperture, the evaporative surface area/volume ratio is lower in the SN-76 shells than in the SN-137 shells (table 14). Thus the smaller snails have a lower surface area/volume ratio, the opposite of the isometric expectation. Water loss rate and evaporative surface area are directly proportional (with a mean water loss rate of $42 \mathrm{mg} / \mathrm{cm}^{2} /$ day) over the range of surface areas measured. Consequently, the SN-76 shells, with a smaller surface area/volume ratio, tend to lose water at a relatively lower rate (\% volume lost per unit time) than the SN-137 shells. The Adaptive Value of Shell Morphology in Relation to Moisture

These results indicate that the shell morphology of snails in drier areas is modified such that a relatively small mantle collar surface area is exposed in retracted snails. This is a consequence of the relatively small whorl cross-sectional area of the last whorl resulting from the lower rate of increase in whorl width and increased angle of descent in shells from these areas. While modification of the aperture through the development of denticles does not affect water loss rate, the presence of the last $45^{\circ}$ of the last whorl strongly reduced the water loss rate. In shells with relatively small whorl cross-sectional area and a larger whorl number, a given percent reduction in body volume will produce a deeper angle of retraction into the shell than in shells with wider and fewer whorls. Thus the morphology of the shells in drier areas should also contribute to 
reduction of water loss by permitting a deeper retraction into the shell for a given percent decrease in snail volume.

That this expected pattern is realized in nature is shown by a comparative field study of SN-65 and SN-137 snails. The angle of retraction of adult snails was measured during daytime surveys of the study plots at the two sites over the course of half a year. A protractor was used to make measurements to the nearest $5^{\circ}$. The point on the periphery where the adult lip first begins to flare out was taken as the reference point $\left(0^{\circ}\right)$. From figure 27 , it can be seen that the SN-65 snails, with narrower whorls, show a broader range of angle of retraction than the SN-137 snails over the course of the year, as would be predicted from whorl geometry. The angle of retraction is greater during periods of inactivity, presumably due to reduced water content and gut contents. The SN-65 snails are also consistently more deeply retracted than the $\mathrm{SN}-137$ snails, indicating that the shell volume/animal volume ratio is higher in the smaller (SN-65) snails. Thus the SN-65 snails produce a relatively large shell in relation to their body size. This contributes to a deeper angle of retraction and consequently to a decrease in water loss during inactivity. While the adaptive value of decreased water loss in drier areas may seem self-evident, the mechanism of selection for shell morphology that reduces water loss is not obvious. In the remainder of this section, I consider this mechanism: in what ways might water loss affect snail fitness? Which aspect(s) of rainfall variation are likely to be most significant? 
Water loss during long-term inactivity. One possible mechanism is the differential survival of snails over long periods of drought as a consequence of dehydration. Numerous studies have measured rates of weight loss in land snails (table 15). This weight loss has generally been assumed to be due almost entirely to loss of water. In the majority of cases, the rates of weight loss are low, ca. 0.1-0.2\% of the original wet weight per day. The unusually high rates found in the studies by Cameron (1970) and Heatwole \& Heatwole (1978) may have been due to activity of the snails during the experiments. The highest rate loss in the study of Heatwole \& Heatwole was found in the rainforest species Polydontes luquillensis, which survived on average only ca. one week under experimental conditions, even in nearly saturated air. The high rate loss might have been associated with the poor health of these snails. Aestivating individuals of Sphincterochila boissieri (Yom-Tov, 1971b; Schmidt-Nielsen et al., 1971) and Trochoidea seetzeni (Yom-Tov, 1971b) in the Negev Desert of Israel show no change in percent water content over the summer dry season. This implies that a significant proportion of the weight loss is due to loss in dry weight. Steinberger et al. (1982) measured a dry weight loss of ca. $0.014 \%$ of the wet weight (with shell) per day

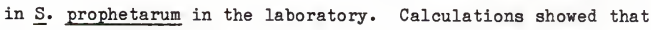
respiration of this amount of dry matter produced water amounting to ca. $0.008 \%$ of the wet weight per day, so that the net wet weight loss due to loss of $\mathrm{CO}_{2}$ would be ca. $0.006 \%$ per day. This accounts for ca. $8 \%$ of the wet weight loss rate recorded for $\underline{\mathrm{S}}$. boissieri by Machin (1967) and Schmidt-Nielsen et al. (1972). Bellion (1909) found a 
slight increase in the percent of water in several major organs in Helix pomatia over five months hibernation in the laboratory at $18-20^{\circ} \mathrm{C}$, whereas snail wet weight (with shell) decreased by an average of 27\%. Von Brand (1931) performed an extensive series of experiments (using $125 \mathrm{~kg}$ of snails!) in which he measured changes in both water and dry weight content in hibernating Helix pomatia. However, these studies are not considered here because of the highly anomalous results: of the four series of experiments, three showed an increase in the total weight of the snails during hibernation. Thus the limited evidence presently available indicates that during dormancy, dry weight and water are lost at relative rates such that no decrease in percent water of the body occurs over the season. Yom-Tov (1971b) has suggested that dry mass may be respired in order to produce water to maintain a constant degree of hydration. Dry weight loss would thus be controlled by the rate of evaporative water loss. This dry mass loss may reduce the fitness of a snail by reducing its reproductive output or possibly by increasing its probability of mortality. However, land snails are known to be able to survive tremendous weight losses during dormancy. Survival of weight losses of ca. $50 \%$ of wet weight (with shell) have been recorded for Bradybaena fruticum (Krahelska, 1910), Helix pomatia (Kuhn, 1914), Helminthoglypta arrosa (Van der Laan, 1975), and Polydontes acutangula (Heatwole \& Heatwole, 1978). Reduction of fitness due to loss of dry mass respired to replace water lost by evaporation seems the most likely mechanism whereby long-term dry periods might select for water-conserving shell traits. 
If this selective mechanism is operating, then snails with narrower and more numerous whorls should be associated with areas with prolonged or frequent droughts. Table 16 gives the frequency of drought (as measured by the percent of months with $\leq 25 \mathrm{~mm}$ rainfall, 1951-1980) at the rainfall stations along the cline transect. Drought is less frequent at Brown's Town (where a large keeled form with high whorl expansion rate occurs) than at the other rainfall stations. Drought is about equally frequent at the two coastal stations (Runaway Bay and Discovery Bay) and at the two stations in the interior (Alexandria and Cave Valley). Because of the higher temperatures at the coast, evaporation rates would be relatively higher, so drought here would be more stressful. This is consistent with the narrow whorls and large whorl number of the snails at the coastal station. However, the similarity of the shell morphology of the snails at Cave Valley (SN-129) and Brown's Town (SN-207) is not consistent with the significant difference in drought frequency. Thus the frequency of long-term drought does not appear to adequately explain geographic variation in whorl expansion rate and whorl number.

Short-term water loss during inactivity. Because of the very high rate of water loss from active snails (up to $4 \%$ of wet weight per hour; see Machin, 1975 for review and also Bellion, 1909, Kuhn, 1914, and Pomeroy, 1968), activity is generally limited to periods of moist conditions (Cameron, 1970; Yom-Tov, 1971a; Machin, 1975; Shackack et al., 1975). It is only then that replenishment of water lost by evaporation or in locomotion can occur. As the environment dries out following a heavy rain, a snail is first unable to obtain water by 
drinking or direct absorption, then later the moisture content of the leaf litter (the food of Pleurodonte lucerna) decreases progressively. At some point the water budget of the snail becomes negative and activity must cease. Smith (1981) established the relationship between snail water content (as measured by water in the pallial cavity) and activity.

Whereas weight loss rates during long-term inactivity are relatively low, weight loss is often relatively high during short-term inactivity (before secretion of an epiphragm). Bellion (1909) found the rate of water loss from inactive Helix pomatia to be ca. four times higher than in hibernating individuals (with epiphragms). In studies in which the time course of weight change was followed, weight losses were found to be higher during the first several days of the experiments and then drop off as inactivity continues (Krahelska, 1910; Kuhn, 1914; Gebhardt-Dunkel, 1953; Warburg, 1965; Schmidt-Nielsen et al., 1972; Riddle, 1975). Because weight loss (and therefore water loss) during short-term inactivity is relatively high, snails that better retain water should be able to continue daily activity for a longer period as the environment dries out over the course of days following a rain.

Data on adult activity in relation to relative humidity for snails at $\mathrm{SN}-65$ and $\mathrm{SN}-137$ provide some support for the proposed relationship between short-term water retention and activity. The number of adults found exposed on night searches (starting $2 \mathrm{hr}$ after sunset) in the study plots at the two sites was recorded ca. once per week. Relative humidity was measured with a ventilated thermistor 
psychrometer at $1 \mathrm{~cm}$ above the leaf litter surface at five places within the study plot at ca. $4 \mathrm{hr}$ after sunset. SN-137 snails (figure 28A) are active at humidities as low as $93 \%$. The very low activity recorded on two moist nights (two points in the lower right corner) occurred during the winter following raing of $<2 \mathrm{~mm}$, an amount sufficient to raise the humidity at the leaf litter surface but apparently not sufficient to activate the snails. At SN-65, most adults are dormant over the winter, despite occasional moist conditions. Accordingly, winter data points were not included in the figure for this station. The SN-65 snails (figure 28B) show reduced activity down to around $90 \%$ relative humidity, somewhat lower than the SN-137 snails. This pattern is as would be predicted if better retention of water due to shell morphology permitted a slightly extended period of activity during the drying phase of the environment. The greater frequency of lower humidities at SN-65 is apparent from the figure, despite the fact that data from the winter dry season were not included in the figure.

The frequency of short-term drought should be primarily a function of the frequency of significant rainfall, with areas getting less frequent showers having a greater frequency of short-term drought. Table 16 gives the frequency of days with rainfall of $>12 \mathrm{~mm}$ for three rainfall stations. Data are not presently available for other rainfall stations. These limited data show close correspondence to snail morphology, with large forms with high whorl expansion rate occurring in areas of higher rainfall (Brown's Town and Cave Valley) and smaller forms with low whorl expansion rates in an area of less frequent rainfall (Alexandria). 
Thus control of short-term water loss rates could be an important selective factor for shell morphology. Extended activity permitted by this adaptation could improve the net energy balance of the snails and thereby increase their reproductive output.

\section{Bird Predation and Shell Morphology}

It was shown above that the presence of apertural denticles has no effect on water loss. It was also shown that bird predation on juveniles was much higher in populations in which adults are small and have large apertural denticles and lower in populations of large adults with small apertural denticles. Evidence of occasional adult predation (through the aperture) was observed only in large adults with small apertural denticles.

Bird predation might select for adult shell morphology in several ways. Even though predatory activity by birds is higher in populations of small adults snails, these adults are not successfully preyed upon. The small aperture size (resulting from small adult size and low whorl expansion rate) and large denticles of these adults must effectively prevent deep penetration of a bird beak into the aperture, thus making breakage of the shell in the characteristic place impossible. These shell characters may be the result of selection by more intense predatory activity of birds in drier areas, where shells of such morphology occur. Selection might act through damage to the mantle collar of a retracted snail. The smaller whorl cross-sectional area, more numerous whorls, and relatively more voluminous shell (in 
relation to snail volume) also permit a deeper retraction of the snail into the shell, which would tend to reduce damage by birds. Such damage could permit invasion of bacteria and/or require expenditure of energy for repair, thereby decreasing snails fitness.

The relatively greater shell thickness of small snails with large apertural denticles may also be the result of higher predatory acitivity in areas where such forms occur. Predation on subadults may favor individuals that continue to thicken their shells during maturation. The thicker shell of adult snails is no doubt responsible for the absence of bird damage to the shell dorsum, which does occur in the thinner-shelled subadults as well as juveniles.

Because bird predation on juveniles is very high, whereas adult predation is infrequent or absent, higher predation intensity would tend to favor snails that mature more rapidly. This selection may act on the genetic variability of the developmental program of the snail so as to favor snails that mature at a relatively small size.

If bird predation is a major influence on shell morphology, then its correlation with rainfall requires explanation. The intensity of bird predation may correlate with rainfall either because of greater abundance of predatory birds in drier areas or because birds show a greater preference for consumption of snails in drier areas. For English Song Thrushes, Cepaea are a secondary food, consumed when preferred food items are not available (Goodhart, 1958). In drier areas along the cline transect, alternative food items such as fruits (Lack, 1976) may be scarcer seasonally or throughout the year and thus birds may be more inclined to prey on snails. 
Predation or damage by birds would tend to select for many of the same shell characteristics as would drought. Selection both by drought and by birds may be acting on shell morphology. The slight southward shift of maximum denticle size on the plateau relative to minimum size might possibly represent a slight southward shift of maximum bird predation relative to minimum rainfall.

\section{Size, Foot Allometry, and Whorl Expansion Rate}

The preceding sections established why the cross-sectional area of the last whorl and whorl number may be related to moisture conditions. In this section I will consider how the interaction of foot allometry with these shell characteristics places limitations on snail size.

Let us consider first the case of isometry. If all portions of a snail increased proportionately with increasing mass, then foot volume would occupy a constant proportion of total snail volume. However, foot surface area would decrease relative to snail volume and thus, with increasing size, the loading on the foot (weight per unit area) would increase. Gould (1969) has suggested that loading could be limiting to locomotion in larger snails and proposed that positive allometric growth in foot volume may occur such that foot surface area keeps up with snail mass. He considered that the increase in relative height observed in the later stages of ontogeny in Poecilozonites may occur in order to accommodate a progressively larger relative foot volume. 
The only published data on variation in land snails foot surface area in relation to snail mass are those of Denny (1981), who worked on the giant slug Ariolimax columbianus. He found that foot loading was relatively low in small slugs and increased rapidly with size up to ca. $5 \mathrm{~g}$. Above $5 \mathrm{~g}$ (up to the maximum measured mass of $22 \mathrm{~g}$ ), the loading remained constant. This implies that above $5 \mathrm{~g}$, foot volume shows positive allometric growth such that foot surface area remains a constant proportion of snail mass. Foot surface area should be even more limiting to shelled snails, which have the added weight of the shell and enclosed visceral mass to shift around using muscles attached to the foot.

To evaluate the relationship between foot surface area and snail mass, foot surface areas were measured in adults from $\operatorname{SN}-137(n=6)$, SN-76 (6), SN-2O7 (2), and SN-37 (3). Juvenile foot surface areas were measured in specimens from $\mathrm{SN}-37$ (7), SN-76 (1), and $\mathrm{SN}-137$ (3). In addition, foot surface area was measured in two specimens of the very large Pleurodonte jamaicensis from SN-137. These are about twice the mass of the large SN- $137 \underline{\text { P. }}$ lucerna. Foot area was measured while the snails were crawling on a vertical piece of Plexiglas. A camera on a tripod was set up in front of the Plexiglas with the snails on the opposite side. The bottom of the foot was photographed in the same frame as a millimeter ruler placed next to the foot on the Plexiglas. The photographs were printed at exactly $2 \mathrm{X}$ magnification by lining up the millimeter marks in the projected image with alternate millimeter marks on a ruler placed on the printing mat. The printed images of the feet were cut out (areas of the head adhering to 
the Plexiglas were not included) and their areas were measured to 1 $\mathrm{mm}^{2}$ on a Li-Cor area meter. The actual surface areas were obtained by dividing the measured areas by 4 . After photographing, the snails were weighed to the nearest $10 \mathrm{mg}$ ( $1 \mathrm{mg}$ for juveniles) on a Mettler balance. Individuals were photographed an average of three times and were characterized by the mean of the replicates.

From figure 29, it is seen that juveniles tend to have low and variable foot loadings. Foot loading is higher for adults and is independent of size within the broad range examined (6-22 g). Pleurodonte jamaicensis shows the same loading. Foot surface area is therefore proportional to snail mass, indicating that larger snails have proportionately larger foot volume. Interestingly, the onset of positive allometric growth producing constant foot loading occurs between 3 and $6 \mathrm{~g}$, around the same point $(5 \mathrm{~g}$ ) as in Ariolimax (Denny, 1981). In an unpublished study, Dr. P. Tattersfield (in lit., 20 June 1982) compared foot surface area/snail mass relations among a series of British land snail species. He also observed that foot surface area increased with snail mass faster than the isometric expectation. Thus positive foot allometry seems to be a general pattern among land snails.

Accommodation of a proportionately larger foot volume in large retracted snails could occur through increase in the relative length of the foot, such that it occupies a greater length of the last whorl when retracted, or through increase in the cross-sectional area of the last whorl. Relative foot length was measured from the cut-out foot photographs and was calculated as the ratio of length to maximum 
width. For each individual, the foot photograph having the greatest relative foot length was selected for analysis, since this best represents the degree to which the foot can be elongated. There is a tendency for feet with larger surface area to be relatively longer (figure 30), but this relationship with surface area accounts for only $13 \%$ of the variance in relative length and is only marginally significant $\left(t_{16}=1.83, p=0.09\right.$, two-tailed test). Accomodation of the proportionately larger foot of larger snails must therefore be accomplished primarily by the increased cross-sectional area of the last whorl demonstrated above. This is the result of the higher rate of increase in whorl width and lower angle of descent of the last whorl of large shells as compared to small shells. Shells with a small cross-sectional area of the last whorl would appear to be limited to smaller snails, which have a proportionately smaller foot. Thus selection acting on shell morphology to reduce water loss would also favor smaller snails because of limitations that the shell morphology places on foot volume and consequently on snail size.

\section{Peripheral Angle}

It was noted in the morphometric analysis that larger snails have an angular or keeled periphery, whereas smaller snails have a rounded periphery. Thus far this relationship has not been accounted for. The roof of the pallial cavity (lung), which constitutes the major respiratory exchange surface of land snails, lies against the inner surface of the last whorl. Its surface area is a function of the 
surface area of the whorl along the length of the pallial cavity. Larger shells, with a relatively wider last whorl that is keeled, provide a proportionately greater surface area than would a similarly sized shell with a narrower, rounded last whorl.

In a comparison of helicid snails varying from $0.4-16 \mathrm{~g}$ (wet mass, without shell), Liebsch (1929) found that oxygen consumption increases approximately proportionally to snail mass. Oxygen consumption was found by Kienle \& Ludwig (1956) and Kienle (1957) to be proportional to mass throughout ontogeny in several land snail species. Under isometry, the surface area of the lung would decrese relative to snail mass with increasing snail mass. The oxygen consumption data suggest that lung surface area should show a positive allometric increase with increasing size such that surface area remains proportional to mass. This expectation is confirmed by the studies of Kienle (1957) and Drozdowski (1975, 1980), which show that in several helicid species, lung surface area varies approximately proportionally to mass. This relationship may account for the keeled periphery that occurs in larger adult Pleurodonte lucerna, since this feature would provide for accomodation of a larger lung surface area than would a rounded periphery. The wider last whorl of larger snails also provides more lung surface area, as well as allowing accomodation of a relatively large foot.

\section{Relative Shell Height}

It was shown above that smaller shells are relatively higher and have lower rates of increase in whorl radius (especially in the last 
whorl) as compared with larger shells. Shells with lower rates of increase in whorl radius will tend to increase in diameter more slowly and thus will tend to become relatively higher through ontogeny. Variation in relative height is therefore interpreted as a geometric consequence of variation in the ontogenetic pattern determining the cross-sectional area of the later whorls. No particular adaptive significance is attached to relative height per se.

\section{Summary of Proposed Selective Regime}

Morphological variation in Pleurodonte lucerna shells along the cline transect is viewed as the result of selection by rainfall and by predatory birds, and their interaction with size-dependent physiological characteristics of the animals. Decreased frequency of rainfall favors snails that have shells with a relatively small cross-sectional area of the last whorl and larger whorl number, since these characteristics reduce water loss in inactive animals. The relatively limited space available in the last whorl of such shells can accommodate only a relatively small foot. Since foot volume increases with positive allometry such that foot surface area tracks snail mass, a relatively small foot occurs only in smaller snails. Thus only a small shell can have the whorl properties that reduce water loss. The lung also shows positive allometry in land snails, in order to maintain adequate respiratory exchange area. The whorl characteristics of larger snails (wider and keeled last whorl) provide 
the additional area needed for accomodation of the proportionately larger lung surface area.

Intensity of bird predation appears to be spatially negatively correlated with rainfall. In drier areas, increased predation on subadults may select for development of relatively thicker adult shells. Attempted predation on adults, which is potentially damaging to the mantle collar of the retracted snails, may select for large apertural denticles in drier areas. Damage by birds would also tend to select for many of the same shell charactistics as does drought--smaller cross-sectional area of the last whorl, larger whorl number (permitting deeper retraction), and smaller size. The greater relative height of smaller snails is interpreted as a geometric consequence of the lower rate of increase in whorl radius in later whorls.

\section{Discussion}

In the review section, it was noted that land snails often tend

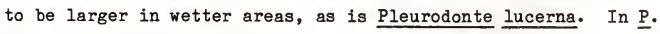
lucerna this relationship is dependent on allometric growth of the shell. If variation in shell form were isometric, then larger snails would have relatively smaller aperture area/volume (or mass) ratios and would therefore be better adapted for drier conditions. No data are available on among-population variation of aperture area in relation to size for other land snail species, so the generality of the proposed causes of size and form variation in $\underline{P}$. lucerna cannot be 
assessed. That this pattern does not apply to among-species variation in size and form was shown by Cameron (1981). In a comparative study of 19 species of British land snails ranging from $0.045-23 \mathrm{~g}$, he found that aperture area was proportional to mass 0.786 . Aperture area/mass therefore decreases with increasing size, but less slowly than would occur under isometry (under which aperture area is proportional to mass ${ }^{0.667}$ ). Smaller species thus have a relatively larger aperture area, so selection for decreased water loss in dry areas would tend to favor larger species (Nevo et al., 1983). Cameron (1981) suggested that the slight positive allometry of aperture area in among-species comparisons might assist larger snails in clinging to the substrate when they are inactive. The larger aperture area would provide more surface area for attachment of the foot when the lip of the shell is pressed against the substrate. This hypothesis does not seem to apply to Pleurodonte lucerna since inactive individuals only occasionally cling to a substrate, and when they do, the shell is not always drawn up against the substrate Since aperture area is strongly correlated with cross-sectional area of the terminal portion of the last whorl, positive allometry of aperture area may be simply a consequence of positive allometry of whorl cross-sectional area in order to accomodate the allometrically growing foot. Large aperture area, permitting tight clamping to the substrate, is perhaps more important in some marine gastropods which are subjected to dislodgement by waves or attack by powerful predators (McNair et al., 1981). 
Cain's (1980) extensive data on whorl number in relation to size in the species comprising the land snail faunas of several areas indicate that both large and small species have similar numbers of whorls. Cameron (1981) interpreted this as indicating that larger species have higher whorl expansion rates and thus a relatively larger aperture area. However, this independence of size and whorl number could also be accounted for by differences in the width of the first whorl, with whorl expansion rates not differing between large and small species. Embryonic shells of larger species generally have a wider initial whorl. Certainly both initial size and whorl expansion rate may be involved in the relationship between whorl size and whorl number and it would be of interest to know what the relative contribution of each may be and how this relates to foot allometry. While positive foot allometry appears to be a general pattern in land snails and its consequences for shell form seem to be significant, several important questions remain to be fully investigated. Is there a critical snail mass at which isometrically increasing foot surface area would become limiting to locomotion? What relationship does foot allometry have to the mode of carrying the shell? Shell danglers (some elongate species) might be expected to have relatively smaller foot surface areas than snails that hold their shell up off the substrate since less force per unit area would need to be applied. What relationship does foot allometry have to variation in the angle of the substrate on which a species or life history stage is active? And how does shell shape interact with foot surface area? Differences in both shell shape and substrate angle may 
have profound effects on the force needed to shift the shell into appropriate positions as a snail crawls along. The greater the force needed to shift the shell, the larger the required foot surface area would be. Otherwise, contraction of the columellar muscle would detach the snail from the substrate rather than shifting the position of the shell. Cameron (1978) has made some preliminary observations on the relationship between shell form and sites of activity of land snails. Snails active on vertical surfaces tend to be elongate. Data on foot surface area of two of these species (both Clausilia species) indicate that they have a relatively small foot surface area (Dr. P. Tattersfield, in lit., 20 June 1982). I suspect that these two species are shell danglers and so would not require an especially large foot surface area. Relatively flattened forms tend to be active on the ground.

While apertural denticles were shown above not to reduce water loss rates in Pleurodonte lucerna shells, this does not disprove such a role for the more extensive denticles that occur in some species. In SN-76 shells, the denticles reduce aperture cross-sectional area by only some 22\%. In land snails such as the polygyrid taxa Polygyra and Stenotrema, the aperture is often reduced to a narrow slot (see Cooke, 1895 and Solem, 1972 for reviews of apertural denticles in land snails). Restriction of the apertural opening by sealing to a substrate might also be expected to reduce water loss signficantly (Machin, 1967). Such behavior must be considered when assessing the relationship of shell form to, for example, moisture conditions. 
The role of apertural denticles in defense against arthropod predators has long been recognized (see Solem, 1972 for review). The present study suggests that predation or damage by birds may also select for the development of denticles. The denticles would be especially effective in reducing predation in species which must be attacked through the aperture, i. e., those that are too large to be swallowed whole and too thick-shelled to break. For example, in the various large species of the Neotropical mainland camaenid genus Isomeria, the denticles do not appear to be large enough to affect predation by arthropods. These denticles may function as defense against birds.

The role of shell thickness in relation to predation has not been demonstrated in land snails, although it is known to be of considerable importance in marine species (Vermeij, 1982). Thrushes are apparently always successful in breaking open captured Helix aspersa and Cepaea nemoralis (Morris, 1954) and therefore would not select against thinner-shelled individuals, unless they differentially chose thinner-shelled snails to carry to their anvil stones for breaking. Because of the much greater weight of calcium carbonate on land vs. in seawater, land snails must incur a much greater expenditure of energy during locomotion than would marine forms. As shell size decreases, relative shell surface area increases. So the relative weight of a shell thick enough to prevent breakage by birds (and therefore the energetic cost of carrying such a shell) increases with decreasing size. Consequently, it should be advantageous only for quite large land snails (such as Pleurodonte Iucerna) to have a 
shell thick enough to provide immunity from bird predation. Smaller snails must deal with predation through other types of adaptations, e. g., behavioral. Data on shell thickness in relation to shell size and predation pressure are needed in order to evaluate these expected relationships.

The role of selection in determining among-population variation in land snails is best understood for shell color patterns in Cepaea. Here at least two major types of selective forces are operating: differential selection by birds as a result of variation in crypsis of different shell color patterns on different environmental backgrounds, and selection by climatic factors (such as temperature) for reflective properties of different colors and color patterns (Jones et al., 1977). It is interesting that the same two general categories of factors also appear to be involved in selection for shell form in Pleurodonte lucerna, although the mechanisms of selection are completely different. 


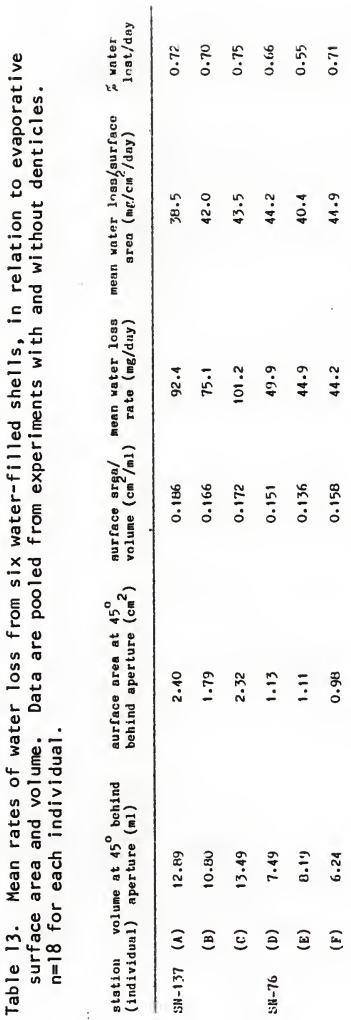


Table 14. Water loss rates from shells with aperture and last $45^{\circ}$ removed. Means are based on 9 observations on each indidual.

\begin{tabular}{llcc} 
station (individual) & $\begin{array}{c}\text { mean water loss } \\
\text { rate (mg/day) }\end{array}$ & $\begin{array}{c}\text { ratio of water loss } \\
\text { with and without aperture }\end{array}$ \\
\hline SN-137 & (A) & 176 & 1.92 \\
& (B) & 188 & 2.50 \\
(C) & 194 & 1.91 \\
SN-76 & (D) & 144 & 2.87 \\
(E) & 125 & 2.79 \\
(F) & 127 & 2.87
\end{tabular}




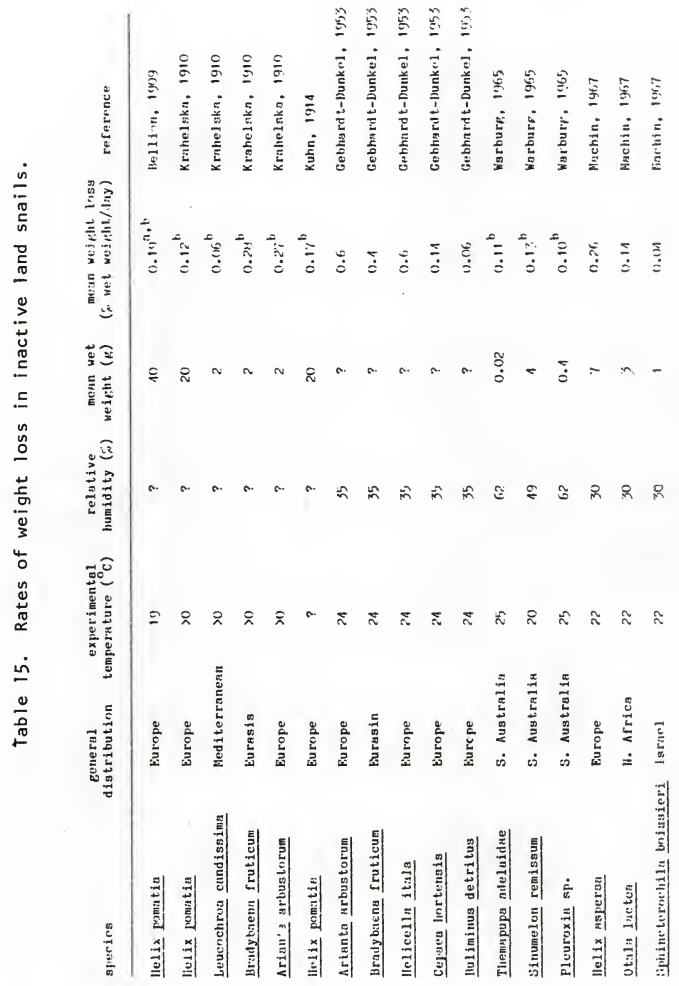




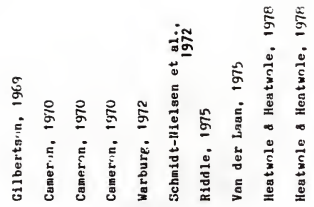

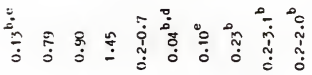

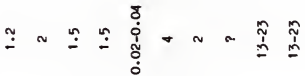

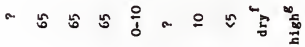

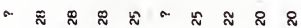

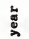

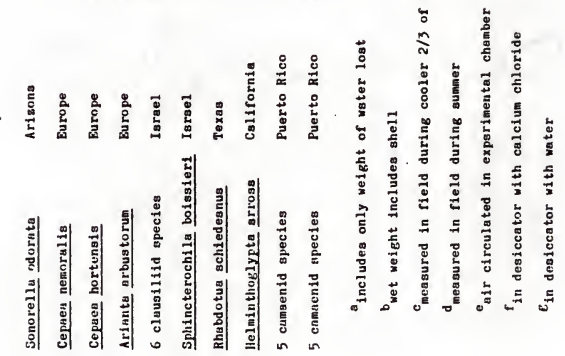


Table 16. Some measures of rainfall at rainfall stations along the cline transect.

\begin{tabular}{lcc} 
station & $\begin{array}{l}\% \text { of months with } \\
\langle 25 \text { mm rainfall }\end{array}$ & $\begin{array}{l}\text { mean no. of days/yr } \\
\text { with }>12 \text { mm rainfall }\end{array}$ \\
\hline Runaway Bay & 15.7 & -- \\
Discovery Bay & 14.4 & 40.4 \\
Brown's Town & 6.2 & 29.7 \\
Alexandria & 15.5 & 42.9 \\
Cave Valley & 15.8 &
\end{tabular}




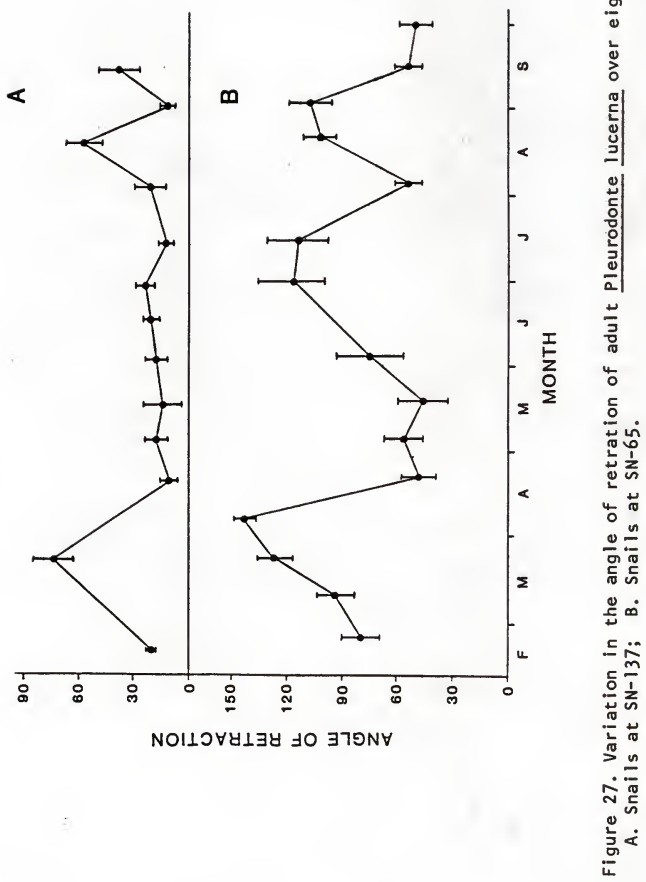




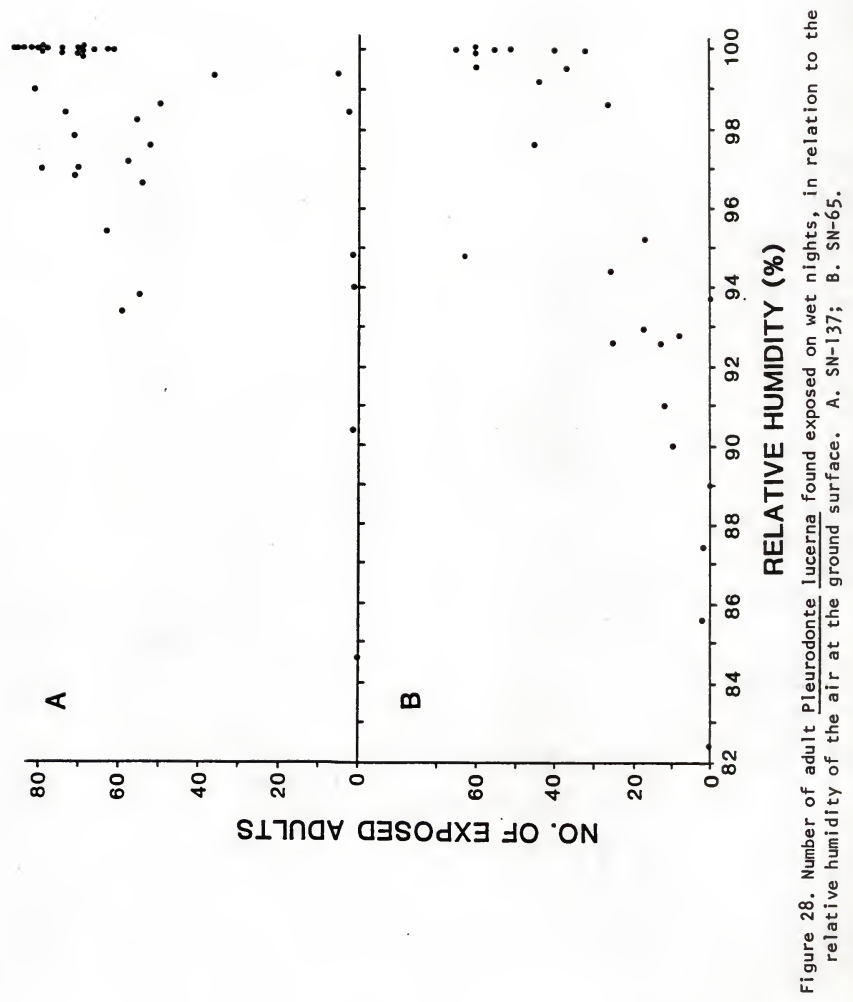




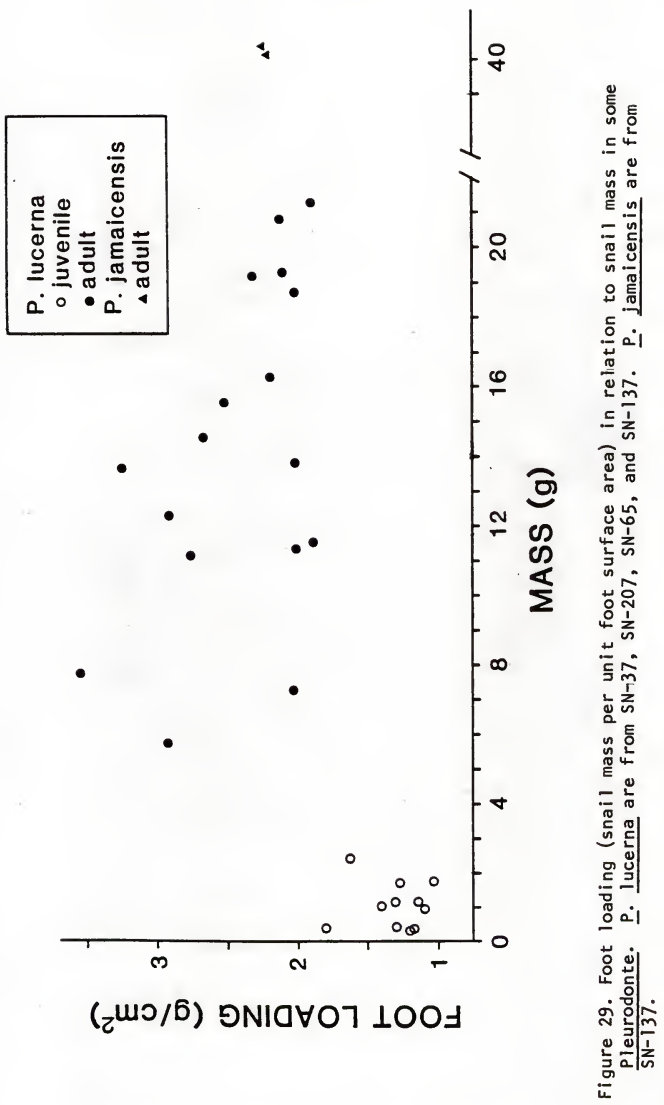




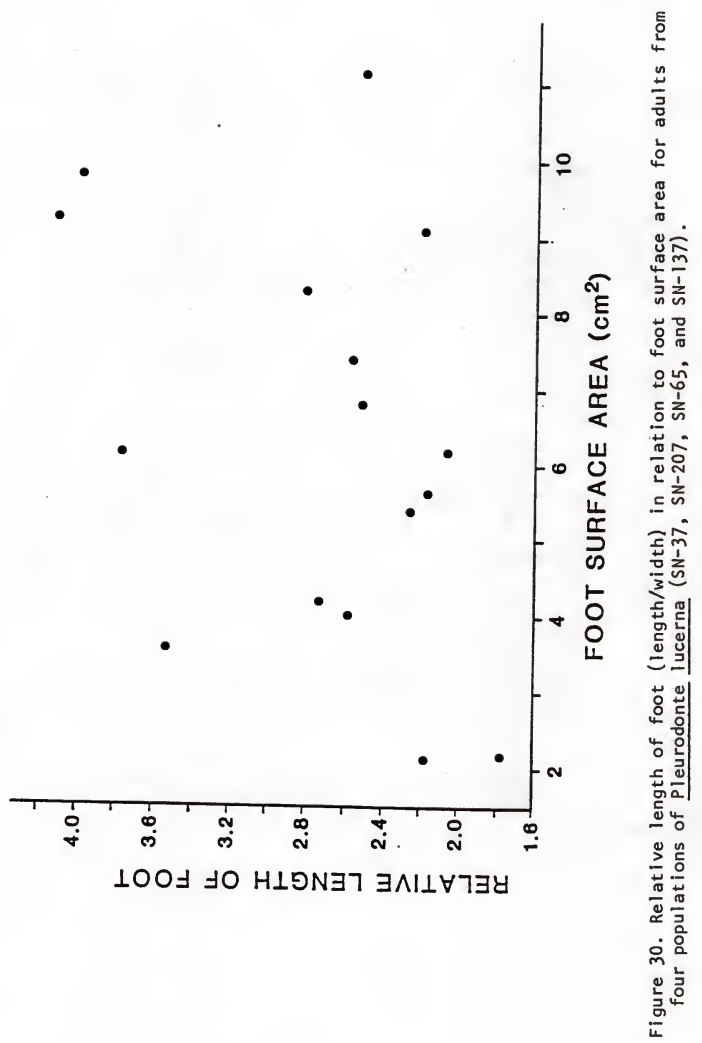


THE EVOLUTIONARY HISTORY OF THE CLINE

According to the selective scenario outlined above, differentiation along the cline is related to geographic variation in rainfall and possibly correlated variation in bird predation. Since rainfall and probably also bird predation would show continuous geographic variation, a mechanism exists for primary (in situ) differentiation of the cline. However, it is also possible that morphologically and geographically intermediate populations might represent products of the hybridization of populations expanding from the nodes of the cline (the populations showing relative minima and maxima of character states).

If the internodal populations of intermediate morphology represent the result of hybridization between expanded nodal populations, then these internodal populations should display a higher degree of variability. The data on the coefficient of variation reviewed above indicate that this is not at all the case. In general, regular geographic trends in variability were not seen. Exceptions to this were relative shell height, in which internodal populations (SN-203, SN-187) showed lower levels of variability, and inner denticle height and peripheral angle, in which smaller means were associated with higher variability. These patterns are not consistent with a hybrid origin for the clines but is consistent with primary differentiation. 
Direct evidence on the evolutionary history of the cline comes from subfossil specimens from cline transect stations. Subfossil refers here to bleached and often worn shells which are not associated with a geological deposit. Such specimens were found most frequently under rock overhangs and under rock piles (where the shells are not subject to the dissolving effects of rainfall) but also in the humus mat. Although systematic collection of subfossil material has not been carried out, the subfossils are often so strikingly different from the living forms that some definite trends are apparent. While no unusually small subfossils have been found, unusually large subfossils have been found at most sites. Table 17 gives the diameters of selected larger subfossil individuals. It is readily apparent that these individuals are so much larger than the living forms at the sites that they cannot represent rare size extremes of the living forms. If diameter is normally distributed (and it is approximately so--see above), then individuals with diameters $\geq 4$ standard deviations above the mean would have an expected frequency of 3 out of 100,000 , and those $\geq 5$ standard deviations above the mean would be expected to occur at a frequency of 3 out of $10,000,000$. The number of subfossils observed at a site in no case exceeded 100 and was rarely as large as that. It is apparent that some time in the past, the snails attained a significantly larger diameter at these sites than they do today. Since they represent a broad geographic and morphological sample of the cline transect populations, this evidence indicates that in recent years the populations along the transect have 
undergone a parallel decrease in size. This provides direct evidence of primary differentiation of the cline populations.

Dating of the subfossil material presents some problems. Radiocarbon analysis of the carbonate of modern Pleurodonte lucerna shells indicates that it is subject to a variable age anomaly of up to ca. $3000 \mathrm{yr}$ too old, as a result of uptake of ${ }^{14} \mathrm{C}$-free limestone and its incorporation into shell carbonate (Goodfriend \& Stipp, in press). Shell organic material would provide a more accurate basis for dating but 1) this too is subject to an age anomaly, albeit a much smaller one than shell carbonate (Goodfriend \& Hood, in press), and 2) the direct counting technique required for analysis of the very small amount of organic carbon available in a shell is not yet available commercially. Accordingly, amino acid racemization analysis has been employed to obtain approximate ages for the subfossils. Dr. Richard M. Mitterer of the University of Texas at Dallas kindly made determinations of alloisoleucine/isoleucine ratios for pieces of selected subfossil specimens. Alloisoleucine is a rare amino acid in living organisms. However, isoleucine slowly converts to its epimer alloisoleucine at a constant but temperature-dependent rate. The ratio of alloisoleucine to isoleucine therefore increases with the age of organic material and can thus be used to date the specimens. The analyses of the subfossil material generally gave ratios of $0.02-0.03$ (table 17). These ratios are indistinguishable from those of the shells of living snails but, because of the slow rate of conversion, could also occur in shells up to ca. $1000 \mathrm{yr}$ old. Thus these subfossil shells can be said to be $<1000 \mathrm{yr}$ old but how much less 
cannot be determined by this analysis. The SN-65 and SN-37 specimens are, according to the definition given above, actually fossils, since they came from soil deposits. The SN-65 specimens came from a soil profile along a roadcut, whereas the $\mathrm{SN}-37$ shells came from soil accumulated in a solution hole exposed in a recently blasted cliff face. The SN-65 shell analyzed showed a higher alloisoleucine/isoleucine ratio than the other specimens but would still be of late Holocene age. A precise calibration of the alloisoleucine/isoleucine time scale is not presently available for Jamaican land snails, although efforts are presently being made to produce this.

From the correlation that has been established between snail size and rainfall, it may be inferred that these very large subfossil shells represent snails that lived at a time when conditions were generally wetter throughout the region of the transect. A recent drying phase must have been responsible for the parallel decrease in size in the cline transect populations. Brown (1911) also reported subfossil specimens of Pleurodonte lucerna from Manchester, Jamaica that were unusually large compared to living populations. The recent drying phase thus appears to be an island-wide phenomenon.

The hybrid zone that occurs between Pleurodonte lucerna and $\underline{P}$. sublucerna at Brittonville is almost certainly of secondary origin. If this cline were primary, then it would represent the site of parapatric speciation of the two species (Endler, 1977). However, both species are represented in Wisconsinan (Last Glacial) deposits in Jamaica (P. Iucerna in Coco Ree Cave, northwest of Worthy Park, St. 
Catherine; $\underline{P}$. sublucerna in Portland Lower Cave, Portland Ridge, St. Catherine). So the origin of the Brittonville cline would have to predate these if it were primary. The finding of a single subfossil P. Iucerna (morphologically like the SN-178 specimens) at SN-57, where P. sublucerna presently occurs, is sufficient to disprove this possibility. The cline must therefore be secondary--the result of the meeting and subsequent introgression of the two species.

These clines fit the classic view that secondary clines often show enhanced variability of intermediate populations, whereas primary clines do not (Mayr, 1963). However, Endler (1977) has shown theoretically that higher variability of intermediate populations might also be produced from primary differentation, if genetically coadapted modifiers are present. Such cases are difficult to document, since the mode of formation is known for relatively few clines. It is generally not possible to tell from the pattern of geographic variation whether a cline is primary or secondary, except in cases of recent secondary contact (Endler, 1977). For several clines, selection gradients have been shown experimentally to be responsible for the geographic pattern of variation and these are therefore primary clines (e. g., Bishop, 1972; Koehn et al., 1980). However, these clines involve morph or allelic frequencies of only single characters and so cannot serve as an adequate assessment of geographic trends in variation. Further use of fossil evidence to demonstrate primary differentation is needed to address the question of variation along primary clines. 
Table 17. Morphometric data and alloisoleucine/isoleucine ratios for some subfossil Pleurodonte lucerna along the cline transect.

\begin{tabular}{|c|c|c|c|}
\hline station & diameter & $\begin{array}{l}\text { no. of standard deviations } \\
\text { above modern population mean }\end{array}$ & $\begin{array}{l}\text { alloisoleucine/ } \\
\text { isoleucine }\end{array}$ \\
\hline \multirow[t]{2}{*}{ SN-37 } & 32.0 & 2.8 & 0.02 \\
\hline & 32.4 & 3.1 & -- \\
\hline \multirow[t]{3}{*}{ SN-19 } & 60.6 & $9 \cdot 3$ & 0.02 \\
\hline & 60.8 & 9.4 & 0.03 \\
\hline & 58.5 & 8.1 & -- \\
\hline \multirow[t]{2}{*}{ SN-65 } & 40.6 & 6.1 & 0.06 \\
\hline & 39.7 & 5.3 & $\cdots$ \\
\hline \multirow[t]{2}{*}{ SN-187 } & 53.9 & $7 \cdot 3$ & 0.02 \\
\hline & $49 \cdot 4$ & 4.6 & 0.02 \\
\hline \multirow[t]{3}{*}{$\mathrm{SN}-152$} & 53.8 & 4.6 & 0.02 \\
\hline & 55.6 & 5.5 & -- \\
\hline & 55.8 & 5.6 & -- \\
\hline \multirow[t]{2}{*}{ SN-194 } & 60.1 & 5.5 & 0.03 \\
\hline & $61 \cdot 7$ & 6.3 & 0.02 \\
\hline
\end{tabular}




\section{LITERATURE CITED}

Adams, C. B. (1849). Contributions to conchology, no. 2. Amherst, Mass.: published by the author.

Adams, C. B. (1850). Contributions to conchology, no. 7. Amherst, Mass.: published by the author.

Agocsy, P. (1963). The examination of some edible snail (Helix pomatia L.) populations (Mollusca). Annls hist.-nat. Mus. Natn. hung. 55: $513-520$.

Allen, G. M. 1942. Extinct and vanishing mammals of the Western Hemisphere with all the marine species of the world. (Spec. Publ. No. 11, Amer. Commission for Internat. Wild Iife Protection). Lancaster, $\mathrm{Pa}$. : Intelligencer Printing Company.

Anderson, S., Woods, C. A., Morgan, G. S., \& Oliver, W. L. R. (1983). Geocapromys brownii. Mammalian Species No. $201: 1-5$.

Arnold, R. W. (1971). Cepaea nemoralis on the East Sussex South Downs, and the nature of area effects. Heredity, Lond. 26: 277-298.

Asprey, G. F., \& Robbins, R. G. (1953). The vegetation of Jamaica. Ecol. Monogr. 23: 359-412.

Baker, H. B. (1935). Jamaican land snails, 6. Nautilus 49: 52-58.

Baker, H. B. (1963). Type land snails in the Academy of Natural Sciences of Philadelphia. Part II. Land Pulmonata, exclusive of North America north of Mexico. Proc. Acad. nat. Sci. Philad. 115: $191-259$.

Bantock, C. R., \& Bayley, J. A. (1973). Visual selection for shell size in Cepaea (Held.). J. Anim. Ecol. 42: 247-261.

Bantock, C. R., Bayley, J. A., \& Harvey, P. H. (1975). Simultaneous selective predation on two features of a mixed sibling species population. Evolution, N. Y. 29: 636-649.

Bar, Z. (1978). Variation and natural selection in shell thickness of Theba pisana along climatic gradients in Israel. J. moll. Stud. 44:

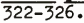


Bellion, M. (1909). Contribution a l'etude de l'hibernation chez les invertebres. Recherches experimentales sur l'hibernation de l'escargot (Helix pomatia L.). Annls Univ. Lyon, n. s. 1, Sciences, Medicine 27: 1-139.

Bengtson, S.-A., Nilsson, A., Nordstrom, S., \& Rundgren, S. (1979). Selection for adult shell size in natural populations of the landsnail Cepaea hortensis (Mull.). Ann. Zool. Fennici 16: 187-194.

Bent, A. C. (1953). Life histories of North American Wood Warblers. Bull. U. S. natn. Mus. 203: 1-734.

Berry, A. J. (1963). Growth and variation of the shell in certain Malayan limestone hill snails. Proc. malac. Soc. Lond. 35: 203-206.

Bishop, J. A. (1972). An experimental study of the cline in industrial melanism in Biston betularia (L.) (Lepidoptera) between urban Liverpool and rural North Wales. J. Anim. Ecol. 41: 209-243.

Boettger, C. R. (1921). Carabus morbillosus Fabr. und Otala tigri Gerv., eine Studie gegenseitiger Anpassung. Abh. senckenb. naturforsch. Ges. 37: 321-325.

Boettger, C. R. (1935). Die Abwehr der Landschnecken gegen Kafer. Sber. Ges. naturf. Freunde Berl. (1935): 93-102.

Bolli, H. M., \& Bermudez, P. J. (1965). Zonation based on planktonic foraminifera of middle Miocene to Pliocene warm-water sediments. Bol. Inform. Asoc. Venez. Geol. Mineria Petrol. 8: 121-149.

Bonatti, E., \& Gartner, S., Jr. (1973). Caribbean climate during Pleistocene ice ages. Nature, Lond. 244: 563-565.

Boycott, A. E. (1919). Observations on the local variation of Clausilia bidentata. J. Conchol. 16: 10-23.

Boycott, A. E. (1920). On the size variation of Clausilia bidentata and Ena obscura within a "locality." Proc. malac. Soc. Lond. 14: $34-42$.

Bradbury, J. P., Leyden, B., Salgado-Labouriau, M., Lewis, W. M., Jr., Schubert, C., Binford, M. W., Frey, D. G., Whitehead, D. R., \& Weibezahn, F. H. (1981). Late Quaternary environmental history of Lake Valencia, Venezuela. Science, N. Y. 214: 1299-1305.

Brown, A. D. (1870). Diagnoses molluscorum novorum. J. Conchyliol. 18: $391-393$.

Brown, A. P. (1911). Variation in some Jamaican species of Pleurodonte. Proc. Acad. nat. Sci. Philad. 63: 117-164. 
Brown, A. P. (1913). Variation in two species of Lucidella from Jamaica. Proc. Acad. nat. Sci. Philad. 65: 3-21.

Cain, A. J. (1971). Colour and banding morphs in subfossil samples of the snail Cepaea. In Ecological genetics and evolution, p. 65-92. Creed, R. (Ed). Oxford: Blackwell Scientific Publications.

Cain, A. J. (1977). Variation in the spire index of some coiled gastropod shells, and its evolutionary significance. Phil. Trans. R. Soc., B, Biol. Sci. 277: 377-428.

Cain, A. J. (1978a). Variation of terrestrial gastropods in the Philippines in relation to shell shape and size. J. Conchol. 29: 239-245.

Cain, A. J. (1978b). The deployment of operculate land snails in relation to shape and size of shell. Malacologia 17: 207-221.

Cain, A. J. (1980). Whorl number, shape, and size of shell in some pulmonate faunas. J. Conchol. 30: 209-221.

Cain, A. J., \& Currey, J. D. (1963a). Area effects in Cepaea. Phil. Trans. R. Soc., B, Biol. Sci. 246: 1-81.

Cain, A. J., \& Currey, J. D. (1963b). The causes of area effects. Heredity, Lond. 18: 467-471.

Cain, A. J., \& Currey, J. D. (1963c). Area effects in Cepaea on the Larkhill Artilllery Ranges, Salisbury Plain. Zool. J. Linn. Soc. 45: $1-15$.

Cameron, R. A. D. (1970). The survival, weight-loss and behaviour of three species of land snail in conditions of low humidity. J. Zool., Lond. 160: 143-157.

Cameron, R. A. D. (1978). Differences in the sites of activity of coexisting species of land mollusc. J. Conchol. 29: 273-278.

Cameron, R. A. D. (1981). Functional aspects of shell geometry in some British land snails. Biol. J. Linn. Soc. 16: 157-167.

Cameron, R. A. D., Carter, M. A., \& Palles-Clark, M. A. (1980). Cepaea on the Salisbury Plain: patterns of variation, landscape history and habitat stability. Biol. J. Linn. Soc. 14: 335-358.

Cameron, R. A. D., Williamson, P., \& Morgan-Huws, D. I. (1977). The habitats of the land snail Cepaea nemoralis ( $\mathrm{L}_{0}$ ) on downland and their ecogenetic significance. Biol. J. Linn. Soc. 9: 231-241. 
Cant, R. V. (1972). Jamaica's Pleistocene reef terraces. J. geol. Soc. Jamaica 12: 13-17.

Carter, M. (1968). Area effects and visual selection in Cepaea nemoralis (L.) and Cepaea hortensis. Phil. Trans. R. Soc., B, Biol. Sci. 253: 397-446.

Charrier, M. (1981). Contribution a l'etude des effets du groupement sur la croissance de l'escargot "petit gris" Helix aspersa Múlller (Gasteropodé pulmoné stylommatophore). Archs Zool. exp. gen. 122: 29-38.

Clarke, B. C. (1968). Balanced polymorphism and regional differentation in land snails. In Evolution and environment, p. 351-368. Drake, E. T. (Ed). New Haven: Yale University Press.

Clarke, B., \& Murray, J. (1962). Changes of gene-frequency in Cepaea nemoralis (I.). Heredity, Lond. 17: 445-465.

Clessin, S. (1897). Ueber den Einfluss der Umgebung auf die Gehause der Mollusken. Jh. Ver. vaterl. Naturk. Wurtt. 53: 68-86.

Cliff, A. D., \& Ord, J. K. (1973). Spatial autocorrelation. London: Pion Ltd.

Colinvaux, P. (1979). The ice-age Amazon. Nature, Lond. 278: 399-400.

Comer, J. B. (1974). Genesis of Jamaican bauxite. Econ. Geol. 69: $1251-1264$.

Connor, E. F., \& Simberloff, D. (1979). The assembly of species communities: chance or competition? Ecology 60: 1132-1140.

Cook, A. H. (1895). Molluscs. In The Cambridge natural history 3: 1-459. Harmer, S. F., \& Shipley, A. E. (Eds). New York: Macmillan and Company.

Cook, L. M. (1965). Inheritance of shell size in the snail Arianta a rbustorum. Evolution, N. Y. 19: 86-94.

Cook, L. M., \& Cain, A. J. (1980). Population dynamics, shell size and morph frequency in experimental populations of the snail Cepaea nemoralis (L.). Biol. J. Linn. Soc. 14: 259-292.

Cook, L. M., \& 0'Donald, P. (1971). Shell size and natural selection in Cepaea nemoralis. In Ecological genetics and evolution, p. 93-108. Creed, R. (Ed). Oxford: Blackwell Scientific Pulbications.

Cook, L. M., \& Pettitt, C. W. A. (1979). Shell form in Discula polymorpha. J. moll. Stud. 45: 45-51. 
Coppois, G., \& Glowacki, C. (1983). Bulimulid land snails from the Galapagos: 1. Factor analysis of Santa Cruz Island species. Malacologia 23: 209-219.

Crowell, H. H. (1973). Laboratory study of calcium requirements of the brown garden snail, Helix apsersa Muller. Proc. malac. Soc. Lond. 40: $491-503$.

Cruz, A. (1977). Ecology and behavior of the Jamaican woodpecker. Bull. Fla. St. Mus. 22: 149-204.

Deevey, E. S., Jr., Brenner, M., \& Binford, M. W. (in press). Paleolimnology of the Peten lake district, Guatemala, III. Late Pleistocene and Gamblian environments of the Maya area. In Paleolimnology. Proc. third internat. symp. Merilainen, J., Huttunen, P., \& Battarbee, R. (Eds). The Hague: Dr. W. Junk Publishers.

Denny, M. W. (1981). A quantitative model for the adhesive locomotion of the terrestrial slug, Ariolimax columbianus. J. exp. Biol. 91: 195-217.

Downer, A. (1978). Snails in White bellied dove. Gosse Bird Club Broadsheet No. 30: 12 .

Drozdowski, A. (1975). Relationship between the body-weight without shell, and the pulmonary surface in Helicella obvia (Hart.) (Gastropoda, Pulmonata). Zoologica Pol. 24: 477-493.

Drozdowski, A. (1980). Vergleichende Untersuchungen uber Lungen von Eobania vermiculata (Mull.). Malakol. Abh. 6: 213-219.

Emberton, K. C., Jr. (1982). Environment and shell shape in the Tahitian land snail Partula otaheitana. Malacologia 23: 23-35.

Emiliani, C., \& Shackleton, N. J. (1974). The Brunhes Epoch: isotopic paleotemperatures and geochronology. Science, N. Y. 183: 511-514.

Endler, J. A. (1977). Geographic variation, speciation, and clines (Monographs in population biology, 10). Princeton: Princeton University Press.

Férussac, d'A. (1822). Tableaux systematiques des animaux mollusques classes en familles naturelles, dans lesquels on a etabli la concordance de tous les systemes; suivis d'un prodrome general pour tous les mollusques terrestres ou fluviatiles, vivants ou fossils. Paris: Arthus Bertrand. 
Férrusac, d'A, \& Deshayes, G.-P. (1827). Histoire naturelle generale et particuliere des mollusques terrestres et fluviatiles, tant des especes que l'on $^{\prime}$ trouve aujourd 'hui vivantes, que des depouilles fossiles de celles qui n'existent plus; classes d, aspres les caracteres de celles qui presentent ces animaux et leur coquilles. Paris.

Frömming, E., (1954). Biologie der mitteleuropaischen Landgastropoden. Berlin: Duncker and Humblot.

Galler, L., \& Gould, S. J., (1979). The morphology of a "hybrid zone" in Cerion: variation, clines, and an ontogenetic relationship between two "species" in Cuba. Evolution, N. Y. 33: 714-727.

Gebhardt-Dunkel, E. (1953). Die Trockenresistenz bei Gehauseschnecken. Zool. Jb., Abt. allg. Zool. 64: 235-266.

Geiger, R. (1973). The climate near the ground. Cambridge, Mass.: Harvard University Press.

Geyer, D. (1927). Unsere Land- und Susswasser-Mollusken. Einfuhrung in die Molluskenfauna Deutschlands $\frac{\text { Aufl. Stuttgart: } \mathbb{N}}{3}$. P.

Gilbertson, L. H. (1969). Notes on the biology of the snail Sonorella odorata in Arizona. Nautilus 83: 29-34.

Goodfriend, G. A. (1983a). Some new methods for morphometric analysis of gastropod shells. Malacol. Rev. 16: 79-86.

Goodfriend, G. A. (1983b). Late Quaternary land snails from the north coast of Jamaica. [abstract]. Amer. Malacol. Bull. 1: 99-100.

Goodfriend, G. A., \& Hood, D. G. (in press). Carbon isotope analysis of land snail shells: implications for carbon sources and radiocarbon dating. Radiocarbon 25: 810-830.

Goodfriend, G. A., \& Stipp, J. J. (in press). Limestone and the problem of radiocarbon dating of land snail shell carbonate. Geology 11 : 575-577.

Goodhart, C. B. (1958). Thrush predation on the snail Cepaea hortensis. J. Anim. Ecol. 27: 47-57.

Goodhart, C. B. (1963). "Area effects" and non-adaptive variation between populations of Cepaea (Mollusca). Heredity, Lond. 18: 459-465.

Gould, S. J. (1968). Ontogeny and the explanation of form: an allometric analysis. J. Paleont. 42: $81-93$. 
Gould, S. J. (1969). An evolutionary microcosm: Pleistocene and Recent history of the land snail P. (Poecilozonites) in Bermuda. Bull. Mus. Comp. Zool. Harv. 138: 407-532.

Gould, S. J. (1971). Precise but fortuitous convergence in Pleistocene land snails from Bermuda. J. Paleont. 45: 409-418.

Gould, S. J., \& Paull, C. (1977). Natural history of Cerion. VII. Geographic variation of Cerion (Mollusca: Pulmonata) from the eastern end of its range (Hispaniola to the Virgin Islands): coherent patterns and taxonomic simplifications. Breviora No. 445: $1-24$.

Gould, S. J., Woodruff, D. S., \& Martin, J. P. (1974). Genetics and morphometrics of Cerion at Pongo Carpet: a new systematic approach to this enigmatic land snail. Syst. Zool. 23: 518-535.

Grant, P. R. (1972). Convergent and divergent character displacement. Biol. J. Linn. Soc. 4: 39-68.

Heatwole, H., \& Heatwole, A. (1978). Ecology of the Puerto Rican camaenid tree-snails. Malacologia 17: 241-315.

Heller, J., (1979). Distribution, hybridization and variation in the Israeli land snail Levantina (Pulmonata: Helicidae). Zool. J. Linn. Soc. $67: 115-148$.

Hinton, H. E., \& Dunn, A. M. S. (1967). Mongooses. Their natural history and behaviour. Berkeley: University of California Press.

Hoff, A. (1923). Zur Variabilität von Arianta (Helix) arbustorum Leach. Z. indukt. Abstamm. - u. VererbLehre $30:$ 99-129.

Imbrie, J., \& Kipp, N. G. (1971). A new micropaleontological method for quantitative paleoclimatology: applications to a Late Pleistocene Caribbean core. In The late Cenozoic glacial ages, p. 71-181. Turekian, K. (Ed). New Haven: Yale University Press.

Jacobson, M. K., \& Boss, K. J. (1973). The Jamaican land shells described by C. B. Adams. Occas. Pap. Moll. Mus. Comp. Zool. Harv. 3: 305-519.

Jamaican Meteorololgical Service. (1973). The climate of Jamaica. Kingston: Jamaican Meteorological Service.

Jamaican Meteorological Service. (ms). Monthly and annual rainfall totals in Jamaica (averages for the period 1931-1960).

Jarvis, P. W. (1902). Notes on the distribution of the Pleurodonte acuta group. Nautilus 15: 137-141. 
Johnson, M. S. (1981). Effects of migration and habitat choice on shell banding frequencies in Theba pisana at a habitat boundary. Heredity, Lond. 47: 121-133.

Jones, J. S. (1975). The genetic structure of some steppe populations of the snails Cepaea vindobonensis (Pf.). Genetica 45: 217-225.

Jones, J. S., Leith, B. H., \& Rawlings, P. (1977). Polymorphism in Cepaea: a problem with too many solutions? Ann. Rev. Ecol. Syst. 8: $\overline{109-143 .}$

Kekauoha, W. (1966). Life history and population studies of Achatina fulica. Nautilus 80: 3-10.

Kienle, M.-L. (1957). Über Beziehungen zwischen Korpergrosse, Lungengrosse und Energiekonsum bei Pulmonaten, insbesondere Helix pomatia L. und Zebrina detrita Müll. Z. vergl. Physiol. 40: $440-450$.

Kienle, M.-L., \& Ludwig, W. (1956). Die Beziehung zwischen Korpergrosse und Sauerstoffkonsum bei Landpulmonaten. $Z_{\text {. vergl. }}$ Physiol. 39: 102-118.

Kimball, D. (1947). A new Pleurodonte from the Miocene, Bowden, Jamaica. Nautilus $61: 37-39$.

Knights, R. V. (1979). Experimental evidence for selection on shell size in Cepaea hortensis (Mull.). Genetica 50: 51-60.

Knipper, H. (1939). Systematische, anatomische, okologische und tiergeographische Studien an subosteuropaischen Heliciden (Moll. Pulm.). Arch. Naturgesch. 8: 327-517.

Koehn, R. K., Newell, R. I. E., \& Immermann, F., (1980). Maintenance of an aminopeptidase allele frequency cline by natural selection. Proc. natn. Acad. Sci. U. S. A. 77: 5385-5389.

Krahelska, M. (1910). Ueber den Einfluss der Winterruhe auf den histologischen Bau einiger Landpulmonaten. Jena. Z. Naturw., n. f. 39: $363-444$.

Kuhn, W. (1914). Beitrage zur Biologie der Weinbergschnecke (Helix pomatia L.). Z. wiss. Zool. 109: 128-184.

Lack, D. (1976). Island biology, illustrated by the land birds of Jamaica (Studies in ecology, 3). Berkeley: University of California Press.

Lais, R. (1925). Dr. Hans Kauffmanns hinterlassene Schneckensammlung. Ein Beitrag zur Kenntnis der Schneckenfauna Sudbadens und ihre Beziehungen zum Klima. Ber. naturf. Ges. Freiburg. i. B. 25: 1-74. 
Lamarck, J. B. (1822). Histoire naturelle des animaux sans vertebres presentant les caracteres generaus et particulieres de ces animaux, leur distribution, leurs classes, leurs familles, leurs genres, et la citation des principales especes qui s'y raportment vol. 6 , part 2. Paris: published by the author.

Lamarck, J. B. (1827). Tableau encyclopedique et methodologique des trois regnes de la nature. Paris.

Lazaridou-Dimitridou, M., \& Daguzan, J. (1981). Etude de l'effet du "groupement" des individus chez Theba pisana (mollusque gasteropode pulmone stylommatophore). Malacologia 20: 195-204.

Lewis, G. (1977). Polymorphism and selection in Cochlicella acuta. Phil. Trans. R. Soc., B, Biol. Sci. 276: 399-451.

Liebsch, W. (1929). Uber die Atmung einiger Heliciden. Eine Untersuchung zum Oberflachengesetz. Zool. Jb., Abt. allg. Zool. Physiol. 46: 161-208.

Lipton, C. S., \& Murray, J. (1979). Courtship of land snails of the genus Partula. Malacologia 19: 129-146.

Machin, J. (1966). The evaporation of water from Helix aspersa. IV. Loss from the mantle of the inactive snail. J. Exp. Biol. 45: 269-278.

Machin, J. (1967). Structural adaptations for reducing water-loss in three species of terestrial snail. J. Zool., Lond. 152: 55-65.

Machin, J. (1975). Water relationships. In Pulmonates 1: 105-163. Fretter, V., \& Peake, J. (Eds). London: Academic Press.

Mayr, E. (1963). Animal species and evolution. Cambridge, Mass.: Belknap Press.

Mazek-Fialla, K. (1934). Die Lebensweise xerophiler Schnecken Syriens, Griechlands, Dalmatiens und er Turkei und die Beschaffenheit ihrer subepithelialen Drusen. Z. Morph. Okol. Tiere 28: 445-468.

McNair, C. G., Kier, W. M., LaCroix, P. D., \& Linsley, R. M. (1981). The functional significance of aperture form in gastropods. Lethaia 14: $63-70$.

Mermod, G. (1950). Les types de la collection Lamarck au Museum de Geneve. Mollusques vivants, I. Revue suisse Zool. 57: 687-756.

Mermod, G. (1951). Les types de la collection Lamarck au Museum de Geneve. Mollusques vivants, II. Revue suisse Zool. 58: 693-753. 
Morris, D. (1954). The snail-eating behaviour of thrushes and blackbirds. Br. Birds 47: 33-49.

Müller, 0. F. (1774). Vermium terrestrium et fluviatilium, seu aninalium infusiorum, helminthicorum, et testaceorum, non marinorum, succincta historia, Vol. 2. Hauniae et Lipsiae: Heineck et Faber.

Murray, J., \& Clarke, B. (1966). The inheritance of polymorphic shell characters in Partula (Gastropoda). Genetics, Princeton 54: 1261-1277.

Murray, J., \& Clarke, B. (1968). Inheritance of shell size in Partula. Heredity, Lond. 23: 189-198.

Murray, J., \& Clarke, B. (1980). The genus Partula on Moorea: speciation in progress. Proc. R. Soc. Lond. 211: 83-117.

Nevo, E., Bar-El, C., \& Bar, Z. (1983). Genetic diversity, climatic selection and speciation of Sphincterochila landsnails in Israel. Biol. J. Linn. Soc. 19: 339-373.

Nopp, H. (1974). Physiologische Aspekte des Trockenschlafs der Landschnecken. Sber. ost. Akad. Wiss., Mathem.-naturw. Kl., Abt. I 182: $1-75$.

Økland, F. (1925). Die Verbreitung der Landgastropden Norwegens. Skr. norske Vidensk-Akad. Mat.-naturv. Kl. No. 8: 1-168.

0ldham, C. (1929). The influence of lime on the shell of Arianta arbustorum (L.). Proc. malac. Soc. Lond. 18: 143-144.

0ldham, C. (1934). Further observations on the influence of lime on the shells of snails. Proc. malac. Soc. Lond. 21: 131-138.

Oosterhoff, L. M. (1977). Variation in growth rate as an ecological factor in the landsnail Cepaea nemoralis (L.). Netherl. J. Zool. 27: $1-132$.

Paul, C. R. C. (1974). Azeca in Britain. J. Conchol. 28: 155-172.

Peake, J. F. (1973). Species isolation in sympatric populations of the genus Diplommatina (Gastropoda, Prosobranchia, Cyclophoridae, Diplommatininae). Malacologia 14: 303-312.

Pfeiffer, L. (1846). Die Schnirkelschnecken (Gattung Helix). Zweite Abteilung Heliceen. Eigentliche Schnirkelschnecken. In Systematisches Conchylien-Cabinet von Martini und Chemnitz 1: 1-400. Nurnberg: Verlag von Bauer und Raspe. 
Pfeiffer, L. (1854). Descriptions of forty-two new species of Helix from the collection of H. Cuming, Esq. Proc. Zool. Soc. Lond. 12: 49-57.

Pfeiffer, L. (1867). Diagnosen neuer Heliceen. Malakolzool. Blatter $14: 126-131$.

Pilsbry, H. A. (1889). Manual of Conchology, $2^{\circ}$ ser., Vol. 5. Philadelphia: Academy of Natural Sciences of Philadelphia.

Pilsbry, H. A. (1894). Manual of Conchology, $2^{\circ}$ ser., Vol. 9. Philadelphia: Academy of Natural Sciences of Philadelphia.

Pilsbry, H. A. (1929). Studies on West Indian mollusks: the genus Zachrysia. Proc. Acad. nat. Sci. Philad. 80: 581-606.

Pilsbry, H. A., \& Brown, A. P. 1910. The Mollusca of Mandeville, Jamaica, and its environs. Proc. Acad. nat. Sci. Philad. 62: $510-535$.

Pilsbry, H. A., \& Brown, A. P. 1911. The land Mollusca of Montego Bay; with notes on the land Mollusca of the Kingston region. Proc. Acad. nat. Sci. Philad. 63: 572-588.

Pollard, E. (1975). Differences in shell thickness in adult Helix pomatia $L$. from a number of localities in southern England. 0ecologia $21: 85-92$.

Pomeroy, D. E. (1968). Dormancy in the land snail, Helicella virgata (Pulmonata: Helicidae). Aust. J. Zool. 16: 857-869.

Prance, G. T. (Ed). (1982). Biological diversification in the tropics. Proc. fifth internatl. symp. Assoc. Trop. Biol. New York: Columbia University Press.

Pregill, R. K., \& 0lson, S. L. (1981). Zoogeography of West Indian vertebrates in relation to Pleistocene climatic cycles. Ann. Rev. Ecol. Syst. 12: 75-98.

Prell, W. L., \& Hays, J. D. (1976). Late Pleistocene faunal and temperature patterns of the Colombia Basin, Caribbean Sea. Mem. Geol. Soc. Amer. 145: 201-220.

Rensch, B. (1931). Zur Kenntnis der Molluskenfauna Timors. Zool. Jb., Abt. Syst. Okol. Geogr. Tiere 60: 429-456.

Rensch, B. (1932). Über die Abhängigkeit der Grosse, des relativen Gewichtes und der Oberflachenstruktur der Landschneckenschalen von den Umweltsfaktoren. (Okologische Molluskenstudien I.). Z. Morphol. ökol. Tiere 25: 757-807. 
Rensch, B., (1937). Untersuchungen uber Rassenbildung und Erblichkeit von Rassenmerkmalen bei sizilischen Landschnecken. $\underline{Z}$. indukt. Abstamm.- u. VererbLehre 72: 564-588.

Richardson, A. M. M. (1974). Differential climatic selection in natural population of land snail Cepaea nemoralis. Nature, Lond. 247: $572-573$.

Riddle, W. A. (1975). Water relations and humidity-related metabolism of the desert snail Rabdotus schiedeanus (Pfeiffer) (Helicidae) [sic]. Comp. Biochem. Physiol. 51A: 579-583.

Robinson, E., Lewis, J. F., \& Cant, R. V. (1971). Field guide to aspects of the geology of Jamaica. In Guidebook to the Caribbean island-arc system, 1970, p. 1-44. Washington: International Field Institute.

Sacchi, C. F. (1961). Dati per una valutazione della predazione selettiva di turdidi e di rodenti contro Cepaea nemoralis (L.) nel Cambridgeshire (Inghilterra). Atti Soc. ital. Sci. nat. 100: 1-24.

Sacchi, C. F. (1965). Ecological and historical bases for a study of the Iberian terrestrial Mollusca. In Proc. first Europ. Malac. Congr., London (1962), p. 243-257.

Sacchi, C. F. (1971). Ecologie comparee des gasteropodes pulmones des dunes Mediterraneennes et Atlantiques. Natura, Milano 62: 277-358.

Schindel, D. E., \& Gould, S. J. (1977). Biological interaction between fossil species: character displacement in Bermudian land snails. Paleobiology 3: 259-269.

Schmid, G. (1919). Zur Variabilitat der Clausilia (Alinda) biplicata Mont. NachrBl. dt. Malakozool. Ges. 51: 24-44.

Schmidt-Nielsen, K., Taylor, C. R., \& Shkolnik, A. (1971). Desert snails: problems of heat, water and food. J. Exp. Biol. 55: 385-398.

Schmidt-Nielsen, K., Taylor, C. R., \& Shkolnik, A. (1972). Desert snails: problems of survival. Symp. zool. Soc. Lond. No. 31: 1-13.

Schubert, C., \& Medina, E. (1982). Evidence of Quaternary glaciation in the Dominican Republic: some implications for Caribbean paleoclimatology. Palaeogeogr., Palaeoclim., Palaeoecol. 39: $281-294$.

Shackak, M., Orr, Y., \& Steinberger, Y. (1975). Field observations on the natural history of Sphincterochila (S.) zonata (Bourguignat, 1853) ( $=\mathrm{S}$. boissieri Charpentier, 1847). Argamon, Israel J. Malac. $5: 20-46$. 
Simpson, C. T. (1894). Distribution of the land and fresh-water mollusks of the West Indian region, and their evidence with regard to past changes of land and sea. Proc. U. S. natn. Mus. 17: $423-451$.

Smith, L. H., Jr. (1981). Quantified aspect of pallial fluid and its affect on the duration of locomotor activity in the terrestrial gastropod Triodopsis albolabris. Physiol. Zool. 54: 407-414.

Solem, A. (1972). Microarmature and barriers in the apertures of land snails. Veliger 15: 81-87.

Steinberger, Y., Grossman, S., \& Dubinsky, Z. (1982). Changes in organic storage compounds during the active and inactive periods in a desert snail, Sphincterochila prophetarum. Comp. Biochem. Physiol. 71A: $41-46$.

Sweeting, M. M. (1958). The karstlands of Jamaica. Geogr. J. 124: 184-199.

Tattersfield, P. (1981). Density and environmental effects on shell size in some sand dune snail populations. Biol. J. Linn. Soc. 16: $71-81$.

Taylor, J. W. (1881). Life histories of British Helices. J. Conchol. 3: $241-259$.

Tillier, S. (1981). Clines, convergence and character displacement in New Caledonian diplommatinids (land prosobranchs). Malacologia 21: 177-208.

van Bruggen, A. C. (1969). Studies on the land molluscs of Zululand. Zool. Verh., Leiden No. 103: 1-116.

van der Hammen, T. (1974). The Pleistocene changes of vegetation and climate in tropical South America. J. Biogeogr. 1: 3-26.

van der Laan, K. L. (1975). Aestivation in the land snail Helminthoglypta arrosa (Binney) (Pulmonata: Helicidae). Veliger 17: 360-368.

Vaughn, H. H., Deevey, E. S. Jr., \& Garrrett-Jones, S. E. (in press). Pollen stratigraphy of two cores from the Peten lake district, with an appendix on two deep-water cores. In Prehistoric lowland Maya environment and economy: questions and controversies. Pohl, $\bar{M}$. (Ed). Bull. Peabody Mus., Harv. Univ.

Vermeij, G. J. (1980). Gastropod shell growth rate, allometry, and adult size. Environmental implications. In Skeletal growth of aquatic organisms, p. 379-394. Rhoads, D. C. \& Lutz, R. A. (Eds). New York: Plenum Publishing Corporation. 
Vermeij, G. J. (1982). Gastropod shell form, breakage, and repair in relation to predation by the crab Calappa. Malacologia 23: 1-12.

Voelker, J. (1959). Der chemische Einfluss von Kalziumkarbonat auf Wachstum, Entwicklung und Gehausebau von Achatina fulica Bowdich (Pulmonata). Mitt. hamb. zool. Mus. Inst. 57: 37-78.

von Brand, T. (1931). Der Jahreszyklus im Stoffbestand der Weinbergschnecke (Helix pomatia). Z. vergl. Physiol. 14: 200-264.

Warburg, M. R. (1965). On the water economy of some Australian land-snails. Proc. malac. Soc. Lond. 36: 297-305.

Warburg, M. R. (1972). On the physiological ecology of the Israeli Clausiliidae, a relic group of land snails. In Growth by intussusception. Deevey, E. S., Jr. (Ed). Trans. Conn. Acad. Arts Sci. 44: 379-395.

Welch, D'A. A. (1938). Distribution and variation of Achatinella mustelina Mighels in the Waianae Mountains, Oahu. Bull. B. P. Bishop Mus. 152: 1-164.

Welch, D'A. A. (1954). Distribution and variation of the Hawaiian tree snail Achatinella bulimoides Swainson on the leeward and northern slopes of the Koolau Range, Oahu. Proc. Acad. nat. Sci. Philad. 106: $63-107$.

Williamson, P. (1976). Size-weight relationships and field growth rates of the landsnail Cepaea nemoralis L. J. Anim. Ecol. 45: 875-885.

Williamson, P., Cameron, R. A. D., \& Carter, M. A. (1976). Population density affecting adult shell size of snail Cepaea nemoralis $\mathrm{L}$. Nature, Lond. 263: 496-497.

Winston, P. W., \& Bates, D. H. (1960). Saturated solutions for the control of humidity in biological research. Ecology 41: 232-237.

Wolda, H. (1963). Natural populations of the polymorphic landsnail Cepaea nemoralis (L.). Factors affecting their size and their genetic constitution. Archs neerl. zool. 15: 381-471.

Wolda, H. (1969a). Fine distribution of morph frequencies in the snail, Cepaea nemoralis near Groningen. J. Anim. Ecol. 38: 305-327.

Wolda, H. (1969b). Stability of a steep cline in morph frequencies of the snail Cepaea nemoralis (L.). J. Anim. Ecol. 38: 623-635.

Wolda, H. (1972). Changes in shell size in some experimental populations of the landsnail Cepaea nemoralis (Linnaeus). Argamon, Israel J. Malac. 3: 63-71. 
Woodring, W. P. (1928). Miocene mollusks from Bowden, Jamaica. Part II. Gastropods and discussion of results. Publs. Carnegie Instn No. 385: $1-564$.

Woodruff, D. S. (1973). Natural hybridization and hybrid zones. Syst. Zool. 22: 213-218.

Woodruff, D. S., \& Gould, S. J. (1980). Geographic differentation and speciation in Cerion--a preliminary discussion of patterns and process. Biol. J. Linn. Soc. 14: 389-416.

Wurtz, C. B. (1955). The American Camaenidae (Mollusca: Pulmonata). Proc. Acad. nat. Sci. Philad. 107: 99-143.

Yom-Tov, Y. (1971a). The biology of two desert snails Trochoidea (Xerocrassa) seetzeni and Sphincterochila boissieri. Israel J. Z001. 20: $231-248$.

Yom-Tov, Y. (1971b). Annual fluctuations in the water content of desert snails. Malacol. Rev. 4: 121-126. 
APPENDIX

\section{LIST OF STATIONS CITED}

Numbers after locality data are the Jamaican grid coordinates, cited east-west, north-south. Distances measured along roads are given in miles; straight-line distances are given in meters.

\section{CLARENDON}

C1-11: Bird Cave Rock, 1.4 mi SE of Balcarres; 403, 442

Cl-12: $0.1 \mathrm{mi}$ SW of bridge, Pedro River; 473,469

Cl-23: $2.9 \mathrm{mi} \mathrm{N}$ of junction at Four Paths; 442,400

C1-27: N of railroad tracks, Clarendon Park; 423, 397

C1-30: $2.4 \mathrm{mi}$ W of Mahoe Gardens, Portland Ridge; 489, 309

C1-40: $3.6 \mathrm{mi} \mathrm{N}$ of junction at Woodside, Teak Pen; 454, 408

Cl-42: $0.2 \mathrm{mi}$ W of summit, Round Hill; 417, 348

Cl-43: $200 \mathrm{~m} \mathrm{E}$ of sugar factory, Broom Hall; 418, 477

\section{MANCHESTER}

Ma-2: mile post 4, Banana Ground; 400,428

Ma-5: $1.2 \mathrm{mi} \mathrm{S}$ of junction at Spring Plain; 424, 363

Ma-7: $0.4 \mathrm{mi}$ W of junction at St. Jago; 415,380

Ma-13: 1.2 mi $S$ of junction at Walderston, Mizpah; 381, 440

Ma-30: $0.6 \mathrm{mi}$ W of junction at Spaldings; 388,454 
PORTLAND

Po-21: W side of Swift River at bridge, Graham; 692, 464 ST. ANDREW

SA-Ki-1: Casa Monte Hotel, Stony Hill; 619, 424

ST. CATHERINE

SC-7: $4.6 \mathrm{mi} \mathrm{N}$ of junction at Old Harbour, Planters Hall; 497, 391

SC-11: 0.3 mi WSW of junction at Guanabo Vale; 524, 412

SC-12: 0.2 mi NE of junction at Sligoville Road, Waterloo; 569,408

SC-16: $400 \mathrm{~m}$ SW of catchment basin, O'Connors, Mount Diablo; 501,479

SC-17: $800 \mathrm{~m} \mathrm{SE}$ of where Camperdown Road crosses parish border, Tydixon, Mount Diablo; 498, 470

ST. JAMES

SJ-6: $1.1 \mathrm{mi}$ NE of Mount Horeb, Brandon; 249, 529

ST. ANN

SN-19: $2.5 \mathrm{mi}$ S of Brown's Town, Wilburforce; 424, 533

SN-27: $0.7 \mathrm{mi} \mathrm{S}$ of Grierfield; 502, 494

SN-37: Green Grotto Caves, E of Discovery Bay; 420, 566

SN-51: $0.6 \mathrm{mi}$ E of junction at Lillyfield Pen, Elgin Hall; 452,548

SN-57: $2.4 \mathrm{mi}$ W of junction with route A1, Brittonville; 475, 531

SN-58: $0.3 \mathrm{mi} \mathrm{E}$ of junction with road no. 32, Lumsden; 470, 532

SN-65: $4.0 \mathrm{mi} \mathrm{S}$ of center of Brown's Town, Train Line; 421, 528

$\mathrm{SN}-68$ : $3.4 \mathrm{mi} \mathrm{S}$ of junction at Alexandria, Aboukir; 423, 496

SN-76: E side of junction at Culloden; 423, 522 
SN-102: ca. $3.7 \mathrm{mi} \mathrm{SE}$ of junction with road no. 134, Colliston; 445,532

SN-117: marl quarry, $0.4 \mathrm{mi} \mathrm{E}$ of main road, Concord; 476, 475

SN-119: $1000 \mathrm{~m} \mathrm{NE}$ of bridge, Pedro River; 476, 472

SN-125: NW of Albion House, Albion; 474, 510

SN-129: E of market at Cave Valley: 422,480

SN-137: $1.1 \mathrm{mi}$ WSW of junction at Clarksonville, Cedar Valley; 427,484

SN-143: $0.6 \mathrm{mi}$ SE of junction with road no. 133, Ballintoy; 445,508

SN-148: WNW of junction of route B3 with road no. 180, Hyde Park; 422,502

SN-152: $1.0 \mathrm{mi} \mathrm{N}$ of junction at Halifax, Old Bethany; 425, 507

SN-163: $0.6 \mathrm{mi}$ E of junction at Albion; 475,508

$\mathrm{SN}-168$ : $0.5 \mathrm{mi} \mathrm{S}$ of junction with route B11, Lumsden; 468, 531

SN-176: NE side of Dow (Motram) Hill at end of road, Wem; 475, 528

SN-178: $0.3 \mathrm{mi} \mathrm{S}$ of junction at Brittonville; 475,529

SN-187: $0.3 \mathrm{mi}$ W of junction at Alexandria; 425,510

SN-193: E of Eccleston School, Aboukir; 425, 491

SN-194: road to Maida, 0.1 mi SE of junction with route B3, Aboukir; 425,490

SN-199: $900 \mathrm{~m} \mathrm{NE}$ of junction at Cave Valley; 424, 482

SN-203: $0.3 \mathrm{mi} \mathrm{S}$ of junction with road to Green Hill, Rosetta; 425,515

SN-206: $900 \mathrm{~m}$ WNW of Brown's Town P. 0., Minard Hill; 419, 542 
SN-207: $0.1 \mathrm{mi}$ S of junction with road to York Castle High School, Egypt; 423, 538

SN-208: $0.3 \mathrm{mi} \mathrm{W}$ of Minard Gate pumping station, Minard Pen; 420,545

SN-213: 300 m S of crushing plant, Chippenham Park; 453, 541

SN-215: $700 \mathrm{~m}$ WNW of junction at Watt Town; 405, 510

$\mathrm{SN}-216$ : $0.3 \mathrm{mi} \mathrm{S}$ of junction with Alexandria-Alderton road, Stepney; 448,504

SN-224: $1100 \mathrm{~m}$ ENE of junction of route B11 with road no. 27, Lumsden; 472,535

$\mathrm{SN}-227$ : $1.3 \mathrm{mi} \mathrm{N}$ of junction with route B11, Forest; 468,538

SN-232: $3.4 \mathrm{mi}$ S of junction with route A3, Murphy Hill; 506, 537

SN-234: $0.2 \mathrm{mi}$ E of route A3, Buckfield Pen; 515, 544

SN-237: $1000 \mathrm{~m} \mathrm{E}$ of roundabout at Ocho Rios, Buckfield Pen; 516,546

SN-246: $2.1 \mathrm{mi}$ S of junction with route A1, Fern Gully; 517, 538 ST. THOMAS

ST-4: $3.0 \mathrm{mi} \mathrm{NE}$ of junction at Yallahs, Orange Park; 709, 359 ST-Ea-4: $100 \mathrm{mi}$ W of bridge, Easington; 692, 370

\section{TRELAWNY}

Tr-29: behind pumping station at Barnstaple; 384, 547

Tr-30: entrance to Windsor Cave, Windsor: 325, 527

Tr-34: $0.8 \mathrm{mi}$ SW of Campbells junction; 355, 539

Tr-48: $2.3 \mathrm{mi} \mathrm{S}$ of junction at Clarks Town, Hyde; 362, 541

\section{WESTMORELAND}

We-25: $0.2 \mathrm{mi} \mathrm{SE}$ of junction with route B8, Water Works; 186, 489 
BIOGRAPHICAL SKETCH

Glenn A. Goodfriend was born in Yonkers, New York, on June 12, 1951. He grew up in New York and the suburbs of Chicago and attended high school in Scarsdale, New York. At the University of Rhode Island, he studied marine, freshwater, and terrestrial mollusks, and freshwater diatoms. He received his B. S. in zoology in 1973. Work on Jamaican land snails began at the University of Chicago, where he received the M. S. degree in evolutionary biology in 1978. Following a year at the University of the West Indies (Kingston, Jamaica) teaching zoology and botany, he entered graduate school at the University of Florida. Since that time he has worked on a number of problems concerning the evolutionary biology of terrestrial mollusks, including convergent evolution of shell color patterns, radiocarbon dating of land snail shells, the paleontology and biogeographical history of Jamaican land snails, and geographic variation in Jamaican land snails. 
I certify that I have read this study and that in my opinion it conforms to acceptable standards of scholarly presentation and is fully adequate, in scope and quality, as a dissertation for the degree of Doctor of Philosophy.

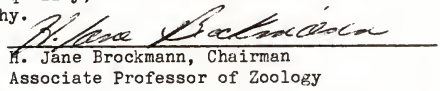

I certify that I have read this study and that in my opinion it conforms to acceptable standards of scholarly presentation and is fully adequate, in scope and qualizy, as a gissertatjon for the degree of Doctor of Philosophy.

Eincoln P. Brower Professor of Zoology

I certify that I have read this study and that in my opinion it conforms to acceptable standarojs of scholarly presentation and is fully adequate, in scope and quality, as a dissertation for the degree of Doctor of Philosophy. Eewane S. Necevey h.

Edward S. Deevey, Jr. Graduate Research Professor of Zoology

I certify that I have read this study and that in my opinion it conforms to acceptable standards of scholarly presentation and is fully adequate, in scope and quality, as a dissertation for the degree of Doctor of Philosophy.

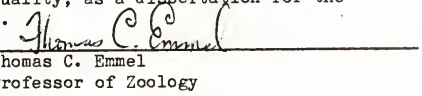

I certify that I have read this study and that in my opinion it conforms to acceptable standards of scholarly presentation and is fully adequate, in scope and quality, as a dissertation for the degree of Doctor of Philosophy

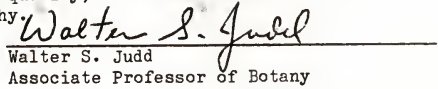

This dissertation was submitted to the Graduate Faculty of the Department of Zoology in the College of Liberal Arts and Sciences and to the Graduate School, and was accepted as partial fulfillment of the requirements for the degree of Doctor of Philosophy.

December 1983

Dean for Graduate Studies and Kesearch 